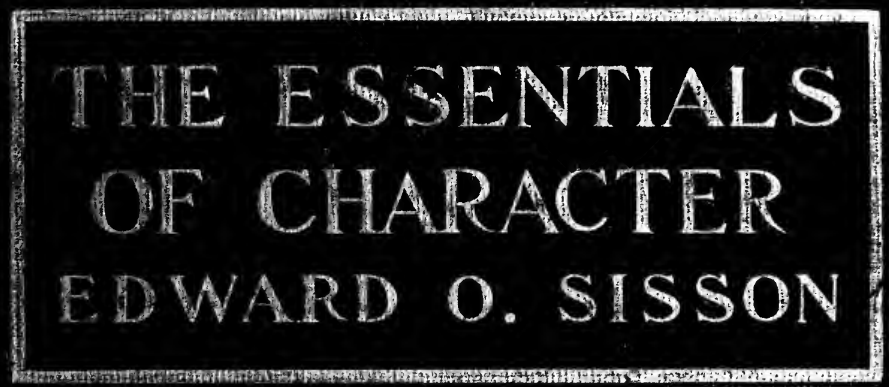




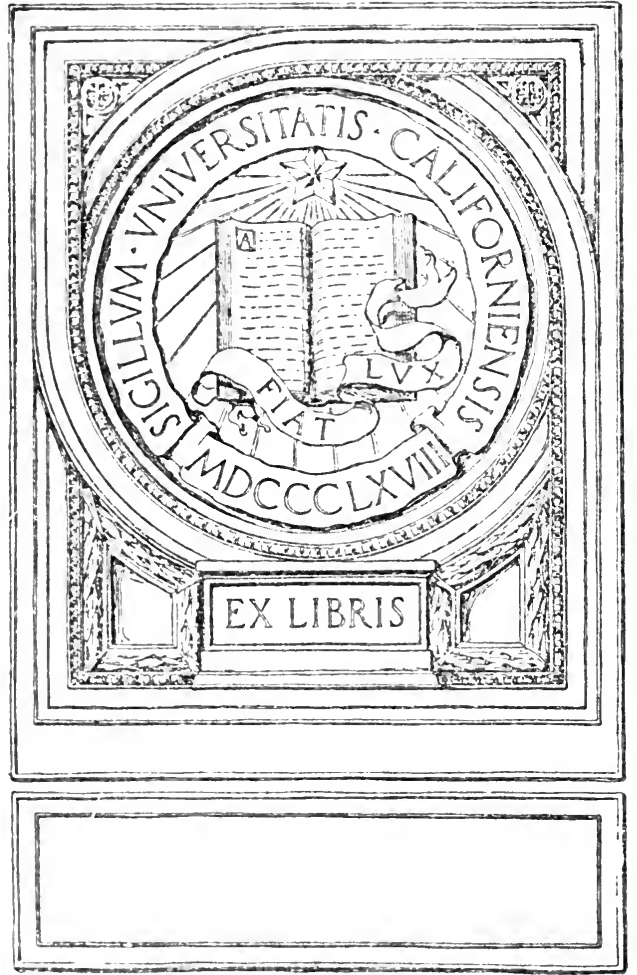




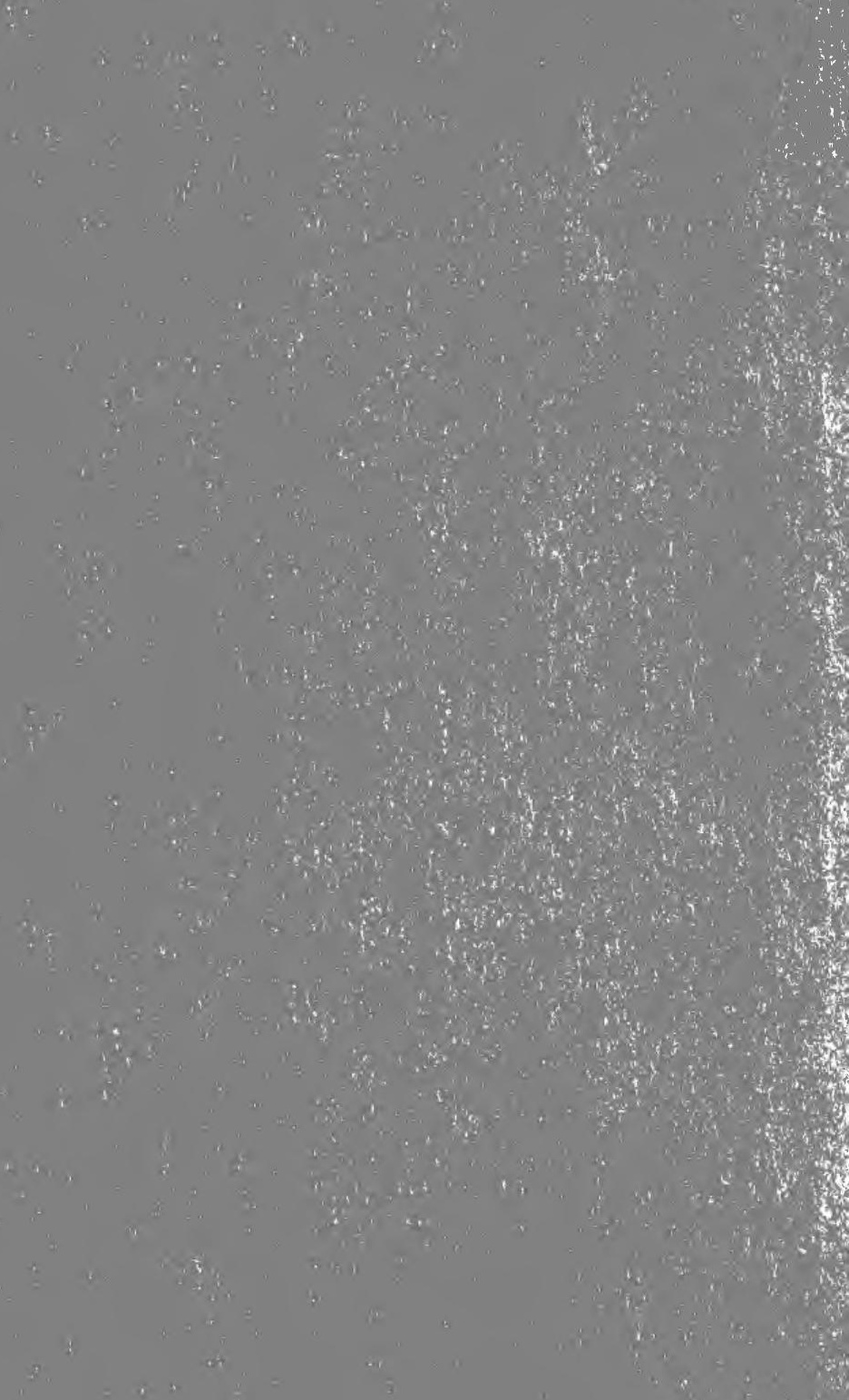


THE ESSENTIALS OF CHARACTER 


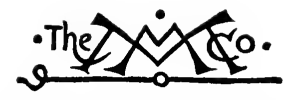

THE MACMILLAN COMPANY NEW YORK - BOSTON - CHICAGO ATLANTA - SAN FRANCISCO

\section{MACMILLAN \& CO., LIMITED} LONDON - BOMBAY - CALCUTTA MELBOURNE

THE MACMILlaN CO. OF CANADA, Ltd. TORONTO 


\section{THE}

\section{ESSENTIALS OF CHARACTER}

A PRACTICAL STUDY

OF

THE AIM OF MORAL EDUCATION

BY

EDWARD O. SISSON, PH.D.

PROFESSOR OF EDUCATION, THE UNIVERSITY OF WASHINGTON

Xrem Mork

THE MACMILLAN COMPANY

I9IO

All rights reserved 
Copyright, rgio,

By THE MACMILLAN COMPANY.

Set up and electrotyped. Published November, rgro. 
UXORI CARISSIMAE FILIOLAEQUE 
Digitized by the Internet Archive in 2007 with funding from

Microsoft Corporation 


\section{PREFACE}

EARNEST men and women everywhere are deeply concerned in the development of character in the young, and many of them, especially parents and teachers, are actively engaged in moral training. This book has been written in the belief that a clear comprehension of what really makes up human character would be one of the first and best aids to the actual worker. The whole plan and style of the work, including the selection of material, - and the omission of many things, - have been determined by this practical aim. This statement is not meant as an excuse for inaccuracy or fallacies, which I have endeavored scrupulously to avoid.

The ruling idea in my own mind throughout, and I hope in the book, is what may be called the dynamic and organic nature of character: that character springs from native impulses and tendencies in the child, which are full of power, of push and thrust, and make themselves felt ; out of these original tendencies, by organization and coördination, and by enlightenment, character arises, through gradual and often imperceptible processes. Moral education, then, must always strive to make connection with these sources of power by directing the impulses of nature into the service of human ideals. 
On the other hand, I have tried to avoid the error of belittling the intellectual element in character: mere knowledge is doubtless impotent enough for moral ends, but ideas united with emotional warmth and volitional power become ideals that dominate life, and the intellectual content is as essential to the ideal as the emotional warmth, for the ideal must contain the particular knowledge fitted to stir the heart and guide the conduct in the right direction.

Moral education is generally recognized to be the most important of all educational questions, as well as the most complex and difficult. The writer earnestly hopes that this little book may prove a modest help in the practical solution of the problem. It need hardly be added that criticism and suggestion will be received with sincere gratitude.

January, xو10. 


\section{CONTENTS}

Preface

INTRODUCTION

CHAPTER I

Native Tendencies

Bodily activity. Sense-hunger and curiosity. Suggestibility. Tastes and appreciation. Self-assertion. Love. Joy. Fear. The growing-up impulse. Love of approbation.

CHAPTER II

The Treatment of Native Tendencies .

\section{CHAPTER III}

Disposition .

Cheerfulness. Kindness. Disposition and habit.

\section{CHAPTER IV}

HABITS .

The formation of habits. Obedience. Industry. Thoughtfulness. Truthfulness. Bad habits.

\section{CHAPTER V}

\section{TASTES .}

Wholesome and inexpensive tastes. Food. Bodily activity. Love of beauty. Good reading. Dangers in æsthetic education. 
The Personal Ideal .

The bodily ideal. The intellectual ideal. The ideal of honor. The workman's pride. Dangers of the personal ideal. Modesty.

CHAPTER VII

Conscience .

CHAPTER VIII

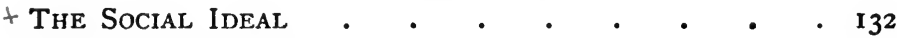

Basic truths of human life. Social intelligence. Love of humankind. Courtesy.

CHAPTER IX

Strength of Character

Sources of strength. Virtues of strength.

\section{CHAPTER $\mathrm{X}$}

RELIGION

Religion of the essence of character. Religious elements. The virtues of religion.

\section{CHAPTER XI}

T Notes on the Cultivation of Character

The force of contagion. The parents' power. Physical health. The school. Self-education.
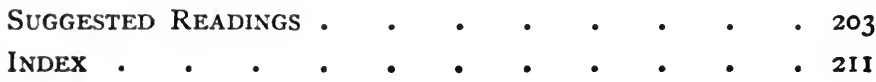


\section{THE ESSENTIALS OF CHARACTER}





\section{THE ESSENTIALS OF CHARACTER}

\section{A PRACTICAL STUDY OF THE AIM OF MORAL EDUCATION}

\section{INTRODUCTION}

Goop is good and bad is bad, and nowhere is the difference between good and bad so wide and so fateful as in human character. For character makes destiny in the individual and in the race. As a child grows into youth and maturity, all well-disposed persons are interested in how he will 'turn out' i) and the phrase reveals two salient facts about the prevalent thought concerning the genesis of character : first, a certain vagueness as to just what is good and bad in it; and second, the feeling that whether it proves to be good or bad is much a matter of chance. Now a believer in education must needs deny the power of luck, and must pin his faith to the proposition that character develops, like all other growing things, in accordance with inviolable laws : and that if we could know these laws, and act always in accordance with them, we should be able, - not to make what we please out of any child, - but to make of every child the best that he is capable of becoming. Even after we admit that development is governed by law, we still must see that in the 
case of a human being the laws are infinitely complex and as yet but little understood, and that both the human soul itself and the world that forms its environment are manifold and intricate almost beyond our conception. Even so, we dare not yield to despair, but must resolutely set ourselves to learn all we can in whatsoever way about the child and the laws of its development, and to turn this knowledge to good use in the cultivation of the best elements that spring in his nature.

Human beings differ from each other indefinitely, and the variations run back in many cases to childhood, and probably have their roots largely in original endowment. No training that ignores these individual differences between children will be very successful. But, on the other hand, there are not a few qualities that we expect in every normal human being, and the importance of these things is immense: the very fact that we require them of all shows their peculiar value: and the fact that all must have them, and not merely a few chosen ones, multiplies their significance in our common life. So much has been said in recent years, especially since Rousseau, about the differences between individuals, that there has been danger of our losing sight of the truth that common humanity and the qualities and character that we can all attain are more important than any peculiar gifts that are bestowed only upon the chosen few. Every child has in him the springs and impulses of honor, of truthfulness, of love, and of all needed virtues: it is far more important to recognize and bring to perfection these universals 
than it is to discover and cultivate the occasional talent for music or art or athletic prowess or oratory, - valuable as these are. Now the most important of these universals of human nature have been summed up in common thought and parlance in the word character; for character means the total of the qualities that make a real man or woman: a person without character is so much less than man: and a man of character is a man in the fullest sense. A clear and definite knowledge of the most important at least of the qualities that make up character is necessary to the educator, by which we mean the parent first, then the teacher, and last, but not least, every one else who influences the growth and development of any child or youth, - and this last evidently takes in everybody.

Moreover, the educator may always safely insist upon the qualities that belong to character in this sense; but respecting the peculiar gifts of each individual, he must, as it were, wait upon nature and be guided by the revelation she makes. It is risky for a father to decide that his son shall be a physician or a man of business except as the son's own development gives the signs of fitness for the calling: but the parent must needs resolve that his child shall grow up into honesty, industry, courage, and the other indispensable elements of character.

The question before us then, however difficult it may be to answer, is easily put: What qualities must be found in every human being to fit him for a happy and useful life, as an individual and as a member of society; in the 
family, the social circle, the church; as a citizen and as a worker; and in the hidden reality of his own inner life? The answer to this great question will portray the genera aim of education; every one who interests himself in the development of a child should rightly think first of this universal aim, and afterwards of the peculiar gifts and individual possibilities of the child concerned. 


\section{CHAPTER I}

\section{Native Tendencies}

THE child, like any other organism, grows from within, and thrives only when his natural tendencies are given suitable room and encouragement. Whoever wishes to succeed in influencing the development of the child must first seek to know these natural tendencies, and then find means for modifying them in accordance with his educational aim. The recognition of these natural tendencies as the ultimate basis of all education is the central idea of what we sometimes call the New Education, although the idea was not unknown even as far back as the time of Plato, and of course has always dominated really good educational practice, whether the educator knew it or not. The Old Education, in the bad sense of the word, implies the attempt to thrust-or foist upon the growing child experiences and characters that do not fit these natural impulses. Whatever we hope to fix in the character of the educated person, we must find in rudimentary form in the child. Hence the problem of the formation of character must begin here, in a study of what we may call native reactions, or impulses and movements that arise in the child in advance of any training or teaching from without. 
A certain by-gone philosophy - which certainly must have quite forgotten all about the real child - used to speak of the child's nature as a tabula rasa, or 'blank page,' upon which experience and training might write what they pleased. As a matter of fact, the child's nature at birth, like that of a calf or a chick, is pretty well scribbled over by the experience of its ancestors. It is far from being blank, for as soon as the little organism comes into the world, it begins to do certain things and do them with much zeal and determination, as every one knows who knows real children. Only in very recent years has the profound importance of these early actions of the child been recognized, and a new science has arisen of Child Study, to observe and record these phenomena, and seek to discover their meaning and value for education. To the numerous works on this subject we refer those of our readers who desire full and technical information concerning the native tendencies of children; we must be content here with mentioning out of the great number of these tendencies a few that are of special importance in the formation of the elements of character.

r. First of all in time, at least, comes bodily activity. The healthy child from the beginning moves body and limbs frequently and vigorously. This tendency increases rapidly in the first few months, until soon the child is seldom still except when asleep, and this constant activity is likely, to last for a good many years, - at least long enough to keep the primary teacher busy for some time after the child enters school. Now the mother and 
sometimes the teacher are very apt to lose patience with this motor activity, as the psychologist calls it, and they dub it plain restlessness, and sometimes ask the child querulously if he cannot sit still a minute. In simple truth he cannot; or at best only on rare occasions, when weary or sated with activity. Indeed, when a child in the first two or three years of life inclines to stillness and quiescence, the chances of its living out the perils of infancy are small, for the restless activity of the little one is the best evidence of its vigor and vitality. Moreover, these restless and often apparently aimless motions are the indispensable basis of several parts of its development : first, its bodily growth and physical control depend upon them; out of the random and confused movements of early life, by a wonderful process of selection and habituation, ${ }^{1}$ arise the power to walk and run and jump, as well as the marvelous skill and versatility of the human hand, and all other forms of definite muscular control. Only through the ceaseless and eternally repeated movements of the infant and little child can the helplessness and confusion of early movements grow into the order and definiteness of adult control.

Besides this, the very health and development of the body and its organs depend upon abundant movement and exercise of all its parts, - just what the "restlessness" of the child supplies. The adult keeps in health by the activity of his daily occupation; the child has no occupation except the activity itself; and he has far more

${ }^{1}$ See Dewey, "Psychology," Chapter on Physical Control. 
need of bodily activity than has the adult, for he is in the period of most rapid growth and development, which doubles and trebles the need of exercise. These are but the simplest functions of the ceaseless motion of the child; still another fundamental use is found in the contribution that motion makes to the operation of the senses, of which we shall speak further on. The most important point for us here, however, is the relation of child activity to one of the basic elements of character ; the habit of industry, with all that it means for success and happiness, springs directly from the restless activity of the child, as the plant springs from the seed. The tramp and the lazy man are persons in whom the precious shoot of activity has somehow been, marred or broken beyond repair; the early activity has been wasted or repressed, and the vital habit that should have sprung from it is lost. These are the thoughts that may help us as parents and teachers to keep down the natural impatience and irritation that the unceasing and often annoying and even dangerous activity of the child stirs in us. It is nature's way of creating the physical strength and efficiency of manhood and womanhood.

This first great impulse of childhood dominates the whole early life of the child in the form of play; but though activity is the mainspring of play, play itself actuates and educates every other impulse and element of the child's nature, and must be given the place of honor and preference in the early years as the fit and proper employment of the child ; in ideal development the inner consciousness 
of play would be continued into adult life, and only the external conditions would make the difference between play, the business of the child, and work, the business of the adult. It is a mere commonplace to say that the best worker is the one who retains the spontaneity, vigor, and enthusiastic interest of childhood play.

2. Sense-hunger and Curiosity. Great is the child's impulse to work upon the world about him through his muscular powers; no less does he hunger, as it were, to take in the world through his senses. Touch, taste, sight, hearing, and other deeper-lying senses, and in a less degree, smell, are all awake and eager. Upon them the child tries whatever comes within his compass; he is not content with sight, but wants to use hand and mouth also upon the object. Few of the native reactions, awkward and annoying as some of them are, are so excessive and so dangerous as the irresistible impulse to thrust everything into the mouth, but there it is, filling the mother's days with anxiety lest pins or poison or choking should imperil the baby's life. This phenomenon of child life, with its incident of dirt eating and thumb sucking, and lasting beyond liquid diet and teething, is enough to make us cautious about asserting that all the impulses of infancy have a use and justification; we shall probably do well to conclude that some of them, like the appendix among our organs, are superfluous vestiges of a previous stage of evolution.

The development of the senses under the stimulus of the sense-hunger is one of the most fascinating chapters of 
child-study. Born deaf and almost blind, with little or no manifestation of smell, and probably inferior touch and organic senses, the little one swiftly gains use and control of the organs that are to reveal the world to him. Peculiarly interesting is the indissoluble union between the development of the senses and that muscular activity we have already discussed: the eye is the best example; the new-born baby has no control over either head or eyeball, and cannot look at anything: hence, while the eye itself is perfect, the child does not properly see anything. Very soon the head begins to turn toward sounds or lights; then the eyes themselves gain the power to move in their sockets and converge, with proper accommodation and focus, upon a definite object; then the child truly sees for the first time. The marvelous delicacy, perfection, and swiftness of the movements of the eye that are essential to complete vision command our astonishment and reverence: these the child acquires in the first year of life; but, like so many other achievements, only by grace of the impulses to activity and to sense perception; without these the eye would linger forever in the dull fishvision of the new-born babe.

Hardly less dependent upon muscular activity is the sense of touch: "Let me see that," with the child, means, Let me handle it, move my hands over it, rub it, 'heft' it, and so forth. The educated touch that we hear of in textile experts, physicians, and others, resides probably as much in the muscles as in the sense organs themselves. Hearing is also, though to a much less extent, in partner- 
ship with movement: posture and movements of the head help to determine direction and distance of sounds.

Out of a union of sense impressions the child gains his ideas of things: the sight of an orange creates the desire to touch and taste and smell it: and these impressions go to make up the orange as the child knows it. So the sense-hunger leads the child mind forward from sensations to perceptions of things, and from things, related to each other, and experienced both actively and sensorially by him, he constructs his world.

Now this sense-hunger of early childhood, while it does not pass away entirely, becomes year by year less conspicuous, and gives place to its natural successor, which we sometimes call curiosity; this name we adopt with the proviso that it is not to carry any of its usual disapprobation. Just as the little child wants to see, touch, taste, smell, everything that comes within his reach, because it is new to him, and, we may also add, because he needs the acquaintance he gets thereby: so the older child wants to know about all the new things that come his way. But it is not usually a matter of color or form or taste or smell; it is more likely to be a more advanced inquiry: "What is it for?" "Where does it come from?" "How does it work?" and a thousand such like, which none but the father or mother of a little lad or lass could begin to enumerate. It is of course very easy to sit in a quiet room with no child in sight or hearing, and expand upon the beauty and power of this child impulse of questioning, and it is pretty hard always to live up to the idea when an 
actual flesh-and-blood child is pelting one with what's and why's and how's, without end, and often, to our comprehension, without sense. But no matter how hard it is to live up to the truth, yet still it is true, that this harassing inquisitiveness is the only root out of which intelligence and mental power can grow, and the parent and teacher must needs pray for grace to treat it accordingly.

The two impulses just discussed, of activity and curiosity, combine in the constructive impulse, and in its close relation, the destructive impulse, both of them being conspicuous in every normal child. The destructive impulse usually, and the constructive often, constitute what the adult terms mischief. This is why the most vigorous and healthy children make the most mischief. The propensity of all children to meddle with what they ought not to touch is perfectly clear: what they ought not to touch is exactly the thing that by that very fact must stimulate their curiosity to the highest degree; and it is much to be questioned if any of us really grow quite out of this stage. The child must needs be doing, and he must needs get new sense experience and later new knowledge; result, infallibly and irresistibly, - mischief. The exceeding value of the constructive impulse needs no emphasis; it is the taproot of all the arts and crafts of the human race. It is one of the most difficult tasks of early training to restrain mischief and destruction within reasonable limits without unduly repressing the wholesome activity of the child. 
3. Suggestibility. One of the commonest fallacies regarding children is the opinion that they are naturally disobedient; as a matter of fact, the child has a natural tendency to do what he is told to do,-provided, of course, he is not too much attracted by something else and has not a positive aversion to the thing commanded. Also, provided the command is given by a person who is not obnoxious to him, and not in a way calculated to arouse his antagonism. A good many provisos, you will say; yes, surely, and I should not like to warrant the list to be complete. But in spite of this, it is still true, that it is natural to a child to do what he is told to do, and, moreover, in actual life, children act in accordance with this, or, in other words, obey, far oftener than they disobey. The trouble is that one disobedience makes more trouble and so more impression upon our minds than a score of obediences. A disobedient child is one who disobeys, as his mother says, often; in strict numerical ratio, his disobediences would usually be few as compared with his obediences. Nothing here said is intended as an excuse for disobedience, nor for the weakness of discipline that tolerates it.

Not only is it natural for a child to do what he is told to do; strange as it may sound, he has a distinct tendency also to do what he is told not to do. And yet again, he has a distinct tendency to do what he sees done, or hears about, or whatever in any way comes into the range of his perception. All these tendencies, which are really summed up in the last sentence, constitute what is called 
suggestibility, or the tendency to repeat in one's own person any act the image of which enters the mind. The most clearly recognized form of this great tendency is, of course, imitation.

It will be noted that while it is wrong to say that children are naturally disobedient, it is hardly safe to say that they are naturally obedient : for obedience is much more than an impulse, and it is not native, but acquired. Moreover, as we have seen, and as all wise parents and teachers know, the child is prone to do the very thing he is told not to do. Hence the danger of prohibitions in school and family discipline: telling boys not to make their snowballs hard nor put ice or stones in them may result in the very conduct that is forbidden. For the very idea of the act has a natural tendency to produce the act; in other words, the child is not naturally obedient, nor naturally disobedient, but is naturally suggestible. The practical inference is clear, and although it is not all of discipline, it is the foundation of it, - to present to the child's mind those actions that we wish him to perform; the very picture of desirable acts and conduct in his mind is a force for good; whether the picture is produced by words or by example, the result tends to follow; and, per contra, to avoid as far as practicable presenting undesirable acts, for the very image of evil deeds and bad conduct is in itself a source of danger, whether the image is produced by bad advice or bad example. Few truths are so profoundly important in education as this, and yet most parents and not a few teachers fail to realize its 
significance; the general public in their attitude toward children seem to heed it not at all.

The child's eyes and ears then are open and hungry for deeds and conduct that he may copy: "I can do that," "See me do that," "Let me try that," are frequent enough on the lips of children, but they are only a corporal's guard of the army of the imitative impulses that swarm in child-consciousness. Nor could it well be otherwise : the baby has no arts nor accomplishments, and must learn all before it can become grown up. The simplest processes of daily life, eating, dressing, manners, all must be learned, and mainly through this suggestibility. The most complex of all the organic arts, speech, would never be acquired but for the dominating impulse that comes at the proper time and leads the child to prattle and chatter, over and over again, every word and sound he hears. Professor James has called the child a behaving organism: ${ }^{1}$ it would be as correct to say that he is an imitating machine, for imitation really precedes behaving, and furnishes the material for it. ${ }^{2}$

To say that the child is suggestible, then, means that he is open to contagion in mind as well as in body, that he 'takes' habits and manners and character very much as he takes measles or whooping cough, from any one who has them. Education must provide quarantine against bad moral infections, as departments of health do against

${ }^{1}$ See that golden book for teacher and parent, "Talks to Teachers on Psychology and to Students on some of Life's Ideals."

${ }^{2}$ For full and expert discussion of this topic see "Suggestion in Education," by $\mathrm{M}$. W. Keatinge. 
bodily contagions; and, what is even more important, it must infect the child, through right example and precept, and noble environment, with good ideals and strong character.

4. Tastes and Esthetic Appreciation. What children like and dislike is a very broad field, and overlaps on some or all of the other natural tendencies we are considering: let us note, however, two parts of the field that seem to be of peculiar importance. First, the child has a natural taste for wholesome foods. What, says the mother, are candy, and dirt, and soap, and pins, wholesome food? And we must admit, of course, that these are but a few samples of the endless list of noxious and repugnant things that the little child takes to with avidity. But here, again, as in the case of suggestibility, the child finds no trouble in combining contrary qualities. He does (though fortunately not with equal propensity) both what he is told to do, and what he is told not to do. Likewise, although we must admit that he likes many contraband articles, it is true that he also likes his milk and bread and rice, and plenty of other good nourishing foods in their season. Moreover, the taste for dirt and pin will wear itself out in the course of nature, if happily the little omnivore survives the perils of choking and poison, as he usually does; but the taste for good honest food, however plain, never wears out, at least in the course of nature. It is sometimes driven out, and that brings us to the practical lesson. The old-fashioned mother may be wrong in thinking sweets unwholesome for children's 
stomachs, but even so, her practice was right, for the taste for sweets is very bad when it usurps the place of authority in fixing the child's diet. There are children who reach school age without knowing the taste of cake and candy, and who consequently devour plain bread with zest; and there are other children whose feeble appetites must be tempted with coffee and spiced viands. The normal and healthy child has a native tendency that may enable him as a grown man to eat bread and butter with more delight than most people find in a dinner at Delmonico's. With him, good digestion does wait on appetite, and health on both.

And what as to æsthetic appreciation? Comenius held that infancy is the time in which all branches of learning and culture should begin; and the capacity to rejoice in beauty of every form is no exception. Before the child can articulate a single word, he shows delight in bright colors and flowers; almost, and in some cases quite as soon, he manifests pleasure in musical sound. $\mathrm{He}$ stretches out his tiny hand toward moon and stars and bright water, not, as is sometimes inferred, to grasp them, but in natural utterance of the joy he feels. Who has not seen a pair of boys, not yet in their teens, dawdling along the homeward road with their hands full of bright and variegated flowers? They gathered them as naturally and unconsciously as the rain falls; five, or even two years hence, it is safe to predict that the same lads will be indifferent or scornful of flowers and of a host of other forms of beauty that charmed their childish eyes; and 
too often, once grown to manhood, the cares of this world have sadly choked the capacity to glow and thrill with the vision of the rainbow and the rose. Boys must be boys, and we must all agree that a boy in his teens had better like flowers too little than too much, for he is in the period of some indispensable natural tendencies that have not much concord with the gentler æsthetic feelings. But the grown man is to renew and embody all the best that springs in every period of immaturity, and the love of beauty is one of these. Education, then, must not neglect the native springs of æsthetic appreciation that abound in the soul of the child. Of the cultivation of these tastes more will be said in a later chapter.

5. Self-assertion. "The baby new to earth and sky" may not know that "this is I" - but he knows how to make all the rest of the world know it; and his own little intelligence seems early to wake to the idea. Under the head of self-assertion we must include a numerous and varied group of reactions that mingle in complicated relations with all the other classes of tendencies. Not seldom to the young mother or the inexperienced teacher it seems as if the self-impulses of the child have driven out all the rest and founded a complete tyranny over child and all about him.

The first sense in which we speak of self-assertion is the mere vim and resolution with which any or all of the child's natural reactions utter themselves, especially when obstacles get in the path of his impulses. It is this push and thrust of the child's impulses that cause our ex- 
clamations that "He has a will of his own!" and the mother's distressed and despairing "I can do nothing with him," or "Did you ever see such willfulness?" and the like. The next point is the child's disregard for the interests and feelings of others, and for the value and safety of the furniture or whatever else comes in his path. People and animals are ruthlessly bruised and maltreated, polished tables marred beyond the power of varnish to restore, and jewelry and bric-a-brac reduced to fragments. Then there are a number of special and extremely important responses to opposition: the little would-be autocrat strikes, scratches, bites, fights, without any rules of the game except to gain his point: when other measures fail, he stiffens his little frame and even holds his breath, until the mother or nurse capitulates in mere terror.

Of course the saving respect in all this, so far as it concerns early childhood, is that the child is not really willful, but only will-full, and this latter he must be, if he is ever to be a real bone-and-sinew man; nor is his destruction of the furniture and ornaments vandalism, but only happy unawareness of the nature and value of what he smashes; and, above all, his fierce attacks upon his mother and nurse are not cruelty, but only defect and ignorance: ignorance of the feelings of any one but himself, and defect of the altruism that comes naturally with a little more growth, - indeed, is even now building in his soul in unmistakable charm. Certainly we may well believe that part of the pugnacity and fury that mark some of the 'spells' of some children might well be spared: but 
education always has to concern itself partly with 'letting the ape and tiger die,' and the little child has its full share of the lower inheritance of the race. The comforting fact concerning these self-asserting impulses is that they are common to all normal children, varying, of course, in form and force; the young mother's shuddering fear that her baby is destined to become a monster of violence and cruelty is quite unfounded. But only devoted love, coupled with wisdom and resolution, can solve the perplexing problems arising from these stormy elements in the child. We no longer believe in the old plan of 'breaking the will'; yet we dare not go to the other extreme of indulging the blind and violent impulses of the little ignorant and undisciplined scion of humanity. Fortunately there are some tendencies yet to catalogue that give light and aid in the control and cultivation of these.

Furthermore, from the crude impulses of self-assertion, disciplined and organized through experience and training, arise the indispensable virtues of self-respect and rational confidence in one's own powers. These are supporting and preservative as well as energizing elements in character, and the dynamic force demanded in them can come from no other source than the native impulses; the energy which without direction is destructive becomes under rational control beneficent and constructive. Just as self-assertion constantly reënforces all the impulsions of the child, so these qualities give permanent strength to character and vigor to conduct.

6. Love. Just as natural and spontaneous as the rest 
of the impulses is the impulse to love. The love that springs in the soul of the child is destined to cover a multitude of sins in that it is the supreme influence in the mitigation and control of all the violent and dangerous elements in his make-up. The existence of this tendency is powerfully impressed upon all who look with seeing eyes upon the outer manifestations of the child's life. It is hard to say just when affection begins, but by the age of a year and a half it has become conspicuous: the wealth and variety of the baby's expressions of affection are wonderful: naturally the mother is usually the prime favorite, and upon her are lavished the ardent gaze of the eyes, tender tones of the voice, and fervid caresses. Even at this tender age, absence, if not too protracted, does make the heart grow fonder, and the delight of the child when the mother reappears is a thing to conjure tears and smiles.

Besides the love bestowed by the child upon its real and actual kin and companions, it has the capacity for a remarkable prophetic or symbolic emotion, which is manifested upon the slightest opportunity, - the love of dolls : a baby just over eighteen months old, who had seen and handled a doll with the greatest delight, rolled up her little blanket, probably more than half accidentally, into something the form of the beloved rag doll, and began with a sort of surprised delight to pat and caress the almost shapeless bundle; so near to each other do humor and profound significance often lie in this life of ours. Herbert Spencer complains in his "Education," that for the 
lone occupation that nine tenths of all people must follow, that is, for parenthood, education provides no preparation; Nature, at least, has not been so delinquent.

We cannot pass from this subject without emphasizing the greatness and power of the impulse of love in the child. Bad things have a way of making more noise in the world than good, as any morning paper will abundantly and often disgustingly demonstrate. So we are apt to miscalculate the proportion of the various constituents of child nature. Love is quiet and soothing: pugnacity is boisterous, and self-will is exasperating; love is grateful and entertaining, curiosity is annoying and tedious. So we fall into the belief, or at least the habit of asserting, that children are naturally willful, inquisitive, meddlesome, mischievous, - and seldom dwell on the far more important truth that they are eminently loving. The child will even turn from its most passionate rebellion with a caress for the parent who is punishing it: so powerfully does the impulsion of love spring in the heart of infancy. It is not well for us to give the evil a preferred place in our thought; spiritual progress depends upon our rather dwelling upon the good, so that its real place in life may expand by virtue of its predominance in our minds. The simple instinctive love of the child for parents, nurse, playmates, and friends is the root out of which grow all the altruistic elements that raise human character and conduct to its highest level. For so great a task it is well that nature has provided so deep-rooted and pervasive an impulse. 
Modern educational thought justly lays great stress upon the social impulse. The effective force of this impulse is that moderate form of love that we call affection or liking. There is also involved a special form of curiosity of great strength, that causes a child to be intensely interested in other children of about his own age; every one knows how even two babies in their carriages will be mutually fascinated at sight. As development proceeds, the original impulse is reënforced by the common life and interests of the child with those of the same age or stage of development. It is also widened to take in other ages, and deepened by affection, and thus becomes a mature social nature.

7. Joy. Nothing is more characteristic of healthy childhood than happiness, and nothing is more conducive to perfect development. The child's countenance lends itself willingly to smiles and laughter : it is humorously suggestive that the same physiological condition that sours the face of the adult draws the baby's features into a counterfeit of a smile, for the doctor tells us that the first smiles of infancy are really the result of some slight disturbance in the small stomach. "Pleased with a rattle and tickled with a straw" would be contemptuous enough applied to an adult, but it expresses a beneficent truth concerning the child, - a truth for which mothers are heartily grateful, and which has a significance far beyond the moment both for mother and child. The physiologist tells us that pleasure is the natural accompaniment of healthy activity: growing pains, of which we used to 
hear so much, are probably a superstition, and growth painless, if not actually pleasure-producing. Certain it is that growth and the joy of life run parallel, and that any environment and regimen that darken the child's life also retard and even deform his development. So while there will needs be some tears and pain, partly through natural causes and partly for discipline, yet no education can hope to prosper unless in the main it conserves the natural light and cheer of childhood. How woefully some systems and methods have sinned against this law has been shown, possibly with some excess of portrayal, by Dickens, in the early chapters of "David Copperfield" and elsewhere. Other things being equal, - and there is much meat in that, - the better educational method is the one that makes the child happy. It must be admitted that the pedagogy of our day, especially in the home, has shown a tendency to let this criterion override some other weighty considerations, and so kindness has lapsed into indulgence, instruction into amusement, and discipline into coddling; this is the sort of treatment that revenges itself early and sharply. Yet the truth still remains, in spite of all misinterpretations.

Manifestly a tendency to be happy and to welcome the objects and incidents of life somewhat as the child does is a quality worth retaining in maturity. With this in mind, one is tempted to declare that this last tendency is the most important of all we have discussed: we recall, however, that several of the others are pretty big with meaning, and decide that it is like the rest not merely 
important, but essential, inasmuch as without it no full and rich human character is possible.

8. Fear. All the other impulses we have considered, while they come into conflict with each other occasionally and, as it were, accidentally, really tend to harmony and mutual stimulus and encouragement. They are all positive, and all grow into the very texture of the mature life, contributing directly to its fullness and perfection. We now come to a tendency which is the opposite of all this, - fear, which is the enemy of every other impulse, blocking its expression, and choking its freedom: and which is no less the enemy of fullness and freedom in the mature life. It is the great negating power in the organism : in its milder forms it chills and discourages all other impulsions, and in its intenser forms it either paralyzes all activity, - as in the case of the "frozen" rabbit or squirrel, - or throws the organism into violent and often confused and aimless movement. Particularly is fear the fatal antagonist of joy; joy is the natural accompaniment and stimulus of healthy activity of every sort : fear checks the activity, and turns the inner sense of delight and exuberance into panic and misery.

The use of fear in the economy of nature is of course the preservation of the organism from dangers ; the young of the lower animals are constantly guided by impulses of instinctive fear, and would never escape the perils that beset them without these safeguards. But the case is very different with the human infant: with it fear plays a far smaller part, and that part mostly a useless one. 
The little child may live day after day apparently without the experience of fear : his utter lack of restraint over his crying shows the contrast between him and the silent babies of forest and meadow; as Fiske has said, the cry of the human infant is a declaration of the sovereignty of his race. Even when fear does arise in the child, it is more often than not a vestigial and useless remnant from prehistoric periods, - as, for example, the terror of fur sometimes manifested by a child a few months old; an impulse that harks back to the cave dwelling subhuman man, and is quite useless to the modern child. Then again the child will cling almost convulsively to the mother whose loving grasp is perfect safety; but he will walk off the steps or the unguarded porch to a perilous fall. $\mathrm{He}$ is likely to be more frightened at an innocent strange man than at a dangerous dog. And alas, for pins and needles, buttons, and poison, Nature has left him quite without the safeguard of fear. In fine, it is evident that fear is a decadent element in the child : it has little place in his inner life, and less use in his outer experience.

And yet we must at once set over against this two points ; first, that the fears of the child that do arise are often terrible and overmastering almost beyond adult comprehension. So far as the infant is concerned, no one can doubt this who has witnessed the shriek and convulsive shudder of the fur terror; as to the fears of later childhood we can read their terror still even in our own faded early memories. The clear lesson from this is the 
need for the most patient and tender consideration for the fears of small children. The frightened child is helpless in the grip of an ancestral terror, now quite empty and irrational, but to the child as real and horrible as ever; the task of the parent or elder is to soothe away the emotion and kindle the light of reason and so emancipate the little soul from the dread inheritance. Playing upon a child's fears, and, above all, creating new ones with stories of the bogeyman, are the very height of folly or wickedness. These forms of fear are to be eliminated by encouragement and enlightenment.

But secondly, fear has its uses even in civilized human life: very early the baby can be taught to fear the hot stove, the fall from the steps, the sharp pin, and many of the other dangers of the environment into which its birth has brought it. These are the first steps of the long path from the panic fears of infancy to the fear of parents, and that "Fear of the Lord," which is the symbolic expression for the highest reaches of character.

9. The Growing-up Impulse. We have next to discuss a tendency that is strongly marked in both childhood and youth, but which is not ordinarily described in works on psychology or child-study as a separate impulse or instinct. Possibly it may be merely a resultant of more elementary tendencies, especially suggestibility and selfassertion, but we incline to believe that it is distinct from either. At any rate, it is so exceedingly important an influence upon development and education, that it deserves a place by itself here. This is the maturing or "growing- 
up" tendency or impulse. All young human beings want to be older: the little child wants to be boy or girl: the boy or girl longs to be a young man or woman, and the youth yearns to be a full-grown man. The lad in high school ardently desires the time for graduation and college to come; once in the freshman class he wants to be a senior.

Now this naturally manifests itself most plainly in imitation, but imitation is not all of it, nor indeed its essence, but simply its most direct expression or channel. The growing-up impulse has a marked negative form, in that the child of almost any age looks down with more or less contempt upon his juniors and all their affairs : two children met, one four and the other two years old; the younger called the older "Baby," and the four-year-old was filled with indignation, and cried, "She called me Baby!" Moreover, the child wants not merely to be like some one else who is older, but to achieve his own older self, which is much more than imitation.

Every parent and teacher is acquainted with the signs of this maturing impulse: one of the most familiar and amusing forms is the fondness of little girls for rigging out in their mothers' old skirts and tripping up and down making calls and serving afternoon tea. Boys affect the characters of manhood as they see them, - loud, masterful tones, long steps, swaggering gait, and, above all, smoking and even swearing. The manners of their younger playmates, on the other hand, are to be strictly avoided and cast off as signs of infancy. 
The educative value of this impulse needs no proof : every wise teacher knows how to say to a boy: "Your behavior would be excusable in a child of eight in the primary room, but it is quite unworthy of a boy of twelve." At every age of developing life, powerful appeal may be made to the instinctive yearning to be older, more mature, more grown-up: in school instruction and discipline, and in home duties and conduct, this impulse is a constant source of stimulus and direction. Particularly does this impulse make for self-control in all its forms and range: the child perceives that older people are quieter, more orderly, less apt to disturb or annoy others, and so on through all the details of mature ways and manners. Then he may easily be brought to embody these desirable qualities in his ideal of his own maturer self, toward which the maturing impulse is moving him.

Few impulses are more in need of enlightenment, for the child in all his periods is extremely susceptible to the common human fallacy of the conspicuous and external. The boy, for example, is prone to seize upon smoking and swearing as the true marks of a man and copy them with avidity; this is the true reason for his peculiar weakness for these petty vices; the best remedy is to imbue his mind, from the dawn of intelligence onward, with a truer view of what real manhood consists; let him see these cheap imitations in their true light as at best mere externals, and often symptoms of weakness and defect, of something less than full manhood and ripeness of power and self-direction. Above all, let him perceive that any habit or manner that 
enslaves the will is quite incompatible with the freedom and independence of full-grown human nature.

The greatest care should be taken not to check or damage this impulse of development: the child naturally takes himself and his affairs seriously, and it is right that he should do so; let his elders then do the same; never ridicule or repress his budding sense of worth and maturity, but rather meet him more than halfway, show respect and consideration for his ambitions and hopes, be eager to treat him as older than his years; don't talk down to him too much, but rather give much opportunity for him to stretch up toward the ideas and ideals you present to him.

Finally, the maturing impulse is the great spring of self-education, and self-education is of course the truest and most important form of education, - indeed, in a certain sense it is the only education worth the name, all other being rather mere training and drilling from without. It is the maturing impulse that can furnish power to keep the inner improvement activities of the child and youth moving out of school hours, and after school years, and carry him indefinitely onward in the upward climb of individual achievement. The full stature of intelligence, capacities, and will power is the goal of the best selfculture; it is the star to which the youth must hitch his wagon, or rather toward which he must drive, and the maturing impulse is the vital force that makes the attachment and provides the motive power.

ı. The Love of Approbation. The fact that children 
are instinctively sensitive to praise and blame is universally recognized. It is not always so clearly perceived that Nature could hardly have devised a more effective means of education, and that the proper use of the impulse should be studied most earnestly and managed with the most scrupulous care. The tendency of the child to seek approval and shun blame from his elders, arms the eye and voice of the parent and teacher with cogent force, and enables them to win countless "bloodless" victories in discipline and training. Through this tendency desired acts may be clothed with preference in the child's mind, and faults may be marked for elimination, and thus the formation of habit may be greatly influenced. In a later period of mental growth, ideals and principles may be reënforced or discouraged by the approval or condemnation of the educator. Finally, there may be developed in the young mind that desirable element of character which is referred to in the Declaration of Independence, "a decent respect for the opinions of mankind."

This particular tendency is peculiarly subject to perversion and decay. It may serve false and foolish ad- ' mirations and qualities as well as good: it may entice the child away from the influence of the parent almost as easily as it may hold him under the parent's power. It is easily overstrained: we must not blame too seriously what may seem to the child a trivial fault or even an innocent deed, for by so doing we may open up a gulf between him and us that may chill and weaken his whole sense of our opinions and attitudes. The parent whose 
approval is still potent when the child has grown to maturity has achieved one of the most difficult and vital tasks in education.

We have described briefly what we believe to be the leading tendencies of early childhood, with which, therefore, education must begin. As the child grows out of infancy his reactions become more varied and complex, and soon outgrow the short and simple catalogue we have set down. The new forms are partly, perhaps mainly, developments from the simpler and earlier ones; acquisitiveness probably springs from self-assertion and curiosity, the clan or gang impulse of boyhood from affection and the social impulse, and so on. But new elements still spring periodically from the fruitful soil of the developing nature. One of the most distinct and most momentous of these is the impulse of sex, the first inklings of which are indeed lost in the obscure recollections of childhood, but whose clear manifestation occurs later and marks what is called the epoch of puberty, when the sexual organs attain physiological completeness. Happily, much expert study is now being devoted to this vital subject by the physiologist, the psychologist, and the student of education. It does not come within the reach of our discussion at this point; in referring the reader to works on the subject, ${ }^{1}$ we add one word of

${ }^{1}$ Some of the most available sources of information are:

Hall: From Youth into Manhood, New York, r9o9.

Wilson: The American Boy and the Social Evil. Philadelphia, I905. Sperry, Lyman B.: Confidential Talks with Young Men.

Sperry: Confidential Talks with Young Women. 
caution: puberty and adolescence in the human being are spiritual more than physical. The way of the youth and the maid is often wonderful in its ethereal purity and elevating power: the first intersexual affection, laughed at as "puppy-love," too often puts to shame the later passion of the maturer man. In this fact lie hope and safeguards; educational wisdom here as elsewhere consists not in attempting to crush natural impulses, but in nurturing the good into domination over the lower elements, and achieving the harmonious coördination of the inner forces. ${ }^{1}$

Hall, G. Stanley : Aspects of Child Life (Ginn). Especially paper on "Curiosity and Interest," pp. 84-I4I.

Valuable pamphlets and full information on this subject may be had free from the following societies:-

The Society of Sanitary and Moral Prophylaxis, 9 East Forty-third St., New York, N. Y.

The Chicago Society of Social Hygiene, roo State St., Chicago.

The Spokane Society of Social and Moral Hygiene, 207 Nichols Block, Spokane, Washington.

${ }^{1}$ See "The Genius of the American High School," Educational Review, December, I909, pp. 471-473, 477-478. 


\section{CHAPTER II}

\section{The Treatment of Native Tendencies}

IN our survey of the native tendencies of the child we have not felt it necessary nor desirable to check the hopeful enthusiasm that arises from contemplation of the elements with which Nature has endowed the healthy and normal child. To avoid serious misunderstanding, however, we need here to explain what we mean by the proper regard for the impulses of the child, of whatever sort they may be. We certainly do not mean that the educator is to throw down the reins, and let the impulses of the child go where they will. He must be something more than an interested spectator or even a self-denying victim. What he must avoid is first ignorance of the profound meaning and value of the impulses, and second, impatience and irritation at the undeniable annoyance and exasperation that often result from them. But the child is to grow into a man or woman, and to that end must gradually and by gentle progressions put away childish things and acquire the intelligence, reason, and quiet self-control of the adult. This he will never do by himself, but only by the aid of his elders, - parents, teachers, and other associates. The impulses are indeed 
the stuff out of which character is to grow; but they are raw material, sometimes very raw indeed; education is in a sense a process of manufacture, and the final product is achieved only through many and profound changes. The educational vices in dealing with children and their native reactions are ignorance, heedlessness, impatience, frivolity, - and in some few cases, meddlesome interference with the hidden process of nature; the virtues to set over against these are lively interest and intelligent study of the native impulses and their function, and loving, patient, resolute activity in their nurture and guidance. It is clear that educational duty will sometimes involve restraint, prohibition, and even coercion; an education without these would be fit only for a jellyfish. The child who is full and running over with muscular impulses has quietness and self-control to learn: the adult who cannot sit still is as pitiable as the child who through low vitality sits still too much. The wise parent will sometimes require and, if need be, compel the child to sit still, even much against its own desire. Likewise, the wise parent must sometimes check the child's flow of questions, - not in irritation or from impatience, but for a good reason, explained to the child if practicable, it being always understood that some good reasons cannot be explained to the child. The native tendencies are absolutely the only stuff out of which human character can grow; but they are still only the raw material. They are to be neither crushed nor indulged, but cultivated; and their cultivation will inevitably demand inhibition 
and even repression as well as the richer process of stimulation and encouragement.

The broadest general principle of education is to fix attention upon the good, both for its own sake and as the final means for conquering the bad. Overcome evil through good should be the constant maxim of parent and teacher. The Apostle's injunction applies to both educator and child, "Whatsoever things are true, whatsoever things are honorable, whatsoever things are just, whatsoever things are pure, . . . if there be any virtue, and if there be any praise, think on these things." Our lives are inspired and molded not by what we must not do, but by what we positively set before us in purpose, plan, intention, aspiration, ambition, and, if we should climb so high, in our life purpose. Moreover, the nobler and finer the character and life, the less it is dominated by the evil to be shunned, and the more by the good to which it aspires.

This great truth has led some to reject all negative and repressive means of training: chief of these is the brilliant Rousseau, who actually declares that we must never lay upon the child any command whatsoever; and there is not a little pedagogy nowadays that follows his erratic lead. There is little danger of any mother or practical teacher swallowing Rousseau's absurd paradox; the facts are too stubbornly against it. Rousseau knew nothing of real children, having shamelessly shirked his own duties in this regard, and we need not concern ourselves with his advice on this point. But there is a real danger to-day lest our enthusiasm for the sacredness and 
beauty of child-life and child-nature blind us to the imperative need for a strong and resolute rein upon the excessive operation of impulse, especially in early childhood, before the child has any real will or wisdom of his own.

Leaving out of the question as of comparatively little importance the damage to breakable things within reach of the child's impulsive movements, and even the personal injury he is apt to wreak on those about him, the truth remains that the educator must protect the child from himself in a spiritual sense; that is, the harmonious and ideal perfection of his nature must be guarded from the damage caused by excessive development of particular tendencies. This is particularly true of the more violent self-impulses, such as obstinacy, anger, pugnacity, violent seizure of the property of others. It is clear that unbridled activity of these impulses will tend to give them injurious predominance, and choke the gentler impulses that should hold them in check, such as affection and social nature. There is a right and wrong even in the affairs of the little child, which is not abolished even by the child's own failure fully to comprehend them. They are to be revealed to him partly through the control and discipline and even punishment exercised by his elders upon him.

As soon as the child is born, its native tendencies begin to come out in actions, and as soon as action begins, the tendencies begin to be modified, and education is under way. The great question in early education is, What are the influences that affect the development of the tend- 
encies, and how do they work? Every time an impulse utters itself in an act, if we can believe psychology and physiology, a trace is left on nerve and upon soul: if the result of the act is agreeable, the impulse is confirmed and the act likely to be repeated; if the consequences are unpleasant, the impulse is discouraged and the act less likely to be repeated. This is a bald and crude statement of the law that underlies all education and regulates all teaching and training. Clearly, then, the simplest rule of education is to strive to encourage desirable impulses and acts and discourage undesirable ones; unfortunately, the law, like so many other wise generalizations, leaves us with the real task still on our hands, to decide which are desirable impulses and how we can encourage them. But still the law is worth something; it would at least make plain the folly of parents laughing at the conceited and otherwise obnoxious pranks of spoiled children. Punishment, in its various forms, from gentle reproof to the infliction of severe pain, finds its justification in the necessity of inhibiting undesirable acts and so preventing the establishment of the evil in permanent form.

But the stimulation or inhibition of spontaneous acts of the child is only part of education; it is necessary also to reveal to the child conduct and manners that he would not be able to evolve from his own nature; this is the work of example, suggestion, and instruction. These all give him pictures or ideas of things to do ; and these ideas, in whatever form they come, appeal to his natural tend- 
ency of imitation or suggestibility. Of course, the parent and the teacher can never have the field to themselves, for the child's eager mind takes in ideas from every available source, at home, in school, on the street; from father and mother and teacher, but no less from the delivery boy and, possibly most of all, from the other children on the playground. Hence the educator must again call upon the above-mentioned forces of stimulation for the good and inhibition for the bad as they appear in this crop of chance-sown suggestions.

These are then the three fundamental educative processes, - the stimulation of good acts, the weeding out of the bad, and the suggestion of new desirable forms. The aim of perfection is to do all this with all vigilance, realizing that the child is being educated whenever he is awake; yet with such skill and delicacy and regard for child-nature as not to disturb his own happy activity nor hinder the delicate processes of nature; and finally, to awake the child as early as possible to take a hand in the work himself ; for he will never be really educated unless he educates himself. Yet this last, indispensable as it is, is one of the most delicate and hazardous tasks, for undue haste is likely to develop a prig, and too much delay may miss the step that leads to moral earnestness and autonomy of the will. Nevertheless, what is true of the physician is still more true of the educator, that his success lies in rendering his aid no longer necessary.

We cannot too strongly urge upon parents and teachers, especially of young children, the indispensable necessity of 
promoting the child's activity by furnishing outlets for his impulses. The most positive results in development take place through free and successful activity in the child himself. Moreover, the tone of the child's life is warmed and heightened by his activity. The baby not yet two years old is quite inspired and delighted with the task of pulling off his unbuttoned clothes: he can easily take off his shoes and stockings, and can make a fair attempt at putting them on. Hard as it is for grown people to realize, these little deeds are the very breath of life to the powers and budding will of the little one: success in them means as much to him as the accomplishment of our most cherished aims does to us. They are the top of his ambition, the tasks just in front of him, which he is burning to conquer. The awkward but eager motions are thrilling with educative nerve currents, and are the true exercises of the infant intelligence and will. Keep your hands off : let him grapple with the task and problem, helping only enough to avert discouragement and surrender. Bend your grown-up soul to rejoice with the child's littlegreat endeavors and achievements, and so be his guide and inspirer toward ever greater things.

It is fortunate that the child's natural attitude toward new tasks is much the same as that of the unsophisticated youth who, when asked if he could play the violin, replied that he 'didn't know, had never tried, but guessed he could.' One of the fine arts of education is to feed this child-confidence with tasks hard enough to be interesting and progressive, but not so hard as to cause despair. 
Let the little one struggle a bit with his own wraps; let him climb the steps with only a safeguarding touch of the parental hand: let the little girl early try her hand at simple household tasks, - while she still possesses a natural enthusiasm for them as new fields to conquer. That is a wise farmer-father who occasionally puts the reins into the hands of his seven-year-old son and lets him glow with the sense of driving the great horses, the father simply standing by, ready to give aid if needed.

All these native tendencies arise from the unconscious depths of the child's nature : he deserves neither praise for the good nor blame for what we may consider the bad in them. He is sometimes as much surprised and perplexed by them as are his parents, or possibly even more so, for they can see in his little tempests of passion the image of their own childhood. The native tendencies spring out of unconsciousness, unbidden, inevitable, and for the time irresistible. But the development of a human soul is a path from the dim, helpless, confused consciousness of the infant, with its utter lack of control over either body or mind, upward by imperceptible degrees, through ever growing clearness and order and ever increasing selfcontrol and direction, to the ripe wisdom and steady will of full manhood or womanhood. This long road is beset with perils and difficulties, and yet also marked with many guideposts of experience; no individual has ever found his way up the path without abundant help from those who have gone farther on it. That help is education, in 
the large and true sense of the word; as Emerson says :-

"Education should be as broad as man. Whatever elements are in him it should foster and demonstrate. If he be dexterous, his tuition should make it appear; if he be capable of dividing men by the trenchant sword of his thought, education should unsheath and sharpen it; if he is one to cement society by his all-reconciling affinities, oh! hasten their action! If he is jovial, if he is mercurial, if he is great-hearted, a cunning artificer, a strong commander, a potent ally, ingenious, useful, elegant, witty, prophet, diviner - society has need of all these." 1

The native tendencies are blind, confused, contradictory; character is intelligent, orderly, harmonious. Everywhere the development of character is the increase of understanding, system, adjustment, among impulses. The human soul, even in its early stages in the little child, is so complex, and the process of its development so largely hidden from our keenest discernment, that we may well shrink from the attempt to discuss or describe it; and yet for our purpose the attempt must be made, with full sense of the unavoidable imperfection of the result. In the succeeding chapters we shall offer for consideration a very plain and unpretentious analysis of the essentials of character, under the forms of Disposition, Habits, Tastes, the Personal Ideal, the Social Ideal, Strength of Character, and finally Religion. But no one can draw a hard and fast line between disposition and habits, nor

${ }^{1}$ Emerson, "Education" (Houghton, Mifflin and Co.), p. Io. 
between tastes and the personal ideal; nor between any two of the third, fourth, and fifth elements. And the last two are really the resultant and consummation of all. Nevertheless, the analysis has a use in helping us to survey the field of character. ${ }^{1}$

Again, we may say that disposition, habits, and tastes in general form early, and with little activity of consciousness; but we must not forget that they are subject to modification, and even profound change, in later life. We must also say that the personal ideal develops most powerfully in boyhood and youth, and the social ideal in youth and early manhood: yet both of these run back into childhood and forward into mature life. A certain phase of the process becomes conspicuous at a certain stage; but it began, at least in dim, half-conscious form, long before. And long after it has taken definite form, it still requires conservation lest it decay or atrophy.

We need, then, to write alongside every page that even the best description in words would be but a meager hint of this most complex and mysterious process in the universe : and, above all, that it must be interpreted in the light of patient and loving study of the living child.

1 The reader will be interested in comparing the analysis of character here given with those of other writers : of special value is that in Schofield's "Springs of Character," Chapters VIII and IX, and the analysis suggested by the general outline of President Hyde's excellent "Practical Ethics." 


\section{CHAPTER III}

\section{DisPosITION}

THE deepest-lying and most pervasive part of character is disposition: it accompanies us everywhere, and shows itself in all we do. It is the attitude of the soul toward life, the way in which we accept our situation and our daily experiences. On the inner side it gives color and tone to our own conscious life: on the outer side it pervades and modifies our conduct toward others and our reactions to events. A good disposition is indispensable to good character, though of course not all of character ; without it one cannot hope for perfection; even with it one may fail through lack of higher elements. It is a sort of foundation layer.

Disposition takes form so early that no one can say how much of it is innate or hereditary, and how much arises through experience and training; but there is no reason to doubt that it is susceptible to the influence of early environment. Its profound importance impels the educator to a diligent search for the truth as to its cultivation. No amount of pains and labor could be too high a price to pay for the secret of a good disposition and the means of assisting nature in its production.

Good disposition shows itself in two forms that may be 
indicated by these questions concerning the possessor: First, regarding his own affairs and experiences is he cheerful, hopeful, reasonable, contented? Second, toward others is he kind, helpful, charitable, in judgment? Cheerfulness and hope are the basis of a happy inner life; kindness and unselfishness the basis of happy relations to one's fellows and of a useful life.

I. Cheerfulness. Disposition may be called the climate of the soul: the varying moods of the day and hour are the weather, and their general average or tendency constitutes the disposition. There would seem to be as much difference between dispositions as between the most diverse climates, and we may fairly assume that the inner life of one man may be as different from that of another as the misty climate of the Grampian Hills is from the sunny skies of Italy. A psychic weather observer might compute the average cloudiness or sunshine of various souls, - some having ninety per cent clear days and others not ten.

A happy disposition is the more important because it seems so largely independent of circumstances: the cheerful man is happy in spite of troubles; the best good fortune fails to relieve the habitual gloom of the melancholy man. Milton might have been thinking of disposition when he wrote: "The mind is its own place, And of itself can make a Hell of Heaven, a Heaven of Hell."

This first element in disposition, the inner cheer and sunshine of the soul, rarely gets its due in our esteem, for 
the very reason that it is internal and eludes perception from without. The man may do all his work well, may meet his obligations in business and social life, may bear a spotless reputation, and even perform great services, private and public, and yet through it all carry a sad or gloomy consciousness; of that no outsider can have any full realization, nor indeed will the man himself usually understand fully what he is losing, for the simple reason that he has no standard by which to judge the difference between his own somber spirit and the sunny atmosphere of a normal life. ${ }^{1}$

Yet all the time this inner condition that affects the man's outer performance so slightly is actually making or marring the worth of his own life to him. The cheerful disposition doubles the brightness of joys, and puts the silver lining upon the clouds of sorrow; it multiplies the value of every experience and makes every hour of life worth living. The man who has a cheerful soul is more fortunate than one who spends the summer in the Adirondacks and the winter in California: he carries his warmth and glow with him.

This inner ministry is the chief service of the cheerful disposition, but it is not all. As happiness, from infancy on, flows naturally from health, so it is certain that there is a reflex, and that serenity and joy are positively hygienic and medicinal; 'laugh and grow fat' is not

1 The finest treatment of this subject known to the writer is in a lecture, as yet unpublished by President William Lowe Bryan, on "The Education of the Disposition." 
merely a jest, for the merry heart is good for digestion and circulation and assimilation, and especially for those mediators between body and soul, the nerves. The old physiologists were nearer the truth than they realized when they identified the elements of disposition with humors, the fluids of the bodily organism. Good humor cannot be put into a measuring glass, but it has a positive beneficence for the blood and is nature's best remedy for "bile" and spleen, either literal or figurative.

Nor is this all: the disposition is, it is true, an inner state and therefore known in its fullness only to the soul that contains it: but there are chinks enough in the earthly tabernacle to let out a goodly share of the inner radiance, for the cheer and enlightenment of others. That is a beautiful prayer which asks for the light of God's countenance; it is mainly fulfilled as things generally go, through the countenances of men and women. A man's value to society is by no means all subject to computation in terms of labor and effort and public service, good as these things are and praiseworthy; some of the highest service leaves no visible memorial, but consists in having appreciably brightened the atmosphere of social life in the home and store and street. Of such a man the homely proverb says, he is a good sight for sore eyes !

But disposition, being the basic health of the soul, does yet more: it clarifies and stimulates all activities. It aids clear thought, quick perception, prompt and resolute will, skillful and efficient work,- " "Give me the man who sings at his work," says the philosopher of common life; 
for not only is it good for him, and for me, who must work with him, but it is good for the work and the output. And how can one refrain from turning aside here to touch the other side of the question, - "Give me a work at which my heart can sing!" may well be the prayer of every man; it will be well when our economic practice wakes fully to the truth that this is a far more important question in real effect than the increase of the product and the decrease of costs. The general value of human life can never be very high so long as vast numbers are bound to tasks that kill joy and deaden the capacity for it.

To miss the joy is to miss all, says Stevenson; there is no surer way to miss the joy than to miss a cheerful disposition, - the very thing that redeemed Stevenson's own life and gave him the victory over disease and pain. A quiet force it is, often hardly recognized as a potent element in life, even by the owner himself; not to be gauged by any of the ordinary rules and measures of conduct and achievement; but underlying all character, affecting all activity, enhancing all conscious existence, worthy, therefore, to be greatly desired and ardently pursued in ourselves and in our children.

It must be clear that the cheerfulness we have been praising is not mere mirth, certainly not levity nor reckless abandon; Aristotle was right in declaring virtue, of every sort, to be a mean between two extremes, and our present case is no exception. It is as great a defect to lack seriousness as to indulge in sadness; cheerfulness 
paid for by frivolity is a poor bargain. The fool's paradise is a mirthful place, for the nonce; but its laughter is like the crackling of thorns under a pot, and is apt to die out suddenly and leave nothing but miserable ashes. Tiresome as the task may be to the superficial thinker, the study of life and character, as of other deep things, must always heed all of the injunctions upon the three successive gateways of the temple, - "Be bold," "Be very bold," "Be not too bold." In mechanics it takes at least two forces, and those opposing forces, to hold a body in equilibrium; and in the spiritual world no truth ever stands by itself nor on one principle, but must be protected from fallacy on both sides. So our exaltation of cheerfulness needs to be taken with the understanding that it is not the only virtue, and that other requisites of character will be found to push somewhat against it, not to thrust it out completely, but to guard it from excess, and preserve the poise and balance of the soul. And what is here said of this particular virtue applies to all; we shall do well to hold in mind throughout the wise old Greek's doctrine of virtue as the happy mean between the two vicious extremes.

Hopefulness is very close kin to cheerfulness, being the bright view of the future that links confidence in destiny with a certain assurance in one's own ability to aid in the desired result. Hopefulness is cheerfulness with forward look and stretched-out hand. All that is said in praise of cheerfulness is true of it, and it has an added practical value. The energetic element in hope probably rises in 
the impulses of activity and of self-assertion, and gives to the virtue its dynamic quality.

In the cultivation of every virtue the first step is the conservation and nurture of the native tendency; the taproot of cheerfulness of disposition is the natural springing joy of childhood; that must be favored and guarded in every way. The capital crime of early training is the killing of happiness; nothing could atone for that loss. Education has always talked much of the necessity of sacrificing the present to a greater future good; but here is one place at least where present and future have the same interest. The joy that illuminates the days and hours of childhood also lays the best foundation for strength and wisdom and health to serve maturity and old age. Let us make the most of these harmonies between the now and the future; they are really far more fundamental than the conflicts. All day long the healthy child plays in unalloyed delight, and every happy moment is laying up store of future good. Then comes an impulse or desire that is dangerous or harmful, and parental foresight interferes, with grief and tears on the part of the child. But before the seconds hand has ticked once around its dial, the sky has cleared, the nursery rings with shouts of happy laughter, - and the deeper education is again at work.

Make way, then, for child joy; let the house and'garden, and all who encompass the little one, conspire and labor to brighten every moment, for every bright moment adds fiber to the tissue of happy and healthy disposition. 
Take a lesson from the mother cat rolling and scuffling with her delighted kittens: and then see how far the child, even of a year old, surpasses the lower creatures in his rich comprehension and exuberant joy in play. Even bodily comfort is worth working for; let pain and annoyance be reduced to their lowest terms, and so the way be left free for higher positive pleasures.

So deep are the roots of disposition that at best we begin too late, and should seize the first weeks of infancy for the starting of our culture. As years pass and the child matures, the general rule is still the same, to multiply and magnify the happiness of the maturing life. If an early age shows success by the manifestation of the desired disposition, the educator must not relax his vigilance, for the present condition carries no absolute guarantee for the future. If the outcome is up to date less satisfactory, and the best opportunities are felt to be behind us, we must still, for so great an end, labor to wrest a measure of success from the poorer opportunities yet to come.

And now for the other side of the shield, - which we know from the beginning must be suryeved. We have been very bold in announcing the maxim, "Magnify the joy of the child"; nor is one iota of that to be abated. Yet that rule alone would defeat its own end, both for the present and the future, and result in spoiled and pampered children, and undisciplined and world-weary adults. Yet more, it must be said that while our fathers, or at least our grandfathers, erred toward harshness, we err to-day 
toward indulgence. So let us look the limitations in the face.

And first, while animals live chiefly in the moment, and by the moment, human life always exists through summation and consummation. So the exuberant joy of the moment is always to be computed in an average with what goes before and what follows. Rousseau fulminates against the schoolmaster who sacrifices the child's natural happiness to a hypothetical future welfare; but it is no better to jeopardize the rich and abundant years of manhood to the unregulated whims of child impulse. Let us write, then, that pleasures which injure body or mind, which sap the forces of digestion or of intellect, or vitiate the tastes, are no part of our duty toward the joy of childhood. Two things are clear : first, the child pays, and pays dearly, for these indulgences. The coffee that he gets by crying for it takes heavy toll from the delicate stomach and nerves, to be exacted soon and late in indigestion and nervousness. The late hours in which the boy or girl is indulged mark the cheek with chalk where it should be tinged with red blood, and by that token reveal the deduction from vigor, bodily exhilaration, and mental power. That the parent pays, too, needs no proof ; but we will not distress ourselves over that, since it is no more than justice.

Moreover, entertainment soon blunts the edge of enjoyment; the secret of child joy is not in being amused, but in needing no amusement, - and it is strange how the same truth fits grown-up life! Even a child's life con- 
sisteth not in the abundance of the things he hath, nor in the multiplicity of his means of amusement. The road to life is not through being amused, but in amusing one's self ; not in being diverted or entertained, but in having something to do that is worth doing, and in doing it. The whole truth is found in graphic form in "The Story of a Sand Pile," or, better still, in a real sand pile, with real children playing in it. Renunciation and abstinence will be recognized; not for their own sake, nor even for the added zest they give to pleasure when permitted, but because they are an integral part of the scheme of life, and contribute to its power and richness in manifold ways. The mother recognizes the truth when she puts a toy away for a week, so that the child's joy in it shall be made as good as new.

If the world were all playground and picnic, cheerfulness might be sufficiently developed by stimulating and cherishing the natural joys of childhood. But the good humor that works only when all goes well will not serve the turn, even in childhood. A more robust cheerfulness must be developed, one that can smile or at least refuse to cry under the test of pain, loss, misadventure, disappointment. Opportunity for the culture of this virtue begins early, before speech or reason have made much progress; the little man must be shown how to resist tears and pouts, and to pluck up cheer when his small affairs, great to him, go awry. The how of this teaching is hard to tell, but it can be done; until language opens the way for clearer communication, the mother's tones 
and manner must convey the proper comfort and encouragement, and waken the spirit of endurance and resistance in the little heart. The right method, as usual, lies in an invisible line of action, found only by grace of tact and sympathetic understanding, between too much comfort and too little stimulus on the one hand, which is coddling, and too little comfort and too much stimulus on the other hand, which alienates the small sufferer and breaks the power of suggestion.

As intelligence develops, the treatment should include the fullest practicable enlightenment of the young mind as to the virtue of courage and good cheer under tribulation, small and great. Very soon will the child take himself in hand, - sometimes with rigor enough to shame his elders.

2. Kindness. The warmth and beauty bestowed on the inner life by the cheerful disposition are imparted to the outer by kindness. Abraham Lincoln is the most beloved of our heroes by the power of his universal kindness; without that his honesty, his wit and logic, his will of flawless steel, and even his incomparable services to the Republic, would never have won him his place in our hearts and his power over our ideals and lives. It is no accident that as his character ripened and was fully revealed, "Honest Abe" became "Father Abraham." How deep in his own heart this quality was rooted is suggested by the comfort he took, late in life, from his sincere conviction that throughout he "had plucked a thorn where he could, and had planted a rose wherever 
he thought a rose would grow." Macbeth deliberately renounced the "milk of human kindness," and lived to find his outward success a sham, and himself poor because he lacked "what old age should have, as honor, love, obedience, troops of friends." All history and literature, as well as everyday life, put this quality of kindness into the catalogue of the indispensable virtues of human character.

There is health and growth in kindness of disposition as there is in cheerfulness; human life is so largely social that development of the individual depends much upon his right relation to his fellows, and kindness is the basic virtue of that relation. The child is to receive most of his early training and culture in unconscious interchange with those about him, and kindness opens up the channels for the healthy operation of this process. Good feeling toward our associates favors interest and confidence, and these encourage the spiritual commerce between elder and younger that is so large a part of education. Thus the importance of kindness of disposition is far deeper than the mere sweetness and charm of friendly and helpful association, and is a genuine condition of growth and cultivation. It is indeed the essential hygiene of social life, and social life is the essential condition of humanity; so without the spirit of kindness true human nature, with its powers of intelligence and feeling, would never have existed, and without the same disposition it cannot be preserved and enlarged.

The first maxim for the cultivation of the kindly dis- 
position is similar to the first in the cultivation of cheerfulness, - make way for the natural impulse of love and affection, so that it may well up freely in the full measure of nature's endowment. Use every means of example and suggestion to quicken and confirm the kindly impulses that spring so powerfully and so abundantly in the normal child. One of the most powerful conditions that favor the growth of kindness is the prevalence of cheerfulness; thus education works into its own hands, here, as in so many other cases ; all that is wisely done to cultivate cheerfulness smooths the way for kindliness also.

Avoid occasions of strife and conflict, either between child and elders, or between children playing together. Especially in the first two or three years, before the child can comprehend any explanation of his social relations, must every care be used in so ordering his material and social situation as to favor smoothness and contentment. This is the golden age for disposition, and in its favor we must, if need be, sacrifice, or rather postpone, some other forms of training; the truth is, there is as yet little danger as to permanent habits or ideals ; if we can conserve the basic strata of disposition, the rest can be built more efficiently and economically later. (It need hardly be repeated here that bodily health and development are of course even more fundamental than disposition; disposition being the first psychic element.)

Not that the mother need be worried by the little tempers and squabbles of children, which are the common lot of the normal flesh-and-blood youngster; only let the 
environment and regimen tend to avoid and minimize these, and so give the fullest time allowance to sunny and loving soul-weather; thus will the traces on the brain be predominantly for kindliness of permanent disposition.

The chief positive generator of disposition in general, and particularly of kindness, is what the modern psychologist calls suggestion, which is largely identical with the good old idea of example. The child is a psychic chameleon (and no one ever fully outgrows the nature), and takes his tone from those about him; whatever you desire in your child, have that in yourself : this is the deepest educational principle, and a wonderfully beneficent one to the educator also, for it spurs him to new moral achievement for the sake of his protegé. The law of example is the scripture, "Give and it shall be given unto you; full measure, shaken down, pressed together, running over," or, again, in adapted phrase, "Whatsoever ye would that your child should be to you, be ye even so unto him."

Yet this needs immediate interpretation: the old saying has it that "good mothers make bad daughters," and in the same sense it is true that kind parents may make selfish children; or even more strikingly true, that kind children may make selfish playmates. The mother who lets her affection overrule her better wisdom, her sense of justice, her knowledge of the child's real duty and welfare may indeed be responsible for the child's selfish and inconsiderate disposition. Especially is that parent perilously wrong who, out of a false softness toward her own 
child, permits the child to impose upon playmates and vent its petty spleen unpunished. True kindness does not always smile, but finds its fit expression rather in sharp reproof or stern command, or even in more decided discipline. Do not doubt the truth, O Mother or Teacher, that this brief necessary sharpness will give tone and power to your habitual and general love and gentleness, and so the two seeming opposites combine their forces toward the longed-for result.

Disposition and Habit. Disposition always lies perplexingly close to habit, and indeed, psychologically, not only disposition, but practically all the elements of education and character, are habit; that is, they consist of fixed ways of reacting to definite stimuli. Disposition, however, runs constantly into habit in the narrower sense in which we use the term. Cheerfulness and hopefulness, at first a general tone and tendency of the mind, embody and confirm themselves into certain definite ways of thinking and acting. The cheerful man gets into the way of 'looking on the bright side,' and of taking deliberate note of 'how much worse it might have been.' Out of the mass of contrasting elements in any situation he gives preference in his attention to the pleasant, the encouraging, the desirable. The hopeful disposition leads to the habit of picking out and emphasizing the more promising facts in the situation, and, what is even more important, out of several possible future results, fixing upon the most desirable one that reason will permit, and so opening the way for endeavor. 
The embodiment of disposition in habits is seen more clearly in the case of kindliness. As faith without works is dead, so kindness without its expression in helpfulness is a sham. The drama and the novel both powerfully stimulate the emotions of love and sympathy, and are both credited with great educative power; the serious question is whether the emotion which is thus smothered within the breast and robbed of all expression in conduct is not more injurious than beneficial. At any rate, it is a familiar fact that the playgoer who has been snuffling and wiping his eyes over the melodramatic woes of the heroine has no difficulty in ignoring the real misery and degradation that lie about him on his way home. Education proper cannot afford to lose the power of outward expression of all the inner emotional elements it seeks to cultivate.

All this points out the further path of training after the first stretch of disposition is covered; the educator encourages, by example, and now also by precept and explanation, all these good habits that grow naturally upon disposition. $\mathrm{He}$ watches the young mind in its encounter with its world, and, as opportunity offers, he puts in help and counsel to throw the balance in favor of the right action and so the right habituation. 


\section{CHAPTER IV}

\section{HABITS}

IN one sense the whole process of development consists of the formation of habits; for knowledge itself, and the powers of thought, as well as the higher elements in the will, all depend upon the establishment of fixed ways of reacting to given stimuli. Consequently, the general laws of habituation underlie the whole of education. But the term habit is more commonly restricted to those established reactions that act with little or no participation of consciousness, or, in other words, mechanically or automatically. Such habits as these begin to form very early, and constitute a kind of supporting framework for the higher elements of character.

The number of such habits is unlimited, and their form and use infinitely varied. Many are purely mechanical, as the movements of walking and running, the little arts of dressing, washing, combing the hair, the use of spoon and knife and fork, and a hundred other small accomplishments that must be mastered, with no small effort and perseverance, before the baby can claim to be boy or girl. The most marvelous of these mechanical habits is that of speech, including the complex processes 
required for the articulation of single words, and the still more intricate task of uttering phrases and sentences.] TOur general aim leads us to select from the great mass of habits a very few that have peculiar importance in relation to character: first, obedience, that stands by itself as the peculiar acquired virtue of childhood, and has a unique rôle in the development of the will; then three habits that should penetrate all activity and later development, industry, thoughtfulness, and truthfulness.].

\section{THE FORMATION OF HABITS}

Because habit is typical of all educative process and exhibits that process in its most definite form, the process of habit-formation is worth close attention. There is a prevalent idea that the mere repetition of an act will create a habit; now the churn dog treads the churn regularly on a certain day each week, but so far from forming a habit of churning on that day he forms a habit of "hiding out" whenever he gets a chance. The indolent boy goes to school every day in the week until Saturday, but he shows no tendency to form such a habit that he cannot stay away on Saturday; and when the vacation comes, or when his school days are over, his mind rebounds from school and all its works like a rubber ball from the side of the house. On the other hand, let the dog be practiced in driving the cows home at night, and he may develop an effective habit that will impel him to the act night after night; and let the boy go frequently to the gymnasium or swimming pool, and a habit will certainly be the result. 
The secret of the whole matter is that a habit is not the mere tendency to repeat a certain act, nor is it established by the mere repetition of the act. Habit is a fixed tendency to react or respond in a certain way to a given stimulus; and the formation of habit always involves the two elements, the stimulus and the response or reaction.? The indolent lad goes to school not in response to any stimulus in the school itself, but to the pressure of his father's will; when that stimulus is absent, the reaction as a matter of course does not occur. The churn dog has two real habits, one of obeying his master, which gets him into the treadmill upon command; the other, of trotting away with his paws when he feels the slats slipping from under him. When these two habits get together, they do the churning; if Rover slips away from sight and sound of his master's eye and voice, the necessary first stimulus is lacking and somebody besides Rover has to drudge at the churn.

The first practical inference is that mere external and visible acts are not a safe criterion as to the formation or existence of a habit: habit is a psychic thing, and its real form and value depend on the two psychic elements, the stimulus and the reaction that responds to it. Whenever the organism (the boy, for example) really and spontaneously responds to a certain stimulus with a certain act, the foundation is being laid for a real habit. The boy hears about what goes on at the gymnasium and has a natural tendency to respond by going; the oftener this natural tendency repeats itself, the stronger and more 
certain the reaction becomes, - always understood that other factors may intervene, as, for example, some more powerful attraction may usurp the time required for the gymnasium. The dog has a natural ancestral impulse to chase cows, and when he has responded under direction from his master, in a certain way for a sufficient number of times, he forms the habit and will go after the cows at the proper time without special command; the waning light, the late afternoon activities, and other signs are sufficient stimulus to provoke the response.

The second practical conclusion is the necessity for rooting a habit in a natural spontaneous tendency; it will never really grow in anything else, and the educator must seek the appropriate root with all diligence.

Finally, it is necessary to discern clearly what response and what stimulus we wish to cement into habit, and labor to embrace them in the training that is to produce the desired result: we must find a way of applying the stimulus, or more truly arousing the native impulse, so as to produce the desired reaction, then we must repeat this process with proper frequency and persistence. Let us pass on to consider how all this may apply to the particular habits we are to discuss.

I. Obedience. [In obedience the stimulus is the expressed will of a person in authority, and the response is the performance of the required act.] The will and its expression may vary almost indefinitely, from the strongest command to the slightest desire couched in the mildest suggestion or indicated by an almost imperceptible sign. 
It is necessary to note clearly that obedience is by no means general in its scope, but that it is confined to certain definite authorities, particularly the parents and elder relatives, and the teacher. The habit of complying with all requests or orders from whatsoever source would, of course, be far from a virtue.

In these days it is peculiarly necessary to understand that obedience, both as an act and as a habit, so far from being in any way derogatory to the honor of a human being or hostile to the happy freedom of childhood, is in vital accord with both of these. It springs from the soul of the child as naturally as do self-respect and personality, having its roots in one principal and several secondary impulses. The principal root is, of course, suggestibility, which makes the child tend to do whatever is put before him to be done. The secondary roots are in the impulses of activity, which makes him, as it were, hungry for things to do, and grateful to whomsoever will help him fill the void; in love, which binds him to those particular persons toward whom his obedience should be principally trained; and both last and least, yet indispensable, in fear, which fills up gaps in the other forces, and holds some ground until it can be occupied permanently by higher elements.

TThe importance of obedience in the evolution of the will, and therefore of character in the fullest sense, is immense. To put it briefly, obedience is the regent of the future independent will, playing a large part in the command of the immature life until the will itself can be formed and fitted to rule. Obedience is thus the virtue par 
excellence of childhood and the child who is not trained to a high degree in obedience is wronged beyond reparation because crippled for anything like full development in mature character. The little child has yet no will of his own, but only impulses, - numberless, unorganized, conflicting with each other and with all the conditions surrounding the child in the actual world. There is only one way of hope and safety, in the overruling power of mature wisdom and rational control. This control works through discipline (in the broad and genial sense of the term) and embodies its first result in obedience. Mainly through this external control and guidance do order and harmony enter into the field of impulses, transforming them graduually into a self-directing will, having unity within itself and acting in enlightened accord with the laws of the outer world.

A profound analogy exists, indeed, between the subordination of the child's caprice and immaturity to the enlightened and rational will of his elders, and that higher subordination of the impulses of the mature will to principles and ideals which constitutes the full perfection of character. Both are in a sense subordination to an external authority: the unseen monitor whose voice Socrates obeyed so implicitly was felt as coming from without his own personal spirit; the heroes and saints of all times have been persuaded of the existence and power of an authority beyond themselves; they have all held, in varying forms, the conviction of Jesus, "The Father, who dwelleth in me, he doeth the works." So obedience in the 
child is an apprenticeship, under simple and concrete terms, for the full mastership of will and the perfect realization of human personality. The child's will looks for guidance to parent and elders, having confidence in the rightness of their decisions ; but by imperceptible degrees his allegiance to these persons because they are right is transformed into allegiance to the right itself: and this is autonomy of the will and human personality.

The army is a sort of working model to illustrate the virtue and evolution of obedience. The young recruit obeys the whole hierarchy of officers, from corporal up to commander. After he has won some skill and practice in obeying, if he is an apt pupil at that, he may be raised one step, and given rule over a handful of men, literally "a corporal's guard" for a limited and special occasion. So upward he goes, his progress in command always depending upon his perfection in obedience. Moreover, military life also gives us the significant picture of grown men finding so much honor and delight in obedience that they go gladly to death in the service of a Cæsar or Napoleon, knowing no higher law or more excellent destiny than to follow his fortunes and execute his commands. Nor are they such men as could be suspected of weakness, pusillanimity, lack of spirit or energy. So little does obedience mean derogation of strength or dignity even among men.

To come nearer home, the child himself rejoices in the hand of a master, if only the hand be just, wise, and resolute. Who has not overheard school children passing familiar verdict upon this teacher and that, deriding weak- 
ness and indulgence, and glorying in the discipline, inconvenient though it was to their tricks and mischief, that abolished trifling and would brook no insubordination.

As to the cultivation of obedience, no one who has observed children's relations to parents and teachers can be in doubt as to the chief means to success : one parent may request, entreat, command, threaten, with scant effect and no genuine success; another needs only to speak or, like the King of the Gods, to nod, and it is done. $\mathrm{He}$ who would be obeyed must be worthy of commanding; then he will not often need to speak twice. Long before the child would understand the phrase, he knows whether his mother means what she says or not. Command is an influence of one will upon another, and it operates in accordance with a sort of mechanical law of superior force; not, be it quickly added, mechanical force, but psychic, volitional, spiritual. To secure obedience, as act and habit, let the educator seek to enrich his own spirit and imbue his rule with these three: the light of reason, in not requiring aught but what is just and sensible; the warmth of affection, in always seeking both the welfare and the happiness of the child; and the power of determination, in seeing through to the end what he has thoughtfully and kindly undertaken. Above all things, do not blame the child for disobedience; punishment you may have to resort to, but the real responsibility rests upon the educator, and he should search in his own spirit and conduct for the cause of failure. 
Very early, as soon as the child begins to understand words, a beginning can be made in simple directions and commands : "Bring it to Mother," "Pick up the dolly," "Put it on the table," and the like, break the path for the fuller operation of suggestibility, while, by the way, they also stimulate the intellectual processes in general and so have an additional justification in the training of the period. It is delightful and instructive to notice with how much pleasure the child exercises his new powers of comprehension and activity; at the sound of the words of request his face is filled with eager effort to grasp the meaning, and when the idea dawns he runs away gladly to carry it out in act. Very early, also, he may learn the meaning of $N o$, and have some training in submission to its authority. This brings us to two of the most useful practical maxims in the cultivation of obedience.

First, and most familiar, and yet far from properly recognized, is the principle of the active and positive. Do this jumps with the very nature of the child; Don't do that contradicts child-nature, and tends to countermand itself. The positive command enlists the mighty impulse of activity on the side of obedience; the prohibition sets that impulse at war with obedience. Certainly prohibition must have a place in all discipline, and the child must learn the force of $\mathrm{No}$; but right discipline has its main current and tenor in doing, not in refraining; the educator-authority is the guide and inspirer of the child's active life, making that life richer, more interesting, more valuable, to the child; and only as authority is thus the rec- 
ognized benefactor will true obedience, as act and as habit, result. The true Holy Spirit of Guidance is always a paraclete, as the Gospel has it, - one who goes on in advance and calls upon the disciple to follow and emulate.

It must be confessed that the school has been a great sinner through its negative morality; the good boy or girl in school is too often the one who does not do wrong, perfect deportment is too often a synonym for mere passivity, such as might be exemplified by a jellyfish. The essence of schoolroom order has been all don'ts: don't whisper, don't make a noise, don't leave your seat, don't disturb or annoy your neighbor, and so on ad nauseam. For all this, as for everything else in the world, there have been sufficient causes, but these do not make out a valid excuse. While pedagogy, both in theory and practice, has been backward, the prophets have long been declaring the truth: any teacher may get both light and inspiration from Emerson's "Education," Dewey's "School and Society," and Scott's "Social Education," to name only three out of many excellent sources.

There is unfortunately no reason to suppose that home discipline is much better: mothers and fathers also tend to mix far too many don'ts in their government, until children come to feel that their parents are the natural enemies of their activities. This is no plea for indulgence or slackness: on the contrary, as things are, discipline often falls into ruin, because a swarm of petty don'ts squander without effect the force that should go into one uncompromising $\mathrm{No}$; authority has spent itself in vain 
on mint and anise and cummin, and has no power to command over the greater things.

A wise old book on education tells the teacher and parent to avoid square issues; the square issue between parent and child is worse than the strait between Scylla and Charybdis: on the one side is obstinacy, resistance, rebellion, resentment, bitterness, the darkening of life for an hour or a day or sometimes for a tragically longer time. On the other is surrender and the loss of prestige and control. The worst strategy is to despise the strength of one's opponent, and it is poor pedagogy to minimize the difficulty of serious tasks; the happy solution of the problems of conflict of will between parent and child is found only "by prayer and fasting" figuratively speaking: that is, each individual must solve his own particular problem, and will need to bring to all his best wisdom, tact, and resolution. Some things may be said in general : first, of course, comes the absolute justice and reasonableness of the requirement made by the parent: the old-fashioned father who declared, not seldom with much warmth, that his will was law, was on the wrong tack, even if his will happened to be right in the particular point. The child must obey the parent's will, even when he cannot understand the reason, still because it is right; and as soon as the parent's will ceases to be right, it loses its authority in abstract justice, and will lose it in the eyes of the child. Be very sure you are right before you go ahead; and if you find out that you are wrong, retract and withdraw from the untenable position; hap- 
piness, dignity, authority, obedience, will all be enhanced in the long run.

The great positive means to obedience is authority; trite as this may seem, it needs emphasis. We have spoken of the suggestibility of the child, which leads him to perform any act that is presented to his mind, whether as an injunction or as a prohibition; but fortunately that is not all of suggestibility, for as soon as the child can comprehend the difference between do this and don't do that, he has a tendency to acquiesce; and as his training proceeds, this tendency to acquiesce is reënforced by discipline and experience, by rewards and punishments, and becomes more and more decisive. There are certainly many occasions when a counter-impulse overcomes the obeying impulse; but one of the most important things about impulses is the fact that an impulse is only a tendency, and its being overcome by another tendency does not abolish its existence and value. Indeed, there is in the child a tendency diametrically opposed to the obeying impulse; namely, the self-assertive or "contrary" impulse, that makes it incline to do just what it is told not to do, - although this impulse is more characteristic of some adults than of children. But, nevertheless, the obeying instinct is there, and the appeal to it is through clear, strong, decided command or prohibition, backed by vigorous action when need is.

The child is naturally responsive to the tones, manner, and attitude of authority, and the natural instinct should be early developed into habit, and so rendered permanent. 
A baby less than a year and a half old feels the difference between the voice of decision and that of irresolution, and acts accordingly. No wonder, then, that the older child has formed a fixed habit of obedience or disregard for father or mother. Nor is the child slow to seize an opportunity to put himself into the place of authority: sometimes the parent might well take lessons in the voice and manner of command from the child who has usurped the throne. The impulses of self-assertion are always ready to thrust themselves into the gap, and when they do rise in revolt, being, like all other child-impulses, violent and unmediated, an intolerable despotism results. Then caprice and whim take command not merely of the child and the household, but also of his development; the domestic turmoil might be endured, but the injury to the growing character is beyond repair or indemnity.

No study of obedience would be complete without a consideration of the place of fear. As we have already suggested, there is a sort of hierarchy of fears, beginning with the lowest form of blind, instinctive, panic fear, which has so little use in human development, and running through all degrees of greater and greater enlightenment and rationality, to such fear as, for example, Ingersoll had in mind when he said that Lincoln feared nothing except doing wrong; or as is implied in Shakespeare's lines, "I dare do all that may become a man; who dares do more is none." Panic fear, at the lower end of the scale, belongs to the subhuman stage of development, and is to be eliminated from the growing human soul with 
all possible speed and perfection; it is an almost unmitigated evil, checking healthy activity, and blocking the currents of genial and wholesome life and growth; besides being in itself one of the most painful experiences known to our consciousness.

Almost as bad is the crude fear of pain or punishment: like instinctive panic fear, it also depresses all the natural processes of life and therefore of growth, and has no light or leading in it. The child who acts or refrains purely from fear of punishment may thereby escape danger or avoid doing damage, but he makes no progress in his own moral nature. The punishment he fears is external to his own self, has no real hold on him except as it threatens to fall upon him; and when the actual imminence of the penalty passes over, the will of the child springs back to the forbidden act. Yet such fear must probably be used in most or all cases in early childhood, to save the yet irrational and uncomprehending child from doing injury to himself and to his surroundings, animate and inanimate. The next step above mere punishment, or the fear of it, is the dread of the disapproval and rebuke of the parent; this, it will be seen, involves much besides mere fear, for it is based upon love and respect. The third step is the fear of those consequences of the act that make it wrong in the eyes of the parent; but this has quite passed the limits of mere obedience and has risen to the stage of rational self-direction.

Fear, then, is to be gradually transformed into caution, prudence, and, best of all, conscience. The process is 
through enlightenment and awakening; in place of mere fear must come the perception of the danger or injury against which the fear was a sort of blind sentinel. Instead of the primitive selfishness in fear must arise a feeling for the opinions and wishes of parent or others in authority, and still higher, a sense of one's own situation and responsibility as a member of a community, large or small.

When all has been said in deprecation of rule by fear, one is driven to the opinion that our times, and particularly our own country, are in far less danger of too much fear than they are of too little respect; in the older type of discipline the child was likely to be repressed and dwarfed; now he is more apt to grow up to insubordination, both at home and toward the laws of the land. Reverence, which Goethe makes the very soul of training, is hardly to be mentioned.

2. Industry. Two factors multiplied together give the measure of efficiency: ability or skill, and industry; and of these industry is the greater, first, because it is more attainable to all, and second, because it not only multiplies skill to make efficiency, but it is an indispensable factor in the creation of skill; so industry enters twice into the calculation. Unfortunately, industry and its product, efficiency, have in this commercial age been elevated somewhat above their own place, dignified as that is. We have set up an idol of efficiency, with industry shining in reflected splendor, all to the neglect of some higher things, as, for example, real happiness and good conscience. So 
we may spare further glorification of industry, and pass to some of its essential elements and its genesis as a habit.

The restless activity of the child is at first, like other organic beginnings, without form and void. It has no purpose nor direction; its immediate external effects are apt to be quite as much injurious as beneficial. It is that energy without direction which, as Emerson says, is terrible. True, even child-nature begins early to provide some direction, for the child manifests marked preferences for some acts and occupations : these are the native or spontaneous interests. In the channels of these interests the activity of the child flows most freely and abundantly. But the native interests are far from being in full harmony with the outer world; many of them have their natural results in broken china and defaced wall paper, and must be inhibited or modified. Besides, they do not run of their own course into the occupations of the grown man or woman. Now the training of these natural activities and interests into a form that works into mature life and its duties, is the problem of the cultivation of the habit of industry.

First is the opening up of sufficient channels to allow the free flow of the natural energy, so that the flow may not be discouraged or checked, but may flourish and increase with the increase in years and powers. As we have seen in considering the impulse of activity, the organic health and development of the child demands much free movement: and especially does the maintenance of his output of energy, which so largely fixes the limit of his 
later efficiency, depend upon the largest scope and encouragement of the child's abundant spring of activity; for the outgoing currents of motor activity send back stimulus and nurture to his organic life. Adult human beings can be computed by a sort of indicated horse power, like engines or turbine wheels; the training of the child should nurture and increase this potential energy for manhood or womanhood.

Too little attention is paid to the educative quality of toys and plays; the plaything that gives the child something to make or do has the beauty of gratifying the child's love of action and construction, and at the same time exercising a subtle yet considerable influence on his development into the habit of activity and industry. ${ }^{1}$ As an example of the wrong method we recall a father who brought home for his ten-year-old son a marvelous play fortress, made in a score of parts to be put together, not without pains and thought, to make the complete model with its walls and bastions, cannons and sentries, buildings and flagpoles. The boy was quite old enough to master the task, would have been enchanted with the doing of it, and, moreover, greatly needed the kind of training it would have given, and yet the father spent a whole hour after the boy's bedtime setting up the model, so that the boy might see it all complete the next day; so far as I know, the boy never set it up himself at all, for fear he should break it, forsooth.

1 See Paulsen's charming and illuminating essay "Village and Village School," in the Educational Review, December, I906, especially pp. 449-450. 
The harmony between the child's nature and the needs of his development is manifested in his love for toys and plays that set him to work; blocks, tops, marbles, puzzles, balls of all kinds, hoops, skates, and so on ad libitum, all set tasks upon which the youngster may whet his energy and persistence. The best toy is the one that will get the most work out of the child; the poorest, the one on which some one else has done all the work in advance. The German fortress was bad enough to begin with, for the lad might better have made most of the parts himself ; the father robbed it of its remaining value and left it only the power to stimulate idle curiosity and militarism.

Next comes the direction of this energy: while the natural interests of the child do not fit his environment nor his prospective occupation exactly, yet education must rely upon them to vitalize whatever direction it wishes to give to activity. We dare not crush nor choke these interests, for that would destroy or diminish the potential energy; but we must - and fortunately we can - find among the native interests those that may be modified or developed into adult activities. Sometimes a child comes into the world clearly marked for some particular work, - he is from the first a musician, or an engineer, or a trader; but far oftener his interests are so manifold and so mutable that no one of them stands out above the rest. But really in either case the essential basis will be found for the development of healthy and useful activities. The fact is that the bare impulse of the infant to be moving, changes at a tender age to an impulse to be 
doing something; and soon the child develops a marked love of making his impress upon his environment, of constructing something, or changing things in some way that suits his fancy.

The great resource of training at this point is another of the native tendencies, that of suggestibility, by which the example and precept of the elder may provide definite forms for the child's activity : he will do with delight what he is shown or what he is told. Indeed, he is constantly on the lookout for things to do, and the mere sight of sweeping or hammering or writing sets off his impulse to attempt the same, long before his untrained hand has power to perfect the trick, or his limited intelligence can grasp the purpose and the method. So the selection and direction of activities is not so hard a task as it might be. It does call, however, for far more patient and extensive observation and study of child-activity than the adult world has yet performed; and this task is largely in the hands of the parent. The secret is to find the sort of things that the child does naturally and easily, and work through them to the desired ends.

As soon as we begin to select certain of the child's interests and try to favor them above others, we meet the problem of concentration and endurance: the child must learn to overcome obstacles instead of giving way to them or merely being exasperated by them; and he must begin to increase his power to stick to the same task even after the charm of novelty is worn off. Both of these powers are small in childhood, but are indispensable to mature 
character. Some one has said that one of the best results of education is the power to do the thing you don't want to do, at the time you don't want to do it. We must not overtask the child's limited endurance, but he must learn the difference between being really tired, and merely tired of the particular task at which he is engaged.

Closely connected with the increase in persistence is the development of the sense of responsibility for a particular task: the moral philosopher is fond of saying that there is a work in the world for each one of us which no one else can do, and the sooner the small man gets this idea, the better for him and his development. Industry is devotion to one's own work, and the child can never get any effective training in it until he has tasks of his very own. Just here is where modern urban life, which is the destiny of so large a proportion of children, is at a serious disadvantage: there are neither cows to milk nor wood to chop, and in many cases not even a chance for the girl to wash dishes or beher mother's responsible aid in thekitchen. Yet for a boy or girl to reach the age of fifteen without having had generous experience of regular, individual tasks, is like letting them go all these years with one arm in a sling; atrophy of the unused capacity is the natural consequence in either case. ${ }^{1}$

School work is doubtless of great use in this direction, the more as the newer ideas of activity and individual work win fuller recognition in the schoolroom. But the

${ }^{1}$ See again Paulsen's essay, "Village and Village School," Educational Review, December, I906. 
older type of school work has little power in the establishment of the habit of industry; and it is not yet safe for the home and parent to depend upon the school; home tasks, in immediate relation to the common family life, are more effective and richer in their results. Moreover, even the school task must be backed up by home forces if it is to bear its full fruit of training in industry: shirking is hard to treat and cure in school, and comparatively easy through home coöperation.

At the risk of getting beyond the boundaries of habit, we must refer here to an element that vitalizes the habit of industry and insures its permanence; that is, the power to pursue a purpose having its realization some time hence, the remote aim, we may call it. The poet says the thoughts of youth are long, long thoughts, and it is partly true; but the child's grasp of future ends is conspicuously weak. The infant necessarily lives in the moment without the faintest idea of the future; the little child clings to the joy at hand, unmoved by the assurance that sacrifice now will give tenfold returns to-morrow. Only by slow degrees is foresight gained and the power to strive or endure for the time, in order to reap the fruit later. The development of this power is intimately related with the habit of industry, each supporting and promoting the other.

3. Thoughtfulness. The world is more and more ruled by brains, and the man who leads must think. Waste, loss, accident, and disease are traceable largely to ignorance and heedlessness; the best remedy for both these 
defects is the habit of thinking. We have already seen how generously nature has provided the impulse to thought in the little child, in the form of sense-hunger, followed by curiosity or the hunger for knowledge ; these impulses grow into a habit of thought as naturally as the tree grows out of the shoot; all that is necessary is that the child's countless and ceaseless questions, What? and Why? and How? shall be reasonably encouraged and satisfied; for thinking in adult life is simply applying the same attitude of query and investigation to the objects and problems one meets from day to day, and to the great world of nature and spirit in which one lives. Unhappily we must admit that the keen edge of child-curiosity is often blunted in early years, and the youth becomes indifferent or even averse to mental activity: how much this is due to parental repression of the child's questions, and how much to school tasks and drill that have no appeal to child-nature, is a hard question; at any rate, it is worth while for both parent and teacher to shun everything that tends to quench the flame of this impulse.

The positive nurture of the native impulse of curiosity into the habit of thought is one of the most delightful tasks of parenthood; here the parent finds a peculiar double relation to the child, being first guide and superior, then, when the child grasps the new idea, standing on the same plane of intellectual equality; for logic and pure reason know nothing of youth or age, and when two minds think the same thought, they experience a happy community. It need hardly be added that the teacher shares 
this experience with the parent, and finds it one of the chief rewards of his work. It is also clear that stimulus rather than information is what the young mind needs: the parent should sharpen the child's senses, helping him to see, hear, feel, perceive, what he might otherwise ignore. This is the first form of mental awakening, and leads almost infallibly to higher forms. A walk in the woods is an ideal occasion for such culture: forms and colors of trees, flowers, moss, rocks, and soils ; the songs of birds and the cries of animals, the shapes and tints of clouds, - all offer natural attraction and stimulus for sensory cultivation. Excellent are also the forms of water, - rain, mist, snow and its crystals, ice and icicles, streams with their rapids and falls, and placid surfaces with their reflections.

As the child grows older, the emphasis passes insensibly from mere perception to judgment and reason, and the rôle of the parent becomes more exacting and perhaps even more inspiring. To be successful now demands that one think well oneself, - not necessarily with great erudition or scientific information, but with clearness, coherence, good reasoning, so that the same excellencies may be formed in the child-mind. Ever and always the great achievement is to let the child think, and so keep open and free the channels of the native impulse, from which alone the habit can be developed.

But the objection will already have risen in the minds of many readers, that so we shall force the child to a false precocity that will mar his natural simplicity and damage 
his health: both dangers are real, but neither has any necessary connection with the training we have been describing. Priggishness is not at all the habit of thinking about things, but rather of prating about them to those who already know more than the would-be informant. Such a tendency is apt to show itself in any child, thoughtful or thoughtless, quite as likely in the latter as the former. It should, of course, be gently but firmly repressed and discouraged, like other spiritual weeds. Moreover, a little premature book knowledge tends far more to obnoxious precocity than does the more natural mental culture we have hinted at, through nature and the child's own surroundings.

As to health, there is no evidence that mental alertness is detrimental to bodily growth and vigor. Some one may answer, "But what about the children who must be taken out of school to recover from anæmia, nervousness, general debility, or arrested physical development?" First, we have said not a word about school ; the most enthusiastic advocate of school education cannot shut his eyes to the fact that the schoolroom as we have it, even in the best form, is not calculated to minister to physical prosperity; it restricts natural movement, taxes sight and hearing, puts strain upon the nerves, and often, probably usually, gives the child impure air to breathe. Happily we live in the hopeful dawn of a better day in school regimen and hygiene; it would be well if those who criticize our present schools so freely could serve a term or two in a school of the old type, with its hard and shapeless benches, its foul 
air, bad light, deadly dullness of curriculum, and harshness of discipline. Besides this, we risk the assertion that the child who has been led to think a little before going to school, in the manner we have indicated, will deal more easily with his school tasks, and be less likely to break down.

The fact is that children stop growing, become nervous, and break down, not from too much mental activity, but from too little fresh air, outdoor exercise, sunshine, sleep, and in general from a false and noxious physical regimen. Naturally a boy of ten or fifteen who spends reading or dabbling in a laboratory the hours in which nature demands that he should play ball, run, shout, wrestle, and work his lungs and heart like steam engines, will be pale and feeble, an easy prey to disease, and a hopeful candidate for invalidism. The trouble is not that he thinks too much, but that he plays too little. The boy who sits behind the stove and reads hour-long, should be driven out of doors; or, rather, no child should ever be allowed to grow into such a boy. Let no one fear precocity, so long as the child eats heartily, sleeps long and soundly, and plays exuberantly, as every normal child does.

We must not omit to speak of one form of thoughtfulness which is of peculiar importance; we mean consideration for the feelings and interests of others. It is true that this is far more than a habit, and reaches up into the highest ranges of our spiritual life; yet its best foundations are laid in the mental habit of taking our fellows into 
account in all our deliberations and plans. The importance of this lower habitual element is shown in those people who have the best intentions, and who, when they are reminded of it, are kindness itself, but who through 'thoughtlessness,' constantly tread on the toes of their friends and associates and omit the simplest acts of helpfulness and regard. Nor are persons unknown whose higher principles are not all that could be desired, and who may be at heart rather selfish, and yet whose habitual consideration for others wins them love and contributes largely to the happiness of their associates. How great, then, is the benefit when to the good heart is joined constant outward manifestation in a habit of kindly consideration. Just as the parent may stimulate and sharpen the child's sense for the outer world, and his comprehension of its forms and laws, so can he cultivate his perception and comprehension of the interests, feelings, plans, and wishes of his associates in the home and at play. The Golden Rule is one of the best auxiliaries in this task: the average child can quickly transfer his own feeling to the case of his playmate, and thus see his problems in a new and true light.

4. Truthfulness. The first thing to say about the habit of truthfulness is that it is not a habit, but something far greater; as Richter says in his golden chapter on this virtue, "Truthfulness - that is, deliberate and self-sacrificing truthfulness, - is not so much a branch as rather the very flower of manly moral strength. Weaklings cannot but lie, let them hate it as they will." 
Under stress of trial and temptation no habit, nor set of habits, will stand; only ideals and principles will then hold a man firm in the truth. Nevertheless there is justification in treating truthfulness along with habits; and, first, because lying is a habit in some defective or ill-starred children.

The child naturally tells the truth as a part of his basic suggestibility: every idea tends to utter itself in word or deed: so when he has seen, heard, experienced, anything whatsoever, and has the image of it in his mind, he naturally puts that image into words. Similarly, when he has in mind an intention or plan for the future, it is natural for him upon occasion to express that in words also. This we believe to be absolutely true, and profoundly important in any study of the real nature of truthfulness and its contraries. But here, as with so many other natural tendencies, we must at once recognize the existence and power of conflicting forces that are just as natural. [ In childhood this natural tendency to truth is almost as fragile as the glassy surface of still water, on which the slightest breath of air will stir a thousand ripples, distorting and effacing the clear image that was just now mirrored in the pool. So impulses and contingencies blow in upon the mirror of truthfulness in the child's soul, and break its clear images into contradictions, exaggerations, equivocations, fantasies, evasions, and all other forms of untruth.] Two questions may be asked: first, What are the chief enemies of truthfulness in the child's life? and, second, How may the frail original tendency to truth telling be 
invigorated and reënforced into that devotion to the truth that is so indispensable to human character?

[Three elements threaten the child's natural truthfulness; imagination, fear, and desire.] $[$ The first produces images that do not correspond with reality, and these images have just the same suggestive power as the real, and lead to the 'romancing' that is so marked in certain children, - naturally in those possessing vivid fancy. Many parents are familiar with this type of untruth; Richter tells of a little girl, truthful in all ordinary matters, who told him enthusiastic stories of how she had seen the Christ Child, and what he had said and done. Sometimes these fancy-pictures are told with evident consciousness of their fiction, or even humor; Sully tells of a little boy who, when asked who told him something, answered, "Dolly"; then burst into a laugh. All these forms of untruth must be regarded as a part of the child's play, on exactly the same footing as his other makebelieves. Only when they take on any shade of real attempt to deceive should they be rebuked and discouraged. To quote Richter: "In all these cases, do not hold before the child the image of the lie in its own forbidding blackness, but simply say; 'Don't joke about it any more, but be serious." " The same talented writer makes the interesting suggestion that children's fantastic narratives may sometimes be dreams which their immature minds have not been able to distinguish from actual experiences.

Far more serious are the falsehoods generated by fear 
and desire, and especially the former. Here let us parents and teachers take to heart that weighty declaration of the Gospel: Woe unto him that causeth one of these little ones to stumble! Avoid as far as may be the inquisitorial question that tempts so sorely to denial of conscious wrong; learn the facts, if you possibly can, without cross-examination of the culprit. It would seem that the criminal court, which does not require the prisoner to testify against himself, is more considerate of human frailty in the adult than the parental and pedagogical judiciary is of the tender conscience of the child! Above all, let parent and teacher keep green the memory of their own childhood fears and the terrors of parental rebuke and displeasure.

To punish the lie of fear is attempting to cure one wound by inflicting another; it commissions a new fear to aid the old one in its attack upon truth. The most effective remedy is the grief that the parent should feel, and wisely manifest, that his child should be so lightly bound to him; and the tender endeavor to renew and strengthen those ties of affection and trust that would make repetition of the fault impossible. Courage and honor must also be called upon to condemn and forbid stooping to deceit in order to escape penalty.

Very different is the lie of deliberation or cunning, told to escape consequences of wrong or avoid unpleasantness of any sort; such lies point to that most perilous of all states, in which shrewdness has outrun conscience, and character is menaced by excess of intellect over principle. Here 
sharp rebuke and cutting penalty are in place; especially must the child feel the contempt and abhorrence of his elders for the lie, - not, be it noted, for him, but for the act: he must be helped to convict and expel the wrong deed and so make it foreign to his own being, and to aid in this the condemnation must be leveled at the deed rather than the young doer.

It need hardly be said that in all cases of escape-lies it it highly important that the escape should fail and the lie prove futile. Letting the children pull the wool over one's eyes is doubly dangerous through the encouragement it lends to dishonesty and deceit. This evil is extreme in certain forms of 'self-reporting,' as when pupils in school answer the roll call at night with a statement of the number of times they have whispered: honest confession is penalized, a premium put on smug deceit, and a general decay of faith in righteousness ensues. Neither parent nor teacher can afford to forget to be wise as serpents, as well as harmless as doves.

Still worse is the contrary error of distrust and suspicion toward the children. It is a very commonplace experience that children will deceive one who suspects them, when they would scorn to tell anything but the truth to those who put trust in them. It is unfortunate for the parent or teacher to be deceived by the child, but it is ten times worse that lack of confidence on the side of the elder should breed lack of candor and good faith in the younger.

Chapters have been written on children's lies; far more 
important and infinitely sadder would be the chapters on the lies of parents. We have not seen reports of any questionnaire on this subject, and unfortunately the returns from such an inquiry would be inherently worthless; but we risk the assertion that in number, variety, enormity, and, above all, in damage done, the untruths of parents would put those of children into the shade. False threats and false promises, lies in jest and lies in earnest, foolish lies and cunning lies, all find their place in the catalogue. The astonishing thing is that men and women who are reasonably scrupulous in their communications to their adult associates will often play fast and loose with the truth in dealing with their children. As to that favorite question concerning the original truthfulness or untruthfulness of children, it would be as easy to prove that children were born truthful and some were corrupted by unscrupulous parents, as that all were born without truthfulness and some were saved by the virtuous precept and example of fathers and mothers.

The little child conceives father and mother as all that we adults embody in our idea of the Divine, and the inevitable disillusionment that comes with wider knowledge is at best a serious and painful experience; can we not recall the sad surprise with which we first became aware that there were things beyond the wisdom and power of our fathers? Happy is the child who at least finds no need of abating his complete confidence in the honor of his parents: he is safe from the greatest peril that can threaten his own ideals of truthfulness. 
Happily, the majority of normal children, probably all of them, have a deep and potent horror of lies : excepting 'coward' only, 'liar' is the most intolerable epithet in schoolboy parlance. Probably most of us can still recall the dark and wretched shame we felt as little children after having fallen in a moment of stress into falsehood, or what we considered as such. The very love of children for 'really-truly' stories is significant; as is the protest the little child will make against the slightest variation from the exact text of a favorite tale. Whether this element of conscience is native or an acquisition of the earliest years does not concern us here; it is there, and is a powerful force for truthfulness.

We may well conclude this part of our discussion by a return to the first proposition, that truthfulness as a positive, resistant, and aggressive virtue is the very flower of a perfected character; we shall meet it again, and its associated higher virtues, in the form of ideals and life principles, in the higher regions of conscious moral life.

Bad Habits. Although our theme is the essentials of character, and bad habits cannot possibly be one of these, yet we must turn aside for a moment to consider what are commonly known as "bad habits," for the reason that they are the insidious foes of all the elements of true character, and therefore the student of moral education or the worker in the field must be intelligent about these pathological forms of habit. Bad habits are so called first because they damage the body or the mind and stunt their development, and, second, because they en- 
slave the will and make full spiritual freedom impossible. In extreme cases the evil habit paralyzes all other impulses and principles and exercises complete tyranny over the life and conduct of its victim; even the smallest habit that defies the sovereignty of free rational choice is a deduction from fullness of life.

Let us emphasize first of all that the only safe and final protection against bad habits is abundance of healthy, happy, natural activity; 'overcome evil with good' is the key to this problem, as to many others. Certainly there are special precautions and remedies for various cases, but these are subordinate and temporary; even if we could by the aid of these drive out the bad habit, unless we provide abundance of wholesome activity, the case is likely to be that of the Gospel parable, where the ejected devil returns to find his former dwelling 'empty, swept, and garnished,' and enters in with seven other devils worse than himself. Children and youths, of all human beings, crave activity and variety with an insatiable hunger; if they do not find healthy occupation and diversion, they will inevitably acquire or even devise abnormal and injurious activities. This is the great excellence of games and sports, and also of various arts and accomplishments that in terest and occupy boys and girls.

By wholesome activity, then, we cut off the bad habit by refusing it time and space in which to take root. Next we must arm against it all the forces of self-respect and personal honor, of which we shall speak fully in a later chapter. One more point here, concerning parental (and 
educational) vigilance against the beginnings of these habits. The very nature of habit is to be weak at first and to grow progressively strong until it becomes irresistible. This is peculiarly true in the case of the worst forms of bad habits, for they are contrary to nature, and so at the outset easily crowded out of the soul by normal impulses; but soon they pervert the very nature of the soul, corrupt the currents of healthy life, and paralyze the very forces that should expel them. The most perplexing and perilous of bodily vices are eminently of this pathological type; probably in every case the pernicious habit might have been nipped in the bud if only some wise and loving elder could have known of the first lapses into the act. Vigilance should include preventive precepts and enlightenment given at the fit time and in an appropriate manner; a prophylactic, as it were, arming the youth against certain particular perils, such as the ones already mentioned, and such minor vices as gambling, cigarette smoking, swearing, and the like. 


\section{CHAPTER V}

\section{TASTES}

OUR likes and dislikes exert a fateful influence upon both our own happiness and our value to others. The ancients recognized this fully, but modern education has long neglected it and is now slowly beginning to rub its eyes and awake to the significance of training the tastes. To like the wrong things may mean the ruin of body and soul, a worthless and wretched life, and all that we may well pray to be delivered from. To like the right things is an indispensable condition to health of body and mind, to contentment and happiness, and to usefulness. Likes and dislikes run powerfully into habits and even affect principles: for when we are fond of a certain pleasure it is hard for us to condemn it, even though our reason bids us do so. It is a too familiar fact that some of the most deadly foes of physical health and vigor are certain tastes, either pathological, like that for intoxicants and narcotics, or excessive, as those of the gormand or sensualist.

Man must fill up his life with something : if good is not at hand to attract and satisfy, then he will needs "fill his belly with the husks" that only swine should eat. Those classes and groups of men who almost universally indulge in drunkenness, as, for example, miners and marine stokers, 
do so in the main not because they are morally worse than others, but because either from natural defect or lack of culture they have nothing better to do: to all higher enjoyments they are strangers, and the universal hunger for pleasure and diversion leads them irresistibly into those coarse and violent indulgences that are within their range. What is shown in lurid colors in them is simply the extreme of all cases in which the education of the tastes has been neglected; their lives are a striking and terrible object lesson; but every man whose tastes have been allowed to develop in wrong directions, or in whom the best tastes have failed of higher perfection, loses thereby from the inner joy and outer value of his whole life. Every good taste is a source and guarantee of happy, healthy hours and days, and thus of the enrichment and elevation of life.

Of social and economic conditions that doom thousands of men and women to such unceasing toil and squalid surroundings that higher tastes are absolutely out of the question, what shall be said? At least this, that education is only half of the remedy: hence the need, emphasized elsewhere, of the educator, especially the parent, working also for general social uplift, in order that his educative labors may not be nullified by the crushing force of unfavorable environment.

The aim of the education of the tastes will, of course, vary in detail with every individual child, in accordance with the peculiar bent of his natural impulses. But here, as elsewhere in human nature, there are some universals, 
and to these let us first turn. First of all is it clear that we should cultivate tastes that are wholesome, that not only do not injure but actually aid and encourage normal growth and healthy function in body and mind. Not quite so evident, perhaps, but quite as true, is it that we should strive for inexpensive tastes; this because expensive pleasures lay a heavy economic burden upon both the individual and upon the community: the man who, in order to enjoy himself, must have costly food, elegant clothing, a great establishment, high-priced wines and cigars, automobiles, steam yachts, and the like, must needs get possession of great sums of money; sometimes it is the woman who has the expensive tastes; in either case the pressure is the same, and the disastrous results to individual and social morals are just beginning to be exposed in our own days. "The love of money is a root of all evil," and costly tastes create love of money, and a host of evils come in the train. Every parent wants his child to be able to 'earn a living' and gain enough to satisfy his wants; but not all recognize that this end may be forwarded not only by increasing his earning power, but also by training him to be happy without much; in other words, by cultivating simple and inexpensive tastes. Fortunately the two kinds of tastes are largely identical: the most wholesome tastes are simple and inexpensive; the unbought joys of life in general minister to health and abundant vigor in soul and body. Let us consider in particular a few of these wholesome and inexpensive tastes. 
I. Wholesome Food. First of all comes one already hinted at in a previous passage, the taste for wholesome and natural food. To harp upon this theme seems almost an affront to the intelligence of the early guardians of childhood; but it is hard to escape the conviction that thousands of children constantly suffer in their present health and their future welfare by indulgence in unsuitable diet. The truth is that certain artificial articles of food have the power of stimulating the sense of taste very highly, and so exercising a sort of fascination upon the child: having once tasted the sugary, high-seasoned, or aromatic, he no longer cares for the milk and bread and other common foods that his stomach really needs. He rejects these healthy foods and demands the others : seldom, indeed, has the mother, who has indulged him so far, the resolution to let hunger, if need be, cure the corruption of taste that indulgence has wrought.

Every day that the child's acquaintance with the taste of complex or high-flavored food and drink can be postponed is a day saved, and an advance made in the grounding of natural tastes. We have already called attention to the presence of strong native appetite for the wholesome foods of childhood; the whole battle consists in feeding these tastes abundantly and religiously avoiding even awakening the others. The method is infallible: the only difficulty is in executing it, and that difficulty will yield to vigilance and resolution; the conflict is of true parental love versus indulgence, of intelligence and foresight against ignorance or feebleness of will. 
2. Bodily Activity. We have already spoken of the powerful native tendency of the child to bodily activity - the first and most notable tendency in the earliest period of childhood. The primitive life of uncivilized men always gave abundant scope and encouragement for this tendency to establish itself thoroughly as a habit, and under those conditions there was no need of special training to secure continued activity and efficiency of the body. Civilization, however, has changed all this, and many of the callings followed by civilized man offer little opportunity and encouragement for physical activity and vigor. The active and stimulating existence and outdoor life of the savage, exposed to the vicissitudes of weather and full of emergencies calling for strength and swiftness of limb, steady nerve, and long endurance, has given way to indoor life, bound to chairs and tables and desks, excluding the breezy open-air stimulus, forbidding all but the smallest amount of muscular movement. The result is that in the majority of cases the impulses of bodily activity in the child are checked and starved, and fail to be established as habits. The grown man and woman become averse to running, leaping, jumping, and other strenuous exercises, lose strength of muscle and keenness of nerve, and lapse into a comparative feeble and indolent physique. As Smiles says, "Hence in this age of progress we find so many stomachs weak as blotting paper, - hearts indicating 'fatty degeneration,' - unused, pithless hands, calveless legs and limp bodies, without any elastic spring in them. . . . The mind itself grows sickly 
and distempered, the pursuit of knowledge is impeded, and manhood becomes withered, sickly, and stunted." Books have been written on the terrible threat of race degeneracy involved in this lapse of physical activity. It is clear that one of the duties of civilized education is to throw its powerful influence into the scale to conserve the native impulses and establish in permanent form the love and habit of bodily activity.

Fortunately, the educational thought of our own time is thoroughly awake to the priceless value of play; the deep meaning of the universal play instinct in the child has dawned upon us, and we realize that intellectual progress which is gained at the expense of the child's love of play and habit of play is too dearly bought. So we find schools, particularly in the primary grades, reducing the amount of mental work, increasing the proportion of physical activity in actual school work and making positive provision in the shape of playgrounds, gymnasiums, field sports, excursions, and the like, for the physical development of the child.

Every boy and every girl should be allowed and encouraged and, if necessary, compelled to keep up his bodily activity and efficiency. He should form what we may call the athletic habit, by which we mean first an intense love of physical activity in a variety of forms and also a settled habit of practicing such activity throughout his life. We have treated this whole subject under that of tastes rather than habits, because the really most important thing is the love of an activity. The child, like the calf, the colt, and 
the lamb, is filled with a physical joy; every muscular movement thrills and exhilarates. This is the thing that we should most strive to preserve. For if the love of activity exists, the opportunity will be found and used. Hence the unrivaled value of play and sport, free and unconstrained, the natural and spontaneous expression of child-nature.

Closely bound up with this athletic habit is what might be called the outdoor habit, - the love of fresh air, fields, woods, and streams; indifference to minor bodily discomfort, such as cold and heat, dampness, soiled hands, and even bruised and scratched bodies. It is a far greater defect in a child not to be able to climb a tree, swim a stream, jump a ditch, or run a half-mile, than to be unable to spell long words or tell the agricultural products of Bolivia.

To take a rather long look at this question, we may note the fact that a human being may actually fend off the encroachments of physical old age by preserving this habit of activity. Gladstone at eighty could still swing a broadax with delight and effect. Our own exemplar of approximate human perfection, President Eliot, is more vigorous in body at seventy-five than the majority of men at forty. In both these cases the joy and habit of bodily activity have been assiduously preserved throughout life. It is surely not necessary to dwell here upon the intimate relation of body and soul, and upon the fact that a perfect human life requires perfection in both sides of its nature; and, furthermore, that every added element of 
strength and vigor in the body is in itself a ground and cause for greater mental and spiritual power.

In adolescence - that great crisis in human development - the battle against the peculiar perils of the period is half won if the boy still possesses the full joy of bodily vigor and perfection. Excessive sexual impulses and morbid or perverted tendencies find no foothold in a body hardened by athletic habits and seasoned by outdoor exercise. Moreover, the very pride of bodily perfection - of which we shall speak more fully in a later chapter - is one of the greatest bulwarks against all forms of vice.

It need hardly be said that the young person who is destined to enter a sedentary calling needs most of all to be cultivated and trained in his physical life. Particularly is this true of the student, whose various occupations in the pursuit of knowledge are nearly all hostile to bodily health and development. Defective vision is probably quite as often due to lack of general physical vigor as it is to excessive tasking of the eyes. Nervous breakdown, which is so common among the more studious, is chargeable rather to neglect of the physical than to overdevelopment of the mental.

When we consider school athletics, which is a subject of so much debate, in the light of these truths, it is quite clear that the great defect of our present practice is not excess of athletics, but a lack of proper distribution. The great importance of the subject may excuse repetition of what has been said so many times before, that while the 
high perfection of a few individuals is, no doubt, a legitimate aim, it is far more important that all the young people be developed to a reasonable normal degree of athletic efficiency. It is a prime fault of the present that the great majority of boys and girls in school and young men and women in college get their physical culture vicariously, and for themselves develop only excessive lung power and strident vocal cords. It is time that the "bleacher and yell" type of athletics for the many gave way to universal participation in plays and games.

So far as the little child is concerned, if we are to conserve and cultivate his natural physique, we must needs exercise a good deal of patience with his restlessness and noise. It is true that both of these must be modified and harmonized with the other demands of life, but the greatest consideration should be used to avoid sacrificing his real bodily welfare in the process. It is safe to say that an education which tends to produce children who love to sit still rather than to romp and play is a fatal mistake. Certainly it must be clear that the active participation of father and mother in the joyful sports of childhood is one of the most powerful educative agencies to accomplish the ends which we have been discussing.

3. Love of Beauty. The pioneer was driven by the inexorable conditions of his existence to devote his attention and energies to the practical affairs of life. This is true both of the individual and the race. Consequently, when intelligent critics of America tell us that we pay too little attention to the æsthetic, we need not deny or 
apologize inasmuch as our history makes it clear that nothing else up to the present could be expected. What we should do, however, is to shape our education in such a way that the rising generation shall in this respect be superior to us who are now on the stage. We need to open our hearts to the truth that an essential part of life is the quiet, reposeful joy found in the contemplation and appreciation of beauty in every form. The ability to find happiness in beauty is one of the great assets of any life, and the familiar lines of Keats express a truth that is ethical no less than æsthetic:-

"A thing of beauty is a joy forever:

Its loveliness increases; it will never

Pass into nothingness; but still will keep

A bower quiet for us, and a sleep

Full of sweet dreams, and health, and quiet breathing."

Moreover, few of the tasks of the educator are so delightful and so profitable, both to teacher and taught, as the endeavor to open the eager soul of childhood and youth to the priceless and beneficent power of beauty.

First of all, for every reason comes the appreciation of the delights furnished free by the hand of nature. It a notorious fact that the majority of grown men and women are more or less blind to the beauties which lie about them in their daily walks. It is no less true that an occasional individual finds pleasure and health-giving delight in these same sources. Here again the educator 
finds the indispensable ground for his work in a natural impulse. The little child who cannot yet talk shows unmistakable joy in bright colors, flowers, clouds, and dancing waves. It is a common sight to see little boys six or seven years old with their hands full of gay blossoms which they have gathered in the woods. It is sad to realize that in most cases these same lads in a few years will have lost that source of joy and that to them the flowers will be no more than was the yellow primrose to Peter Bell. No more convincing argument can be found for the right of the child to have an æsthetic education than these powerful natural impulses of æsthetic joy. The duty of the parent and teacher is clear: simply from time to time, whenever opportunity offers, to direct the child's eye and mind toward the object of beauty that is before him. Such training can begin in infancy and be continued throughout developmental life; by such quiet, unpretentious means a permanent trend may be given to the attention and interest of the mind, and so this source of life and satisfaction, which so often perishes from inanition, may be preserved through youth into maturity and become a permanent element of the soul.

Certainly those who dwell in regions of scenic beauty with mountains, lakes, streams, and forests are peculiarly fortunate in this respect; we praise the parent who could actually find a motive for changing his place of residence in the desire to let his children grow up in a favored situation in respect to natural beauty. However, any rural region offers sufficient possibility for the development of 
the love of natural beauty. Cloud scenery alone, which is as fine in the boundless plains of the Middle West as anywhere in the world, offers an almost limitless realm for the cultivation of the æsthetic sense. The beauty of familiar objects is everywhere to be enjoyed, and the child may easily be habituated to appreciate the forms and colors of flowers, the figures of crystals, and the grace of animals.

We have said that the tastes in general should be wholesome and inexpensive. In these respects the love of nature takes first place. It tempts one out-of-doors into the fresh air, to take excursions on foot or horseback, or on the water. It carries us away from the beaten paths into the healthy solitude of woods and hills. It has power to soothe and heal the irritation and nerve strain of urban life, and in every way to contribute to soundness and sanity of body and soul. To all, except the unfortunate submerged tenth of our great cities, these pleasures are offered quite or almost free of charge, and fortunately municipal and civic progress are doing much to open the same joys to the poor by means of parks and playgrounds in the midst of our cities, and inexpensive excursions to seaside and country. It would seem that the opportunities for access to natural beauties are greater than the capacity of our people to experience these joys. The richness and value of life, both to the individual and to the nation at large, can be wonderfully enhanced if home and school will do their full duty in the cultivation of this taste. 
After the appreciation of nature comes logically a capacity to enjoy the products of human creative art. While we must give these a secondary place and emphasize the fact that the appreciation of nature is deeper and more fundamental, as well as more universal and accessible, nevertheless the cultivation of the appreciation of artificial beauty is a great end in itself and also a powerful agent in stimulating the taste for natural beauty. Moreover, creative art overcomes the limitations of time and space and opens to us the beautiful creations of remote ages and distant lands. It is doubtless true, also, that the object of art has a certain æsthetic superiority over nature in that it is carefully selected: all irrelevant and inharmonious elements are excluded, and thus the picture or statue may make a peculiar and powerful appeal to the æsthetic sense of the beholder. Certainly no one who is to live in a civilized community, and particularly in a city, can afford to be without a fair degree of capacity to appreciate art. In these days when excellent reproductions of art can be obtained at slight cost, it is easy for every home to possess the essentials for a simple yet effective art education of the children. Only let the pictures be of unquestionable merit and the reproductions faithful. Happily, in this task the schools are showing the way; and it has been abundantly proved that little children in the first grades of the elementary school are susceptible of a genuine love for beautiful pictures. Probably nowhere more than in these schools has it been shown that really good pictures do not wear out. 
In a certain schoolroom the children had money enough to buy a single picture; the teacher hung in the room a copy of "The Gleaners" and told the children that the picture would be exchanged at the end of the month if they so desired; at first the children had small interest in the picture; as the month went on, however, the teacher took occasion from time to time to call their attention to the picture and talk to them about its meaning and beauty; at the end of the month the class unanimously declined to allow the picture to be taken away. The experience manifested two things, the absolute excellence of the picture itself and the full capacity of the child's soul to rise to an appreciation of genuine art. The thing of beauty had become to them a joy forever.

Any argument to prove the power and value of music in human' life would be impertinent. We need only to plead that it be given more place in the education of our children. The ancients not only recognized the power of music to touch the heart and affect the emotions for the moment, but they also ascribed to it a peculiar and profound influence over permanent character. While it is not the custom in modern times to lay stress upon this permanent influence of music, it must be said that nothing has been brought forward to disprove its existence. However, the claim of music to an important place in the education of children can be sufficiently established by its great and unique power to afford delight and diversion to the soul. The interest shown by savage races 
and little children in simple forms of music indicates clearly enough that a love of music is an organic part of human nature, and would naturally lead us to assume that musical culture is an indispensable part of a complete education.

The method of culture in music is similar to that in art and other forms of æsthetic capacity: it consists in bringing the child within the reach and influence of the æsthetic stimulus. Let him from the earliest years hear good music sung or played; at first the music should be of the simplest kinds, and as the child matures he will naturally gain the power to comprehend more complex and highly developed forms. The great thing is to let music be a regular and frequent part of his life so that the rudimentary powers of appreciation found in the child may have no opportunity to languish through disuse, but may grow and be confirmed into a permanent element in character.

With reference to both music and art it should be noted that the capacity to appreciate these forms of beauty may be highly cultivated without the power to create. Comparatively few children can or indeed should be highly educated in artistic or musical accomplishments. In both cases the training for the accomplishment includes long and tedious drill in mechanical processes. The instruction is costly, and the study absorbs an enormous amount of the child's time and strength. A reasonable capacity to appreciate music and art, on the other hand, quite suffices to enrich life and exercise a wholesome influence upon character, and can be achieved with far less expense of 
time and energy, and should be cultivated in every child.

Two simple forms of accomplishment may well be recommended for all children except the very few who are markedly deficient; namely, singing and simple free-hand drawing. All good schools give training in these two arts, and the home can well coöperate in both.

4. Good Reading. The modern world is so much concerned with books and periodicals that there is no need of laying stress upon cultivating the habit of reading. In fact, the chances are that the great majority of educated people read too much rather than too little. But the habit of reading is one thing and a taste for good reading is a very different thing. Unfortunately the business ideals which so largely dominate the publisher do not always minister to the development of good taste in the readers. The sentimental, the spectacular, that which amuses and tickles the fancy, the extraordinary, whether it be true or not - these characterize too much of the output of our printing-presses, and all of these characteristics tend to run to dangerous excess. Two great dangers result from this condition, - the actual corruption of the minds of youth by suggestive and immoral reading, and the loss of power to concentrate the mind on anything which calls for serious thought.

The taste for good reading is inseparable from a taste for good thinking, and home culture must strive for both ends at once. It is not sufficient to provide good reading for the children in the home and to urge them to read it. 
To this must be added the active interest and participation of the parents, manifested in their own reading and in the discussion of subjects in which they desire the children to become interested.

It is a great mistake, of course, - which, however, very few parents of this generation are at all likely to make, to expect small children to take pleasure in mature literature: education has come to recognize the legitimate place of children's literature, and fortunately a very large body of excellent reading for children is now available. It is not always so fully recognized that there is educational value in everything the child reads, and that so long as the stories to which he devotes himself have nothing positively bad in them, he is likely to be benefited by the reading. Every page he reads is likely to add to his store of words and ideas, and the exercise of reading itself stimulates and increases the play and vigor of his mind. It need hardly be repeated here that the child who wants to read when he ought to be playing should be driven out of doors for the good of his body and soul.

5. Some Dangers in Asthetic Education. It is probable that every bad habit involves a bad taste. Hence, what has been said about certain habits will throw light upon unhealthy tastes. The great weapon with which to fight these dangers is the filling of the child's life and soul with plenty of good, vigorous, wholesome activities and healthy tastes. It may be necessary, however, to use positive repression in some cases. The taste for tobacco and for gambling are two cases in point. American 
morality condemns gambling throughout, and tobacco in boyhood and early youth. It is surely the duty of the parent to be vigilant and resolute in discovering and crushing out either of these two tastes in childhood or youth. The taste for tobacco is fortunately a very unnatural one, the first efforts to acquire it being usually accompanied by a strong physical reaction and probably some remorse; if the father or mother can put in an influence at this point, the whole thing may be nipped in the bud.

Another of the serious dangers in the development of the taste is the development of excessive fondness for certain things legitimate in themselves; and here again parental vigilance must be the remedy. Some of the frequent forms of this evil are the taste for candy and sweets, for such amusements as cards and dancing, and for overfrequent attendance at theaters and entertainments. These excessive tastes tend to wasting of time and loss of interest in more important things, in some cases to ill health and debility and to the retardation of education and development.

We have spoken frequently of æsthetic education, but have tried to make it clear that we do not refer to the kind of culture which leads to overfastidiousness and an affected contempt and dislike of everything simple and common. There are not a few unfortunate and misguided people who are ashamed to confess admiration for anything which can be enjoyed by the uninitiated. They despise all ordinary pictures, all simple and unpretentious 
music. They demand absolute perfection in technique, and so can find no satisfaction except in the performance of a virtuoso. The chief purpose of æsthetic education is to increase the capacity for æsthetic enjoyment; the development of the hypercritical and fastidious attitude, on the other hand, decreases the total capacity for æsthetic enjoyment. It cannot be denied, of course, that culture in either art or music will inevitably modify the range of appreciation and render one dissatisfied with some forms of art which previously pleased. Only let it not be forgotten that this is an incident of æsthetic culture, and not its essence. 


\section{CHAPTER VI}

\section{The Personal Ideal}

"WhAT am I going to be" is a question that early fascinates the young human being; about it center much thought, many yearnings, hopes, fears, and, best of all, many earnest resolves. It is the natural offspring of the maturing or "growing up" instinct, previously noted. The question in its most conscious and definite form usually refers to vocation, "Shall I be farmer, or lawyer, or merchant, or physician?" But it also has a far deeper meaning and content, "What sort of man or woman shall I be ; what kind of life shall I propose and hew out ?" The answer the youth frames to this latter question is his personal ideal, and will exercise a potent influence upon the development of his character and the direction of his conduct. Toward it the growing soul strives, day after day, year after year; its outlines, first existing only in the imagination of the heart, gradually, almost imperceptibly impress themselves on the soul and body, and manifest themselves in the outer life; "As a man thinketh in his heart, so is he."

The personal ideal distinguishes man from lower creatures; and its perfection and power mark the high and full development of humanity. Very early it becomes 
the directing influence in self-culture, - which is by far the most important part of education; all truly higher education is self-education; the mission of all training from without is to stimulate and aid and guide the youth to take charge of his own culture and career. Conscious education is always directed by some sort of an ideal: the school, the home, national education are laboring to mold men and women into certain general forms of excellence and virtue; the personal ideal is the image that the child and youth forms of his own possible self.

Self-respect is the very cement of character, without which character will not form nor stand; a personal ideal is the only possible foundation for self-respect, without which self-respect degenerates into vanity or conceit, or is lost entirely, its place being taken by worthlessness and the consciousness of worthlessness; and that is the end of all character. It is often said that if we do not respect ourselves no one else will respect us; this is rather a dangerous way to put it; let us rather say that if we are not worthy of our own respect we cannot claim the respect of others. True self-respect is a matter of being and never of mere seeming. As Paulsen says, "It is vanity that desires first of all to be seen and admired, and then, if possible, really to be something; whereas proper selfesteem desires first of all to be something, and then, if possible, to have its worth recognized."

The personal ideal must have power over our lives, else it is not an ideal at all, but only an idea. The youth must not merely dream of strength, of wisdom, of skill 
and power, of honor and righteousness, of nobility and generosity, - he must resolve to attain them. He must see himself pursuing and achieving, and be inspired and energized by the vision. 'Such a vision of power is the personal ideal.

A full account of the personal ideal would necessarily cover every part of human life. It is quite clear also there would be the greatest variation in different individuals. For the purpose of education, however, it is worth while to emphasize certain elements which should be found in every case. We shall speak first of the bodily ideal.

I. The Bodily Ideal. We have already spoken in previous chapters of the inborn tendency to bodily activity and of the exhilaration and delight to be found in physical exercise and of the habit and taste which should be developed from these sources. It remains to add a conscious interest and rational pride in developing and maintaining the highest degree of bodily perfection. Every boy and every girl should grow up with the ideal of a healthy, clean, and efficient body. He should be taught the intimate relation of the body and soul, in that the soul is absolutely dependent upon the body both for its knowledge of the outer universe through the senses, and for its power to make itself felt in the world through external activity. As the child's mind gradually rises to fuller understanding, he should be thoroughly imbued with that great truth which is expressed figuratively in the apostle's words, "Your bodies are the temples of the Holy Spirit." The cleanliness of the body, of course, should go farther 
than the mere use of soap and water, and should include the abhorrence of everything which could in any way pollute the body or its organs. In this way cleanliness is bound up with health, and both naturally lead to the third element in the bodily ideal, that of vigor and efficiency.

Fortunately the ideal of physical perfection has a powerful appeal to every normal child and youth; the boy especially is extremely susceptible to this motive; he admires strength and agility in others and longs for it in himself. As already noted, the great fault of our education in this respect is that it trains the many to be content with admiring the physical perfection of the few, and neglecting it or despairing of it in themselves. The very children who most need stimulation in their physical life are comparatively neglected, and are allowed to fall lower and lower, not only in their bodily health and strength, but also in their hopes and ambitions for physical perfection.

It need hardly be repeated here that the abundant and healthy physical life, with the exhilaration and exuberant delight of bodily strength and vigor, forms one of the most powerful safeguards against many of the temptations and dangers that threaten boys and young men. The bodily ideal is an implacable foe to all forms of vice, and especially to those that more easily beset the adolescent youth. This ideal involves keeping one's self, as it were, in training. The true educational aim would be to give to every boy and girl something of the sense of reponsibility for keeping in training that is felt so strongly 
by the members of an athletic team. Such a sense would conduce not merely to higher physical development, but would radiate its good influence into all parts of life.

The poet Browning, himself throughout life an example of bodily vigor and enthusiasm, has given us a noble eulogy of the bodily ideal in a passage from "Saul," with which we may well sum up the theme:-

"Oh, our manhood's prime vigor! No spirit feels waste.

Not a muscle is stopped in its playing nor sinew unbraced.

$\mathrm{Oh}$, the wild joys of living! the leaping from rock up to rock, The strong rending of boughs from the fir-tree, the cool silver shock

Of the plunge in a pool's living water, the hunt of the bear, And the sultriness showing the lion is couched in his lair, And the meal, the rich dates yellowed over with gold dust divine,

And the locust-flesh steeped in the pitcher, the full draught of wine,

And the sleep in the dried river-channel where bulrushes tell That the water was wont to go warbling so softly and well. How good is man's life, the mere living! how fit to employ All the heart and the soul and the senses forever in joy!"

2. The Intellectual Ideal. Next comes the ideal of good thinking. Abraham Lincoln tells somewhere that as a boy when he met an obscure or ambiguous sentence in his reading it threw him into a sort of rage. The fact is that this was simply a form of instinct for clear thinking which is found in every child and manifests itself abundantly to the perception of the good teacher. Far more important than any particular piece of knowledge, 
than geography or arithmetic or spelling, is this love of clearness in our mental life and instinctive hatred of confusion and obscurity. Let the child early learn to know what he knows clearly and definitely, and as soon as possible let him learn also how he knows it. Both teacher and parent can minister in the early years of intelligence to the culture of this intellectual ideal.

The great intellectual need of men and women in the outer world is not so much more knowledge as it is better knowledge and better thinking. There is much philosophy in the humorist's remark, "It was never my ignorance that done me up, but the things I know'd that wasn't so." The great enemies of intellectual life are superstitition, gullibility, and fallacious reasoning. A mere knowledge of facts, important as that is, is no safeguard against these. A conscious desire and resolve to think clearly is the true remedy.

It need hardly be said that this characteristic is peculiarly important in the citizen of a republic, and particularly so in this complex modern world. Man is engaged in a strenuous endeavor to understand himself and the world in which he lives. The problems that confront civilized man to-day, especially in connection with industrial and social problems, will task the best intelligence of the future. Our national success will depend largely upon the development of a generation of men and women who have formed a love and habit of clear thinking and who can do their part in solving these problems.

3. The Ideal of Honor. It would perhaps seem nat- 
ural after speaking of the bodily ideal and the intellectual ideal to name as a third in the series the moral ideal. We have purposely avoided this term because we are dealing with children, to whom the word "moral" usually conveys either no clear idea or a rather unpleasant one. That is, to the boy the word moral is likely to mean either something very vague and obscure or else certain prohibitions and negations which hinder him from doing what he would like and not infrequently cause him to be punished. We have used instead a word which has a peculiar appeal to the heart of youth. Here, as elsewhere, or rather more than anywhere else, it is absolutely necessary to find the road to the heart. What we are seeking is an ideal, and an ideal, as we have already emphasized, is no mere notion or conception, and above all never can be a repugnant or unpleasant thing, but must always have the power to charm and fascinate the one into whose character it is to enter.

Both history and romance, as well as everyday life, give abundant illustrations of the power of what men call honor. At the command of honor men and women, youths, and even children will dare and endure the utmost. One of the most striking things in school life is that schoolboy honor which will lead a pupil to obstinate defiance of authority and unhesitating endurance of punishment in order to preserve what he considers good faith with his fellows. Fortunately the home is seldom troubled by these strange conflicts between the moral sense of childhood and the moral code of the adult. 
No one can deny the difficulty which this conflict in children and youth causes in school life, but it must still be said that this troublesome sense of honor is the stock upon which must be grafted the best things in character. The youth's sense of honor has the two clear indispensable elements of character: it has dynamic power and it means right. To ignore it is to neglect the most precious spring of righteousness, to quarrel with it or attempt to crush it is fatal to all educational success. The duty of both parent and teacher is clear: on the one hand to cherish and guard this native root of honor with the utmost patience and sympathy, and on the other hand to enlighten it by all means in our power.

This sense of honor is the sense of right. It is the soul's instinctive love for the good, the true, the commendable, and its instinctive scorn of the base, mean, and vile. The road to perfection is through two main processes. First, the intelligence must be opened to a larger view : the child sees and feels only what is immediately about him: he has a keen sense of his own interests, and of the affairs and notions of his playmates, but little sympathy for the standards and ideals of mature life. These juvenile interests for the time being direct and control his sense of honor and right: it is the duty of education to open his eyes to the interests of others, especially of older persons and those remote from him. The boys who see no harm in stealing a gate on Hallowe'en, or in breaking windows "for a lark," may be brought to take a new view when they are impressed with 
the annoyance and hardship which is caused to other persons.

In the second place, the child and youth fall easily and almost universally into a confusion between that false honor which cares only what another thinks or says, and the true personal honor which cares first for what we are. It is too true that many a man who would resent with a blow the epithet of "thief" or "liar" will lie and steal in secret apparently without a qualm of conscience. The true root of honor demands reality and hates shams. The youth should be taught to abhor and reject in his own heart everything which he would resent in an accusation made by another. He should learn not to tolerate in his own inner consciousness what he would fear or blush to have known to friends or foes. This is the sense of personal honor that dominates and molds character and that endures the heaviest stress of life.

4. The Pride of the Workman. A very plain and practical element in the personal ideal is a just pride in the work of one's hands. Probably no one ever saw a competent skilled workman in any calling who did not look upon the finished product of his labor and pains with loving eyes and some warming of the heart. A considerable part of most lives must be spent in work: and in a democratic state of society no one can measure up to the full standards of character unless he possesses efficiency. The lack of this element of the personal ideal produces the sloven and the bungler, its full development stimulates effort and improvement and so creates 
skill, and besides that it cheers and dignifies the long hours and years of toil; it is the most potent means to turn drudgery into happy employment. Both home and school can find abundant and easy opportunity to nourish this excellent quality.

5. Some Dangers of the Personal Ideal. It will have already risen in the mind of the reader that there are serious perils along the way that we have been describing. The bodily ideal may tend to produce the extreme type of athlete, or physical culturist, or even the scented exquisite, whose thoughts are largely devoted to immaculate physical perfection. The intellectual ideal may produce the pedant, the wiseacre, or the bore. The ideal of honor may tend to produce on the one hand the haughty cavalier, or duelist, or on the other hand the extreme puritan or pietist. Emphasis on the personal ideal in general may produce egotism or even selfishness.

The fact is that all of these are faults of defect and the remedy in every case is fullness and roundness of development to prevent the excess of any individual element of character. The personal ideal itself must contain in harmonious proportion all its necessary elements, and the wholesome personal ideal thus made up must be balanced by interest in others and a sense that after all the perfection of one's own personality is justified only by the service that one may render to his fellow men, a conception which forms the basis of the next higher region in the elements of character, that of the social ideal.

6. Modesty. It will easily be seen that modesty, that 
choice excellence in character, is immediately connected with the personal ideal. The essence of modesty is not contempt for one's self, but rather a reasonable estimate of one's own worth, sobered and modified by several clear considerations: first, the recognition of the worth of others, always remembering that being naturally prone to overestimate our own value and underestimate the value of others, we should be distrustful and critical of the favorable opinions which we form concerning ourselves and of the unfavorable opinions which we form concerning others. Secondly, modesty is encouraged by comparison of what we have attained with what we might have accomplished or still hope to achieve; in this process the possession of a high personal ideal, so far from tending to vanity or conceit, is the strongest basis of genuine modesty. 


\section{CHAPTER VII}

\section{Conscience}

THE personal ideal in a strict sense relates to the individual's attitude toward himself and his own individual credit and honor: it consists in his being true to himself. A little later we shall have to consider the relations that each of us bears to his fellows, our social relations, as we call them. Now these are separate only in our discussion of them, whereas in real character and life they run into one another and blend inseparably; neither can ever be richly and fully developed if the other is weak or defective. Between them, and pervading both, is the element that we call conscience, or the sense of right and wrong and of obligation to do the right.

Wordsworth calls duty the 'daughter of the voice of God'; Kant describes it as a categorical imperative that says to every human soul, Thus must thou do! Froebel speaks of an eternal law that hovers as it were above and between two persons who come into relation with each other, rebuking when necessary the inclinations and desires of one or both of them, and dictating with authority what both shall do. The philosophers differ almost infinitely in theories of conscience, and both its origin and its validity are subtle and perplexing questions; but 
human experience, in history and literature and in common life, has no doubt of its existence and its mighty import in human affairs and the progress of the race.

Savages, we are told, have little sense of right and wrong, and that little far from agreeing with our standards. The little child beginning to talk and walk is probably quite devoid of the moral sense, and is led altogether by impulse and spontaneous interests. Of course he is not therefore immoral, but simply nonmoral; he is not bad, nor is he good; he is yet to become one or the other, or, rather, some of both.

Leaving theory and debated points aside as much as possible, let us see what we can agree upon as to the beginnings of the sense of ought in the child's mind. First, it rises into consciousness through conflict between the child's desires or impulses with the order of things in which he finds himself, - usually with the will of his parents. The power of his elders and his fear of them create at first a must; this is probably the necessary first step in his moral development. It is the stage in which his native impulses are checked and regulated by an external law; sometimes he resents and rebels; sometimes he yields, more or less cheerfully; but still the law is quite outside of him, as is shown by his tendency to break it when he finds himself alone or thinks that none of the representatives of the law can know of his deeds. The wise parent will not be troubled or discouraged by this stage of growth, but will accept it as natural and as leading to something higher. 
Authority and discipline, firm, uniform, dignified, kindly, are the means of culture of this sense of must; the chief practical maxim is to be quite firm without the least unnecessary violence or irritation; suaviter in modo, fortiter in re is the true rule, - let the manner be as gentle and agreeable as possible, but see the thing through to the end.

From must to ought is a process of internalization; that is, the child gradually adopts the law into his own heart, makes it a part of his permanent ideas, and submits his own native impulses, previously dominant, to the authority of the law. Every normal child proves the existence of a natural tendency to do just this very thing; very early he begins to surprise his elders by doing, upon occasion at least, quite willingly and sometimes with an air of importance or self-approbation, things that until now he had to be compelled to do either by force or authority. Especially does he take great delight in virtuous acts that for the moment fit in with his own plans: so young do we begin to suffer from mild hypocrisy; then he is fond of compounding for sins he is personally inclined to, by condemning the misdemeanors of his little brother or playmate in the most righteous indignation.

It is hard to doubt the universal presence, in very early years, of a profound and somewhat mysterious reënforcement of the ideas of right and wrong from the depths of the child's soul. Many of us can remember the almost intolerable pain and darkness of soul that came with the sense of guilt, when we had done something that we knew 
to be contrary to the will of father or mother, or to the established order of the house. The depth and power of this feeling is probably nature's index of its vital importance in later development and in the affairs of human life. This element in the soul of the child furnishes the dynamic or driving force of the adult conscience ; it is the root of the quality which marked Lincoln so strongly that one said of him, "He knew no fear except the fear of doing wrong."

Naturally the sense of law arises through the child's contact and relations with those about him. Thus duty is a distinctly social matter, and will be much illuminated by a consideration of social relations and feelings in general, in the next chapter. The child soon begins to feel the force of the principle that is best expressed in the Golden Rule; it comes home in a very effective way when he finds that the best way to get others to do what you want them to do for your benefit is to be willing to be equally considerate and accommodating toward them. So develops the basic idea of all ethical truth, that each one must conduct himself in a way that would work out well as a rule for all; and so gradually caprice and whim, impulse and desire, and all the irrational and unorganized elements of the child's will may be subordinated to the law of justice.

Conscience has two sides, the feeling of right and wrong, and intelligent judgment between the two: both of these sides must be cultivated in fair proportion to each other. First, the tenderness of the child's heart regarding wrong, 
his aversion to it, and the pangs of remorse he feels after breaking the law as he knows it, must be cherished and conserved. Above all, he must not get hardened against repentance by being constantly in conflict with law and constantly made to feel that he is a wrongdoer: hence the law laid upon him must be tempered to his small strength, so that under ordinary circumstances he may have strength to resist temptation; then guilt and the pain of remorse will be rare and exceptional, and will keep their power. Whenever guilt usurps a large place in the child's consciousness it tends to lose its sharpness, and what was first hated as soon as seen, the little man, like his elders, is apt to "first endure, then pity, then embrace." The stings of conscience, like all other punishments, fall into impotence as soon as they cease to be rare and unusual. Require of the child little, and that comparatively easy, and draw an unmistakable line about that requirement; so may the sense of law and obligation retain its most essential quality, that of the imperative. As strength and knowledge grow, the demands upon the conscience may be enlarged and heightened.

The other side of conscience is moral intelligence to know what is right. This grows by the same processes as any other form of intelligence, - by experience, instruction, counsel, and above all by reflection and independent thought. The first great agency in this development is the common life of children with each other, and in a less degree, with their elders. But experience alone is as poor a teacher for children as for 
adults: its lessons stand in need of constant interpretation and explanation, and this must be provided largely by parents and other educators. The boy who has been "sent to Coventry" by his playmates may have gained for himself nothing but anger and grief from the experience; he needs to be shown that it was his refusal or failure to play the game according to the rules that caused his expulsion; and that if all behaved as he had done the whole game would be ruined. Sometimes a child that is quite stuck in the attempt to unravel such a situation, and can do nothing but grieve or sulk, may need only the slightest hint to set him on his rational way to the true solution and to a new perception of social law. Similarly in the child's relations to elders : their requirements, especially their prohibitions, often seem like mere tyranny, with no discoverable purpose except to dash his pleasure and check his enthusiasm; this is a fact that no parent or teacher should ever lose sight of. Yet the requirement has a clear, rational justification, and intends' the child's own good; let this be patiently and lovingly expounded to him, just as fast and as fully as his mental capacity permits. Take him into your confidence, and thus help him up to a new step in his growth both moral and intellectual. Nothing here said is intended to contradict the practical truth that children must learn to do many things against their natural impulses before they can comprehend the reasons for the compulsion; and they must often do immediately something which would take time to explain; hence a part of the essential 
training in obedience, as we have pointed out, is prompt compliance with commands without demanding to know why. Success in obtaining such implicit obedience is greatly favored by the fullest consideration of the child's growing intelligence concerning conduct.

The modest but invaluable virtue of reliability may perhaps be set down as a form of conscience; it is the sense of ought that holds a man at his post or his task when ease beckons or hardship and danger try to drive him from it, - and that is reliability. Such a man is also said to be responsible, - he can be counted on to answer for himself on points of duty, simply because he has an inward monitor that checks him up even more sharply than do the rules of occupation, business, or social life. But reliability or responsibility finds its perfection only when reënforced by the virtues of strength of character, which are to be discussed in a later chapter.

We have said that development in conscience is a process of internalizing; the must is a force from without, the ought is from within, - or perhaps from above or beyond the individual soul; at least it does not come from any visible outward authority. The sense of ought is indissolubly blended with three great motives which are mentioned elsewhere in our discussion: first, with the sense of personal honor, as already said. Second, with the sense of social obligation, of which we shall speak in the next chapter: by far the greatest and most powerful commands of the voice of duty concern our relations to others; probably none of them could possibly be limited 
strictly to our individual selves, - which indeed are after all only an abstraction and not real entities. Third, duty tends always, as character broadens, to be dissolved into love; the noblest souls, saints and martyrs and heroes of self-sacrifice, those who do their duty most abundantly, are least conscious of any compulsion, but act in joyful freedom, through love of their fellows and the absorbing desire to do them good. And what is writ so large in these supreme souls is a universal experience in the life of man: the little child does many things first from absolute compulsion, then from fear or dread, later from a coercing sense of duty, often sadly against his own preference; later he will do these same things, and far greater and more self-sacrificing ones, in complete freedom, with every counter impulse quite abolished, and with a heart full of joy in the deed and the good it is intended to work out. Every act that can be transferred from the realm of duty to that of love is a step upward toward that perfect inner freedom that is the goal of man's moral evolution. This of course is one of the peculiar messages of Christianity; when Plato in the famous myth of the men in the cave seeks to send the educated back to do their duty in enlightening their fellows still in darkness, he finds no other motive except legislative enactment and civil authority; and those whom he must thus coerce are the choicest spirits of his commonwealth; how different the moral attitude of the great apostle when he explains his boundless self-sacrifice by saying that "the love of Christ constrains him." 


\section{CHAPTER VIII}

\section{The Social IDEAL}

EDUCATION may be briefly summed up as the process of enhancing the value of the individual and binding him to the race. Thus far in our study of the essentials of character we have dealt mainly with individual worth, touching nevertheless frequently, either expressly or by implication, upon social relations. Now we turn definitely to the social relation; we need not be surprised if we find here constant reference to the elements of individual character, and come to realize that individual worth and social character are inseparably linked and cannot approach perfection except as they develop side by side. It ought also to become plain that all morality worth the name is based upon social relations, and really consists in right thinking and right conduct toward those with whom we in any way come in contact.

While the social feelings show themselves at the very earliest period of life and never cease to grow under normal conditions, yet they rise into striking prominence in the period of early adolescence, and we shall therefore have that period primarily in mind in this chapter.

From the beginning of our discussion we have been gradually rising from the instinctive and mechanical 
strata of character, such as native tendencies, disposition, habit, into the higher realms of conscious and deliberate life. The social ideal is more than any previous element imbued with consciousness, and in dealing with it we shall find feeling and instinct constantly rising into thought and reason. It would be impossible to isolate them even in discussion, and in the actual development they grow side by side in intimate union. This social development and culture we shall consider under three heads: first, certain great truths that underlie all social relations and therefore all truly human life: next, social intelligence, or an understanding of the details of the social situations in which we are to live, so far as we need to know these details in order to know what is right and what is wrong in our social conduct; and, third, the widening of our native impulse of affection to take in all the children of men, as far as we enter into relations with them in any way whatsoever.

I. Basic Truths of Human Life. ${ }^{1}$ The deepest of all truths in human life is the essentially social nature of man: that "no man liveth unto himself," but that, to use another phrase from the same writer, "we are all members one of another." These are no mere figures of speech, but are statements of fact; he who lives unto himself ceases to be a man and lapses into a mere animal in human form; in so far as any human individual cuts himself off from his fellows, just so far does

${ }^{1}$ See "The High School's Cure of Souls," Educational Review, April, 1908, pp. 366-372. 
he fall below the perfect standard of humanity. Let any one try the experiment of turning his attention to his own inner life and stripping away all that is social in its nature and origin: all memories and feelings concerning parents, friends, books, civic and national life, all that in any way comes from others. What is left? Certainly not the soul of a man or woman, but at best some poor, blind, obscure, subhuman consciousness.

Equally true is it that we constantly touch each other's lives: my deeds and my fate affect you, and yours affect me, inevitably and profoundly. Most deeply is this true of all deeds and experiences that are felt as distinctly moral, and as springing from character or bearing upon it. Crime and virtue alike radiate their influence upon those in any way bound to the doer ; fortune and disaster never fall upon the immediate victim alone, but often mean as much or even more to some one attached to him.

But all this, while perhaps always a profitable theme, needs no long exposition to men and women who have lived and have reflected on life. The child, on the contrary, is surprisingly blind to it. One of his most characteristic expressions is "I don't care!" in regard to the wishes, requests, opinions, and even welfare of others. Moreover, he is prone to think himself independent of the help and sympathy of those about him, except, indeed, so far as the more material needs are concerned. The small boy reading "Robinson Crusoe," — or, still better, "Swiss Family Robinson," with its comfortable and untroubled flow,-dreams with unalloyed delight of 
being cast upon a desert island, where he might escape all the tedious and monotonous details of home and school life, and revel in the outdoor activities that appeal so strongly to his boyish heart. Crusoe's passionate yearning to escape from the.island and return to home and friends the lad simply cannot understand; he would desire nothing so much as just to stay there. Now there is nothing unnatural in all this; if our boy should somehow be actually separated from home and parents even for a few hours and in a far less trying place than Crusoe's island, his poor little heart would be almost broken. That very feeling is the spring or source which is to lead naturally, with proper guidance and enlightenment, to the full ripeness of social intelligence and sympathy. But the guidance and enlightenment cannot be dispensed with.

A very simple illustration may be taken from a frequent occurrence in school life, and the case is one that will enter into the experience of every school principal, especially in the high school. A lad of fourteen or fifteen wants to leave school; why? 'He wants to go to work,' or 'he doesn't like school,' or any one of half a dozen other reasons, - none of them, by the way, in themselves blameworthy. "What do your father and mother think about it?" "Well, they want me to go to school; Father says he wants me to go through high school and go to college." All this with many variations in various cases. "How will your father and mother feel if you insist on quitting school?" As he will honestly tell you, 
this simple question has not entered the boy's head, he has been too much absorbed by the hot ambitions and eager desires of youth. Yet he only needs a word to set him thinking in a new and vital direction. For whether the conversation, of which we have given just a hint, keeps the lad in school or not is a minor consideration (although the writer has known more than one case in which it did) ; far more important is its almost inevitable influence in helping the lad to take an upward step in his feeling and comprehension of the basic conditions of human life. The thought that his conduct and his welfare must inevitably enrich or impoverish the lives of those nearest and dearest to him, - this is clear, and may work great good in his life and character; and, better, it may easily start a train of thought and feeling that may deepen his whole social nature. ${ }^{1}$

The most important point in the foregoing illustration is the fact that the incident in the boy's life might easily have passed over without stirring a ripple on the surface of his social consciousness; indeed, it might even have been so treated by both home and school as to blunt the boy's feeling toward others and hinder the opening of his social intelligence. Home and school life are full of occasions for the teaching of social interdependence and resulting social duty. History and literature also abound with examples of this basic principle of life; but through it all the child is very much in the condition of him who

${ }^{1}$ See a wonderful passage in Rousseau's "Émile," pp. 238-240 (Payne's translation, Appleton, r9or). 
read the Scriptures, but could not understand, for "no man explained it to him." And yet we dare assert that for his own fullness of life, and for his usefulness to his fellows, no element of character is more essential than a profound and all-pervading sense of this great truth, that we are indeed 'members one of another,' and cannot, if we would, live unto ourselves.

The second great truth of human life is the debt of the individual to the community and the race; for from them he receives life itself, and all that makes that life worth while. The educative form of this truth is the debt of the young to their elders and to the past, and accordingly we consider it in this light. Childhood receives from the elder generation the most lavish gifts that life knows anything about. Born helpless, and dependent for years, the young human being would be an intolerable burden to be inevitably cast off and perish, were it not for the redeeming element of parental love and devotion. Neither is the motive of parenthood by any means confined to actual fathers and mothers, nor restricted in its application to children according to the flesh; rather is it racial and spiritual: all normal grown men and women are moved to concern themselves on occasion for the welfare, and especially the happy development, of children or youth. The sacrifice and devotion of the home are supplemented by the nurture and education bestowed freely, and in the main gladly, by the community.

Strangely, as it may seem at first glance, yet in fact 
inevitably, the child has by nature no conception of this second great social truth: it is perhaps even less likely to dawn upon him spontaneously than the first. Especially as he feels strong upon him the sense of maturing powers - in early adolescence, and when he begins to grasp a man's work in the world - is he likely to think of the world as his legitimate possession, and upon whatever he can seize, in the form of property, power, privilege, or pleasures, as his fair booty. The attitude of most young men toward money is a familiar case: few indeed distinguish between getting and earning, or concern themselves seriously over the question whether they are rendering a fair and honorable equivalent in service for what they receive in money and the things that money buys. Too often they behave as if they really believed the miserable fallacy of "The world owes me a living," instead of realizing that up to date they are deeply in debt to family, school, church, and state, for years of benefits without any return on their part.

In many cases the child grows through youth into manhood and never, until he has children of his own, does he get a glimmer of appreciation of the almost boundless devotion and self-denial involved even in very imperfect discharge of the duties of parenthood. And recognition of the rather more obscure social debt - the debt to the community for free institutions, education, general culture and progress - often never comes, but the individual ends his life without the touch of this great unifying and stimulating conception. 
In this matter we might well take a lesson from the ancestor worship so frequently found in so-called heathen religions ; for the debt of youth is of course to those who have gone before, beginning with the immediate parents and elders still living and working, and running back through all the generations of the past which have labored for the elevation of the race or the community. Yet probably few of us, youth or adults, have any real sense of owing any thing personally to Washington or Lincoln, to Patrick Henry or Horace Mann, to say nothing of John Robinson and Miles Standish, or Socrates and Epictetus.

We have used the word debt, but it must be clear that there is nothing slavish or depressing in the indebtedness involved. It is purely a debt of honor on both sides: parents and elders give freely, hoping for no recompense to themselves; they give because they love, and they love to give, and find their best joy in loving service and tender nurture of the younger generation. So the feeling of debt on the part of the youth is rightly one of joyful gratitude, and enthusiastic resolve to live worthy of the benefits received freely; the motive is not compulsion, but rather noblesse oblige in its finest form.

All this leads us most naturally to the third great ethical idea-the ideal of service. "Freely ye have received; freely give." The past pours out its treasures for us: it is for us to pass on the benefits to the future. Thus each man and each generation is a link in the eternal unity of the human race, receiving the light and power of life through heredity and education and pass- 
ing it on through parental devotion and varied beneficent activity.

The ideal of service, based first on a grateful sense of benefit received, is reënforced by the sense of honorable obligation, which springs into ready flame in the heart of youth. The lad would be stung to the quick if accused of shirking in the football game or the tasks of the summer camp; the same sense of honor is the strongest force in social, economic, and civil or political duty. Let the unearned dollar or the undeserved preferment be scorned and resented as are the imputations of shirking the obligations of the common occupations of boyhood.

Finally, the ideal of grateful service as the only honorable return for benefits received should have power just in proportion to those benefits: it should appeal most powerfully to the most favored. First, one is tempted to say, to those who have inherited wealth; and yet one feels little hope or confidence in the appeal. The truth is that the mere inheritance of wealth is seldom a real benefit, and more often paves the downward path for the individual and the family. Doubtless such inheritance is potentially an advantage, and constitutes a great obligation; but as a matter of fact it will usually cause degeneration in the holder and loss of all social usefulness unless it is accompanied by a high degree of the right kind of culture and spiritual training; accordingly we pass to those in general who have enjoyed the privilege of higher education, - whether rich or not in this world's goods; on them, above all others, lies the debt of youth, and the 
obligation of service in return. No inheritance so surely springs from unselfish devotion in the past as a good education: a man may gather money for his own narrow and selfish satisfaction, and then drop it grudgingly out of his death-stricken grasp into the hands of heirs for whom he cares nothing or whom he even hates. But the effort and sacrifice that have built up the possibilities of higher education, laboring through all the ages of progress toward that end, have been inspired by the most unselfish motives known to the human heart. Education is essentially altruistic - its genius is most completely expressed in the words of the Greatest Teacher: "I am come that they might have life, and that they might have it more abundantly."

As a matter of fact, higher education exhibits a vast amount of indifference to these obligations and not a little flagrant ingratitude: for the latter, consider the cases of men who have received the most liberal education from the generosity of the state, including often both general culture and professional training, and then have turned the sharpened weapons thus acquired against the very communities that had fostered their growth. Yet these are far less important to our present consideration than the vast number of well meaning and honorable men and women who go out from higher institutions simply unconscious and unthinking, because the idea of a special social obligation has never been properly brought to their minds, nor the sense of service duly stimulated.

Two facts should be clearly taught to the youth above 
the elementary grades: first, that schools, colleges, universities, professional schools, do not grow like trees in the forest, but are the results of centuries of development, always made possible by disinterested service and devoted efforts; that human knowledge itself is an inheritance from devoted and inspired labors, and that educational institutions are the fruit of the loving thought of earlier generations for us as their posterity. Moreover, this idea must include the present, and embrace the work that goes on in every progressive community for better schools and general educational conditions. These facts are more important than half the present content of the curriculum, and can be dealt with in a very few hours every year.

Then every youth in the ranks of higher education, and higher education begins in the high school, - should be familiarized with the fact that he is a selected and privileged individual : for every boy of fifteen or sixteen who sits in a high school, there are several of similar age who are working for their daily bread; and of course every year of advancement increases the number who are shut out, and increases the degree of selectness and privilege. The high school student is ripe for the plain ethical suggestion that such peculiar advantages create special social responsibilities; he will sit up straight and take a new view of life as he hears the truth set forth. It is a sad fact that if the educational duty of presenting these facts is delayed until the college years, many of the young people will be found already to have hardened their hearts 
against the moral appeal. If the proper beginning has been made in high school years the college period offers the opportunity for the finest and loftiest development of a social spirit that may dominate the whole career, for both noble happiness and the richest social usefulness.

2. Social Intelligence. Head and heart must always unite to make up human character: intelligence without goodness is a menace, and goodness without intelligence is blind and helpless. One of the most perplexing facts in history is the truth that the children of this world are so often wiser in their generation than the children of light. The need of both wisdom and goodness is most clearly seen in social relations, for instinct is quite unable either to solve the problems involved, or to furnish grace to carry a solution into effect; only educated reason, furnished with abundant knowledge, and cultivated human sympathy can avail here. And it is clear that social problems lie immediately in the path of our progress in this day and age. While, then, in the interest of clearness, we shall talk of social intelligence and social sympathy separately, it must be remembered that the two must never be separated in the culture of human character, but must always grow side by side, in constant unity and interrelation; only so will they coalesce and coöperate in perfect human life.

First, all must possess a reasonable degree of economic intelligence. Money and "business" form part of all lives, and the most extensive and prominent part of very many lives; it is impossible that any one should live well 
in modern society without a fair comprehension of the truth concerning these things. First comes the idea already suggested, of the vast difference between the mere getting of money and goods and the genuine earning of money by giving a real return in valuable service to the community. This idea should be thoroughly explained to the youth, and become an unforgettable and persistent part of his thinking. Money, he should be shown, is nothing more nor less than a counter or symbol, representing on one side human labor, and on the other the satisfaction of human needs; he should see vividly that the production of material goods costs toil, struggle, exhaustion, and even bodily injury or death. These are facts without which no one can think clearly or safely on questions concerning the use and consumption of wealth. He should also be seized with the fact that money, or the things that money buys, can in a marvelous way mitigate or banish many forms of pain, sorrow, and trouble, especially in case of the weak and helpless, of widows and orphans, of the overworked and the underfed, of the sick and afflicted.

The most dangerous fallacies and abuses of our own day, and possibly of all times, concern what is known as business: business, in the common sense of the term, has a constant tendency to run into conflict with the honor and truthfulness of business men, and with the health, happiness, and character of men and women and even children. Two great economic truths form the remedy for all these fallacies: first, that business exists for the sake 
of human life, and that no human life can ever exist for the sake of business ; that business is accordingly justified only as it adds to the richness and satisfaction of life. Second, that the interests of business itself, except when taken in the narrowest, most selfish, and most unintelligent sense, coincide with the interests of life in general. Particularly it must be shown that there is no conflict between moral principle and business principles: that while some one individual banker or grocer or contractor may profit for a time by dishonesty and chicanery, yet business as a whole, the business of the community, must necessarily be damaged by such methods: and that the business of the community can prosper only by means of honesty and the square deal. In other words, that many so-called "business methods" are the most unbusinesslike in the world, leading always to loss on the whole, and often to fearful disaster and destruction of life and property. Fortunately also the business world furnishes a good array of disaster even to the crooked individual himself; and when he does come down, great is likely to be his fall, in this world's goods and in the more precious things of life.

All this means the widening of the youth's horizon on all questions touching the production, distribution, and consumption of wealth, so that he may grasp once for all the truth that every economic question has its ethical side, to neglect which is to be shallow and narrow in one's thinking. He is to be deeply impressed with the utter difference between social parasites and vampires, no 
matter what their wealth or position, who suck the life blood of the community without giving any benefit in return, and the social member who, whether humble or eminent, gives an honest man's service for a fair remuneration.

No argument is required for the necessity of intelligence concerning the rights and duties of the citizen, - what he may fairly expect from his government, and what he justly owes in civic and political duty. There is much reason to think that republics in general, and our own in particular, tend to overemphasize the rights of the citizens, at the expense of the right of the state; consequently education is called upon to do what it can to correct this error and impress the young citizen with his obligations rather than his privileges. Fortunately the study of civics in schools is rapidly occupying the field of education for citizenship: no single educational move is at present more positively encouraging than this, and we may well hope for its further progress and for beneficent results, sorely needed, in our public affairs.

We cannot too often remind ourselves that liberty and wisdom must go forward hand in hand, and that wisdom is not knowledge in general nor discursive erudition, but definite knowledge and intelligence relating to the particular tasks to be performed. One of the most dangerous mistakes of educational thought and practice is the application of the general culture idea to the work of civic education : how little general culture avails against special training is seen in the helplessness of the average college 
graduate in a political struggle against the generally ignorant but politically sophisticated "ward heeler" and his ilk. No valid reason can be given why the school should not discard a great mass of useless erudition, from the first grade to the university, - in order to make room for an adequate training in civic knowledge and a political habit of mind. The greatest weakness of the American educated man, as a general rule, is the lack both of this knowledge and of the habit of turning his mind to the problems of what is called practical politics.

As to the content of this civic education, any good textbook of school civics will give a fair idea; with only this repeated suggestion, that the young citizen needs much preception on the duties of the citizen and rather less on his rights. Among other topics may be mentioned particularly the citizen's relation to law, both as to making the laws through the election of representatives, and obeying the laws when made; one cannot avoid here the bitter thought that the American people are charged by their own best authorities with being the most lawless nation in the civilized world. Instruction is also necessary in more particular public duties, such as jury service, payment of taxes, and then, of course, the obligations of public office.

Doubtless the idea will be put down by most people as utterly Utopian, but we cannot pass this subject without urging the desirability of requiring a modest degree of civic intelligence as an absolute prerequisite to full citizenship, and especially to the exercise of the franchise. 
Only the most superficial mind fails to recognize the franchise as a duty and a privilege, and not as a right: the only rational inference is that it should be vested in those who are competent to exercise it wisely, and in them only. Certainly nothing could stimulate the study of civic and political affairs among theyoung more than the knowledge that an intelligent acquaintance with these subjects was the only stepping-stone to full enfranchisement and the ballot. Pitifully inadequate as are the existing statutory limitations on naturalization and the franchise, yet some of them may be considered as possible forecasts of a genuine and rational safeguarding of the fundamental power of republican government.

Then perhaps it might be well for the young American, like the young Athenian, to be inducted into full citizenship with some solemn ceremony of initiation, and to take the oath of civic loyalty in some such words as the young Greek used: "I will never disgrace these sacred arms, nor desert my companion in the ranks. . . . I will transmit my fatherland, not only not less, but greater and better, than it was transmitted to me. I will obey the magistrates who may at any time be in power. I will both observe the existing laws and those which the people may hereafter make, and if any person seek to annull the laws or to set them at nought, I will do my best to prevent him, and will defend them both alone and with many. I will honor the religion of my fathers. And to these things I call the Gods to witness."

3. Love of Humankind. The greatest message of 
Jesus and of Christianity is the supremacy of love: that truth has transformed our ethics and is transforming our morals, both individual and social. We have already met this element of character twice, first as the native tendency of affection, and then as a part of the ideal disposition: we might almost as well have treated it also under the head of habits; and we shall certainly meet it again as we trace the further development of character. It is in truth the deepest and most potent force in every individual character, and is the active principle of progress and the elevation of human life. All that has been discussed hitherto and all that may be said hereafter as to tendencies, disposition, habits, ideals, and the rest, can be of no avail if this source of warmth and power is neglected, - which is merely a commonplace way of saying what was said for all time in the familiar thirteenth chapter of the first epistle to the Corinthians.

Yet we must not be allured by the greatness and beauty of love to miss its lowlier forms and ignore its common and everyday uses : life does not often rise to great emotional heights, and much of the time love is to work quietly, quite inconspicuously, and even unconsciously, in directing and inspiring the plain duties and occupations of ordinary days. It is at all times to permeate our relations to all about us; and since we are never fully disjoined from our fellows, even when we are in the utmost solitude, love must never take its hand off the guidance of life.

It is necessary that the youth - and before him the 
educator - should conceive the 'love of love' that Tennyson praises, - he must here, as always, admire before he imitates and adopts. To this end the youth should learn the history of the world's greatest admirations, - its devotion to men and women who greatly loved. Nearly every race in the world's history has had some one beloved hero, who won his eminence by complete devotion to the welfare of his people. Socrates loved Athens and its young men too well to stop teaching them the truth even to save his own life. The central distinction of the traditional King Arthur is his devotion to the highest good of his knights and his folk. The greatest world-hero came that men, - without distinction of race, - might have life more abundantly. America is fortunate in the possession of the tender-hearted, sympathetic Lincoln, who loved too well to flinch from the bloodiest conflict, and yet could not bring his heart to sign the death warrants of boyish soldiers who had slept on duty, no matter how the military authorities stormed. These and others in plenty are invaluable to save the youth from the subtle fallacy of identifying love, the strongest thing in the world, with weakness, which above almost everything else the youth hates. Let him once catch full sight of love and strength, in natural union, and his education in both virtues is assured.

The native tendency of affection widens in a simple and natural manner as the child grows into youth and manhood. First he loves mother and father, brothers and sisters, playmates, acquaintances, friends. These are the 
intenser individual forms of altruistic emotion. Gradually knowledge widens; he meets more people, and learns of the life and conditions of still more; with the widening of knowledge should come the widening of sympathy. Perhaps the chief auxiliary in this process is that very knowledge mentioned earlier, that his own deeds and destiny are in touch with many near and remote, and that he may, if he will, help or hinder, lift or thrust down, cause increase of joy or increase of pain. And so in a perfectly natural course, proceeding for the most part in secret and under indirect influences, the narrow, petty, self-centered soul of the child expands and reaches out to take in widening circles of friendship and acquaintance and interest, and still wider reaches of community, nation, race, and finally the whole of mankind.

4. Courtesy: A Note by the Way. Courtesy is strictly not an essential of character, but an attribute of conduct. Yet it is so essential, both to the individual and to society, and it lies so close to character that we can hardly ignore it here. True courtesy is the appropriate manifestation of right character in immediate social contact. Of course a man may be lacking in courtesy and yet possess excellent character, although good character tends in itself to courteous behavior; and a man may behave in the main according to the most exacting rules of courtesy, and yet be a scoundrel, although good manners tend to exercise a wholesome reflex action upon character. These two cases are both abnormal; the natural course of development is the growth of good 
character and the acquisition of habits and manners that show forth the good character in social relations.

Especially do the personal ideal in all its forms, and social sympathy and intelligence, contribute toward the right basis of courtesy. Given these inner qualities, and all that is needed further is training in the forms of courtesy, - what we ordinarily call good manners. The teaching of manners is simply an external auxiliary and addendum to the formation of character. The subject would claim a far larger place in a discussion of moral training than it does in a study of the essentials of character. None of these statements is intended to belittle the importance of manners, indicated above, for the comfort and beauty of human life in social relations. 


\section{CHAPTER IX}

\section{Strength of Character}

\section{THE SOURCES OF STRENGTH}

NATIVE vigor of impulses and desires conserved by education and experience, the establishment of inner harmony and cöoperation among the powers and capacities of the soul, the formation of a life purpose, and the direction of the individual life in accordance with the eternal principles of right that underlie human progress, - these are the elements of both strength and righteousness in human character.

I. Conservation of Native Vigor. Power arises, as we have seen, from secret sources in body and soul, and manifests itself in the form of impulses, instincts, desires, and other original tendencies; these powers spring up throughout life and in all its periods, but are especially interesting and important in childhood and youth, as they are then the prophecy and description of life's possibilities. The first great maxim of education is the nurture and conservation of these sources of power. Repression, even when necessary, as it sometimes is, in itself is an evil, a negative and depressing factor; it is justified only when the reduction and loss in the impulse repressed is more than recompensed by enlarged scope and prosperity in 
some other perhaps more valuable element. Only when a particular element threatens either some other indispensable element, or the balance and harmony of the whole soul, must it be pruned or eliminated.

The main tenor of education, on the other hand, is stimulative, encouraging, positive. The nurture of what springs from the native spiritual soil is the chief and usual work of parent and teacher. All healthy impulses are to have room and opportunity; time must be found for every psychic process to rise into its appropriate place in consciousness, and fix itself through association and habit. The channels of energy, varied and manifold, are to be kept open, that the flow may augment with the growth of the whole organic life.

Especially are the elementary forms of will to be cherished; and play is the universal exercise ground for them all. The old education is bad education so far as it fills the child's life with "don'ts," and meets his abounding activity at every turn with prohibitions and limitations. Also the parental or pedagogic discipline that crushes the child's will instead of directing it sins against the hope of strength in adult character. Two types of child impulsion are peculiarly liable to undue repression, the noisy and conspicuous, and the delicate and hidden. The turbulent impulses arouse opposition in the elders, and may be treated so harshly as to cause deep permanent laming of the will (when they are not indulged and allowed to choke the finer motives, - the path of wisdom here as always is a golden mean). The secret impulses, hidden 
by child ignorance, or by the reserve of youth, are apt to be trodden down unawares, through lack of that fine perception in the educator which looks through the concealing veil of the external, - often by virtue of his own experience held in memory from childhood days, or by grace of long and sympathetic practical study of the developing soul. The true educator, whether parent or teacher, also will not "break the bruised reed nor quench the smoking flax."

For each one of the infinite variety and number of the tendencies of childhood and youth is a potential strand in the mighty fabric of that strong character in mature life that will stand the strains of temptation; or, to change the figure, it can add its quota of vital energy to the total that shall be available to grapple with the heavy tasks that enter into every life of real worth. This is the motive and principle of the conservation of the natural dynamic forces of the child and the youth.

How these forces are to be made permanent and operative in character we have seen in our study of disposition, habits, tastes, and the ideals of personal and social life. The value of these established parts of character depends in large part upon the amount of dynamic energy that has been saved for them and set to work through them. In every case of habit or ideal, there is a form of right action, which is one factor in the value of the habit, and there is a motive power of drive and force, that constitutes the other factor. The lapse or defect of either spells failure.

2. Inner Harmony and Coördination. But it is a famil- 
iar fact in history and fiction and life that sometimes the most dynamic characters go most terribly wrong. Moreover what we have been saying in favor of the conservation and nurture of the forces in childhood impulses is often carried to excess by parents and teachers who have learned only one side of the truth; too many fall into the foolish fallacy of Rousseau, who to guard the native will of the child against parental repression tells us that we must "never command the child anything in the world" ! The truth is that there are forces in most normal children which if undisciplined are calculated to crush and ruin other elements that are indispensable to perfection, and so by thrusting themselves into an unjust predominance destroy all hope of full development. Such are anger, pugnacity, many forms of appetite and passion, and, later in life, a great variety of desires. Hence control and some degree of repression are absolutely demanded for the child's own safety and future possibilities. It goes without saying that these measures of discipline are also necessary to fit the child for his social relations both in childhood and in adult life.

The ideal here has been worked out for all time by the Greek thinkers on ethics and education: it is the harmonious development of all the powers and capacities of the soul. There is an inner health and balance of our spiritual natures that is destroyed by the exaggeration of any of the capacities, and consists in such culture of each that the totality is thereby enriched and energized. Now the inner life of a human being is in such intimate 
dependence upon his social life, his environment, his station and duty in life, that it is absurd to try to regulate his development entirely from within; yet something may be said without reserve as to the true relation of some of the elements of character that we have been studying.

First, then, there is a sort of natural hierarchy or gradation of rank and authority among the elements: And particularly must some of them be subordinate, playing the part of servants and ministers, and never presume to the mastery. Such are the impulsive elements in general, along with tastes and appetites; these under the control of higher powers furnish power, and enrich the content of life. But when a taste or an appetite or an individual desire becomes too strong for the rest of the character, it becomes a source of weakness and not of strength. Thus a certain amount of what is ordinarily called temper is an element of strength, making one capable of strenuous attack upon obstacles, of determined resistance to hostile forces, and of righteous indignation; but if temper gets beyond control, its strength is weakness to the character as a whole. Even a good appetite is a source of power in life by its contribution to bodily health and to the wholesome pleasures of the palate; but when appetite is the strongest force in the conduct of life, character falls into ruin, and the man degenerates into the drunkard, the glutton, or the roué.

We are to be masters of ourselves, as all ethical sages have declared; which must mean that the higher in us is to be lord over the lower. That is, mere impulse and 
appetite must be less authoritative than desires, desire must be subject to good habits, and all these must bow before the personal ideal, as we have sketched it. Much morality has tended to stop here, with the idea that if the personality is rightly formed the life must be completely right; as Polonius has it, "To thine own self be true; And it must follow, as the night the day, Thou canst not then be false to any man." But this is true only when we enlarge the idea of self to embrace the whole world, that is, all with whom our lives come into contact: the personal ideal must lose itself and be perfected in the social ideal, in altruism, in self-forgetfulness, in those devoted attitudes we know as family and friendly love, public spirit, patriotism, and finally love of all mankind. The study of all the greatest moral types, from Socrates down to Lincoln, including Jesus himself, exhibit this culmination of all character in love.

This rule of the higher over the lower is often spoken of as the supremacy of reason; impulse and appetite are blind, seeing only the immediate object of desire, and ignoring all the rest of the world, - sacrificing one's own larger future good, and treading down the interests and happiness of others. The righteous character strives to perceive all the considerations that affect the case, to do justice to all who are concerned, and to act upon a fair balance of rights and interests. Thus clear vision and intelligence form an essential part of this subordination of the lower to the higher.

3. Formation of Purposes. Character utters itself 
only in action; and the forces of character flow most effectively into action only when they are rallied to the achievement of clearly conceived and firmly held purposes running through life or considerable stretches of time. It cannot be denied that very many human beings, possibly the great majority, never form any such life purposes, but live a hand-to-mouth existence, doing each day or each week what the time seems to dictate. Still it remains true that such life purposes are indispensable to the fullest realization of human character, and are peculiarly marked in the strongest and most effective characters of history and general experience.

What these purposes shall be is a question for the individual himself to answer : unless he has self-reliance and initiative to conceive and adopt his purposes, he is not likely to possess the greater strength required to carry them out. Older persons should be chary about interference with the formation of purposes; only those who know the youth best and understand his nature and circumstances can safely give advice even when asked; it is doubtful if any one ought to tender it unasked. On the other hand, education, both in home and in school, should at least be such as to open the eyes of the youth to the task that devolves upon him of finding or creating for himself an aim of life that shall be fit and worthy.

The commonest and most definite form in which this question arises is in the choice of a calling. Too many lads stumble blindfold into an occupation; few indeed under present conditions can use any intelligence in the 
decision. Both parents and school might and doubtless in the near future will do much more than they do now to throw light upon this important problem of youth. Most important of all for the larger welfare is the point we have touched elsewhere, that every occupation should be genuine social service, and that work should be real value given for the remuneration received. It is unreasonable to condemn this as unpractical ; for many men already fully recognize the truth and honestly work by it, and all men to a greater or less extent measure their work by the standard of genuine service.

The unexpended balance of life left by the occupation is to be appropriated to other purposes, - worthy amusement and recreation, intellectual pursuits, and, most important of all, civic and social activities. All these vary so much with the individual that no general discussion can be of much value. But the wisdom with which they are chosen, and the authority they exert over the conduct of life, greatly affect both character and achievement.

4. Concord with the Larger Purposes and Ideals of Humanity. The actual efficiency of a character depends not only upon its native strength and its inner harmony, but also upon its agreement with the trend of human progress. Great souls are sometimes in harmony with their own times and with the progress of the race; sometimes in harmony with the times and in conflict with world progress; sometimes in conflict with the times and still in harmony with human progress; and perhaps sometimes out of harmony with both. The latter cases, if such there 
are, can make little mark and do not find a place in history. He who fits his time but works against progress will be called great in his lifetime and then sink into insignificance; it is clear that the character that is to leave a lasting work must work in harmony with the general trend, whether he works with his time or against it. Lycurgus, Solon, Moses, Washington, Lincoln, are illustrious examples of men of character who worked with their times and in harmony with world progress. Napoleon is a striking example of one who worked with his own times, or at least with his own race and generation, but largely contrary to the general trend of human development. So his name grows gradually less in our esteem. Socrates and Jesus are perhaps the most illustrious of many names of those who came into violent collision with dominant powers of their own time, but led the race powerfully in its onward march. The inquisitors and persecutors of many times worked with their own times, but against world progress, and so their work availed nothing, even to silence the heresies of their victims.

What is true of these great men, and vividly revealed in their lives, is true in its proportion of all human characters and lives. And in order to be in harmony with world progress, each man, small as well as great, must strive to take into his own heart and will all that he can apprehend of the best in human thought and aspiration, as he finds it in experience, in history, literature, and all forms of culture. Above all, he must unceasingly strive to escape from his narrower self, with its own individual desires and 
ambitions, and gain insight and sympathy for the lives of his fellows. So may the force of his will be added to the great stream of human endeavor that 'makes for righteousness,' and his life becomes a part of the upward struggle of the race, the struggle that is the basic distinction between man and the lower races of the animal kingdom. This union of the individual will with the will of mankind is the consummation of both strength and righteousness of character. "A man is a little thing," says Emerson, "whilst he works for and by himself, but when he gives voice to the rules of love and justice, is godlike, his word is current in all countries; and all men, though his enemies, are made his friends and obey it as their own."

We can only mention here the profound truth that so closely knit are the inner and outer sides of character, the individual and the social, that there can never be the fullest degree even of inner strength without at least the consciousness of harmony with the great currents of righteousness. Napoleon was by all accounts pitifully small in many of the inner elements of human nature, lacking especially in the personal ideal, both as to dignity and honor, being an unscrupulous liar, and, according to very good authorities, a good deal of a buffoon. The fullest strength comes only when the man feels himself to be in harmony with the great movements of human life and advance. Historically this feeling has usually taken a religious form, and the unity has been felt and expressed as harmony with the will of God; the greatest 
souls that earth has produced have had this sense of oneness with the divine, and consequent harmony with the onward march of life. Such characters seem to be lifted quite above the weaknesses and failures of the ordinary man; over their wills temptation has little power; they stride forward in their life purposes over obstacles and through trial and agony. Here, again, what is writ large in these heroic souls is true also in modest degree of each life: just in proportion as we get our wills into concord with that great world power that makes for right and truth, are our own characters reënforced and energized, raised above the reach of petty and transitory motives, and made an effective part of the achievement of the race.

\section{THE VIRTUES OF STRENGTH}

A goodly number of admirable qualities are really forms of strength, or special ways in which strength shows itself in action. These may be considered under three heads : first the virtues of courage, including courage itself in the ordinary sense, perseverance, endurance, patience; then the forms of integrity, - truthfulness, honesty, justice; and, finally, self-control. In all these virtues the essence lies in holding fast that which we have chosen to hold, in spite of opposition, pain, loss, and peril. Courage looks mainly toward the outer world; integrity is concerned more with conditions in the soul itself. But there is a deeper distinction: the virtues of courage are not necessarily virtues, but are good or bad according to the cause in which 
they are enlisted ; the virtues of integrity are intrinsically good.

I. The Virtues of Courage. For courage itself we may adopt a modified form of Plato's famous definition, and say it consists in daring all that ought to be dared. Macbeth, guilty wretch though he was, phrased it well when he declared, "I dare do all that may become a man; Who dares do more is none." Admirable as bravery is in almost any form, it becomes a true virtue only when it consists in pursuing or defending a truly worthy object or cause. Physical bravery, and some forms of spiritual courage, are largely a matter of native endowment; the truer courage of the definition cannot be given by the hand of the most generous original nature, but is a resultant of the highest development of character as a whole. For into the decision of the causes for which we shall dare must enter our whole spiritual life, - tastes, personal ideals, and, above all, our grasp and sense of social relationships. It is a mere truism to say that often the bravest externally will fall far short when tested not merely by the visible boldness of his deeds, but also by the causes in whose service the deed was done. Too often the act that seemed bold was really craven, for the doer faltered from the support of what in his heart he knew to be highest; he 'dared more than may become a man.'

It is clear that education must qualify the mind of youth to distinguish between mere native boldness, as a thing to be desired indeed, but having no special moral merit; and courage in wrong causes, especially in selfish 
and unsocial purposes; and, finally, the true courage that stands for the defense and vindication of the best things in life.

Perseverance, endurance, and patience, are all forms of virtue in which the force and permanence of the inner movements of the spirit oppose and defeat opposition and obstacles of all kinds. Especially must these virtues suffice for the conquest of toil and weariness, pain, drudgery, tedium, and, possibly most serious of all, discouragement and failure. The youth must learn not to know when he is beaten, but to return with increased energy to the task. His temper, like that of steel, must grow with blows. Especially must he learn that certain things are imperative and not to be surrendered, and that of these he must never say "I cannot," but only, if necessary, "I have not yet achieved, but I am still striving."

2. The Virtues of Integrity. Courage and its relatives consist in standing by our own purpose and ideals, whatever they may be; integrity lies in having ideals that stand the most penetrating scrutiny we can give them, and then standing by these tested ideals. This is strength of character in the highest sense. The first stage of integrity is inward, and consists in the testing and ranking of ideals. Life holds out to us countless and varied aims and ends, all beckoning us to pursue. Impulses, desires, appetites, duty, love, ambitions, and whatever else may appeal to our wills - upon these judgments must be pronounced, and ranks conferred. The first integrity consists in clear sincerity and honesty with one- 
self: the putting first things first, and relegating less worthy to a lower place. This may seem like an intellectual process, but it sounds the very deeps of the soul, and its outcome is really a verdict upon the soul itself, and sways the balances of fate. The man of integrity is he who has chosen without self-deceit, and has sworn fealty, as it were, to what he finds most worthy. The experience is at bottom a religious rather than merely moral one, and is best illustrated by the ancient leader who declares, "As for me and my house, we will serve the Lord" ; or by the alternative urged by the prophet, "If the Lord be God, serve Him ; if Baal, then serve him." So in the early years of life, and especially in adolescence, the mind turns upon the many-hued prospect of life, and judges it; not in a day nor a year, even, but as time passes and as the spirit grows and enlarges. And the verdict is for integrity or against it; the conclusion is whole-hearted and without misgivings and reservations; or it blinks some things, denies others, and indefinitely postpones others.

The second step in integrity is steady and active fidelity to the chosen ideals, and life in accordance with them. Here it passes into courage in its truest form and in its various manifestations. The virtue of integrity par excellence is truthfulness, which is making our outward expressions and declarations a true representation of our inner spirits, and this quite without regard to whether the expression is by word or in any other form. We have already discussed this virtue, especially with reference to 
childhood; what is there said all lends force to the idea that truthfulness as a positive virtue is really a form of strength. Fear and desire we found to be the great enemies of the truth; strength of higher elements of character is the only possible safeguard against these foes; as Richter says, "Weaklings lie, no matter how they may abhor it." Every lesson in truthfulness is really a lesson in being strong; and every influence that reënforces the higher elements of character tends to truthfulness.

Of honesty and justice little need be said, for they are among the oldest and most admired virtues. Their value lies in the resistance of desire and fear when these motives would lead one to trespass upon the rights of others. They rest first upon moral and social intelligence, by which the rights of self and others are decided; and then upon strength of character to act in accordance with the decision. The commonest defect in these virtues is that men who would not rob a neighbor of a penny, will unhesitatingly plunder the state that nourished them, a corporation, or men and women whom they have never seen or at least do not know. The strength needed here is not only widened sympathy, but also broader perception, to see and appreciate the situation and interests of those remote from us in space or social rank, whose lives our conduct yet influences for weal or woe. The broadest and most trustworthy justice is based upon the full development of that social intelligence and feeling spoken of in a previous chapter. Its extreme opposites are 
typified by Cain's guilty question, “Am I my brother's keeper?" when he had just murdered the brother; or the heartless scorn of the rulers who had corrupted Judas, and mock his remorse with "What is that to us? See thou to that." Justice is clear vision and determined will to see all and act upon full consideration, even at the cost of private and personal comfort or profit. To it all the other virtues of strength minister, and for its perfection all the elements of character must contribute; this perhaps is the justification for Plato's elevating it to the supreme place among the virtues.

The inner perfection of the will is self-command. By which we mean not merely self-restraint, the checking and subjugation of injurious impulses, indispensable as this is ; but also the higher positive virtue of self-direction, self-energization, self-activation. Self-restraint, or temperance in the true significance of that word, arises mainly through the harmonization of spiritual impulses that we have already discussed. Even self-restraint is really accomplished not by any mere negation and quelling of the lower impulses, but rather by the greater force and activity of the higher elements. Such self-restraint is the necessary basis for effective character, inasmuch as insubordination among the lower elements of the soul chokes the growth of all higher processes, and blocks the way to perfection. Only through self-restraint can a character be even safe, either toward itself or for its environment. But the higher virtue is positive and dynamic self-direction. 
To receive all facts and conditions into one's intelligence, to hear all evidence, as it were; to form one's own aims and plans, and to turn into them the power to carry them into effect, - this is self-command in the higher sense, and is the perfection or efficiency of the will as a working organ. It is this quality that makes leaders, whose own strong decision moves the wills of others as the magnet draws the iron. This self-command includes initiative and resolution and abundant force of will, to conceive and adopt purposes and plans, to press them through obstacles and opposition, and hold to them until the end. Of this, perhaps even more clearly than of the other virtues of strength, we perceive that it is a consummation of harmonious coöperation among all the forces of character, and that its attainment is possible only through the broadest nurture and discipline of all powers and capacities. 


\section{CHAPTER X}

\section{RELIGION}

WE have in this chapter nothing to do with dogmatism or theological disputation; but if any man doubt that religion is of the essence of human character, let him read again the life of Abraham Lincoln, - the most perfect model for American character; let him hear Lincoln speak under the shadow of the approaching conflict, "I know there is a God, and that he hates injustice and slavery. . . . If $\mathrm{He}$ has a place and a work for me, and I think He has, - I believe I am ready." Or again, when the storm was at its worst, "If it were not for my firm belief in an overruling Providence, it would be diffcult for me, in the midst of such complications of affairs, to keep my reason on its seat. But I am confident that the Almighty has His plans and will work them out. . . . I have always taken counsel of Him, and have never adopted a course of proceeding without being assured, as far as I could be, of His approbation." As the great soul of the man grew under the fiery discipline of his labors and experience, religion became daily more and more predominant in his thought and expressions.

Or look for evidence into other history, and see how all the greatest spirits have been either actually religious 
leaders, like Moses or Mahomet, or have inclined profoundly to religious thought and feeling, as in the case of Socrates, Plato, Epictetus, Alfred the Great, Washington, Gladstone. Or, best of all, let any man examine his own consciousness when the best thoughts and emotions rise to unwonted height, - when love, or compassion, selfsacrifice, forgiveness, benevolence, stir the soul with more than common power; or, most of all, when grief or trouble press heavily upon the spirit; and he will find himself seeking instinctively for those deep experiences that make the essence of all religious life.

The very word religion is an indication of the intimate connection between religion and conduct, for the word means rather scruple or conscience than any rite or ceremony; and the great definitions and formulas of various religions all agree in making life and action the final embodiment and evidence of genuine religious spirit. Especially is this true of Christianity, as will appear in all the public discourses of Jesus, particularly the Sermon on the Mount and the Allegory of the Last Judgment.

The truth is that one essential part at least of religion is simply the consummation of ethics; some one has called religion morality touched with emotion, and the statement is so far true. It has also been wisely said that no virtue is safe that is not enthusiastic; and the enthusiasm of virtue is a religious passion. The growing religious tone in Lincoln's utterances already referred to shows how naturally a lofty morality under intense pressure passes into religious conviction and fervor. It seems clear that 
Lincoln was intellectually a thoroughgoing rationalist, but because life had for him so deep a meaning, and duty such imperative authority, when hours of darkness and strenuous trial came his whole consciousness became filled with the religious spirit.

The union between religion and morality is so intimate and vital that one ought to apologize for any argument on the subject; but there is real need for reminder and insistence, in this day and age, and particularly in America. We have created here the first great system of public education the world has known in which religion is not a part of the regular curriculum and one of the acknowledged means of cultivation. Our Roman Catholic fellow citizens naturally condemn the system unsparingly; the rest of us mostly ignore the situation or take it for granted as the only right and proper way of conducting schools. The truth probably lies somewhere between the two camps. But the point for us here is that educational thought has followed educational practice, and we have gradually come to omit religion from our mental schemes of pedagogy, and comfortably accept the serious fact that a great part of our youth are growing up without any education in religion, - or rather without any religion in their education. Do we so completely discredit the wisdom of Gladstone when he says, "It is a dangerous thing for a young man to start out in life without the thought of God"?

That similar conditions exist or are arising in other countries is evident from the ejection of religion from the 
public schools in France in 1882, the strong movement for nonsectarian schools in England, and the discontent over the existing religious instruction in Germany. The whole question relates to a great world movement in human thought and life, and its answer will not be written by any man or set of men, but will needs be worked out practically by education, the church, society, and governments. Certainly no one who knows the public schools has any sympathy for the charge that they are irreligious or tend to irreligion; the truth probably is that for the majority of American children the school is the most religious influence they meet. Nor can we hope, even if we wished, to introduce in our schools any such type of religious instruction as now exists in Germany and other European lands: we certainly cannot adopt what they are discarding as obsolete and ineffective. But after all we dare not forget that religion is an integral part of human life and culture, and hence of education: the great question is, as we have hinted, not education in religion, but religion in education, as one of the indispensable agencies and resultants in the training of any human soul.

It is with natural hesitation and misgiving that one approaches so difficult and disputed a question as the actual place of religion in character and education: we must, however, endeavor to outline, first some of the most vital elements in religion that enter essentially into character and moral education; and then some of the virtues in character that spring peculiarly from the religious elements. 
I. Religious Elements. Religious conceptions group themselves naturally about God and Man; the thought of God, which is in itself religious, and the religious conception of Man, both work powerfully upon character.

The thought of God, to the normal human mind, means chiefly two things, natural law in the universe, and moral law in human life and affairs. It means order instead of chaos, cosmic intelligence instead of the reign of chance, progress and uplift instead of a meaningless recurring cycle of change. This thought of God as the ground of natural law has been a loadstar for thought in all ages; the mind of man has wandered away from it at times or in individual cases, but has as constantly come back to it. About it have been built the most influential systems of philosophy, from the days of the Greek nous to the modern idealistic absolute. It has been a tonic for intellect, and has exerted a reflex influence of stern, high power upon ethics and morals. It is the best safeguard against pessimism and despair. In all ages it has had a positive fascination for the minds of men; in a word, it seems to rise out of the very nature of human intelligence and flow into health of intellect and will.

Besides natural law, the thought of God means moral law. Especially in the Hebrew theology, which, refined and elevated in Christianity, is our religion to-day, God is the judge of human conduct, loving righteousness and hating iniquity. Hence Wordsworth's "Duty, stern Daughter of the Voice of God," and hence the ascription of the Decalogue to the very finger of Jehovah. In fact, 
with the Hebrews, religion and morality were one and inseparable, in spite of the extreme degree of symbolism and ceremony in their cult. Hence also the invocation of God in the oath to solemnize testimony and confirm obligations. No considerable part of any race or people has ever got away from the conviction that righteousness and God are somehow one and the same; even the intellectualists for the most part agree with Arnold as to the real existence in the universe of a "Power, not ourselves, that makes for righteousness." Certainly to the common man, that is to the great majority of us all, the voice of duty and conscience is still the voice of God, and our wrong-doing is felt to be, like that of the Prodigal, 'against Heaven.'

This identification of God and moral right has sprung from the uttermost beginnings of the spiritual life of man, and has grown with his growth through ages and centuries of culture and mental advance; the strongest and best men and women of all periods have been most deeply imbued with it, and it has kept equal pace with the upward movements of races and peoples; it deepens with the deepening of life and reaches its culmination in our individual souls when we most fully realize the best potentialities of our nature. The strife of theologians and the doubts of skepticism, however honest, are merely the temporary aberrations of the intellectual conception of God, and neither indicate nor forebode any final loss of the real and potent sense of the Divine.

2. The Religious Conception of Man. After the con- 
ception of the Divine itself, the most powerful thought in religion is the startling assertion that Man himself is akin to God. It would be hard to find a more utter paradox than this stupendous claim; yet the very religions that have conceived God in the most sublime and majestic nature, and have most emphasized the gulf between His perfection and man's frailty and weakness, are the ones that have most unequivocally declared that man is the Son of God, created in His image, vivified by His breath. One must feel that the claim itself is nothing but the voice of man's boundless aspiration, and that his aspiration is the best proof of the truth of the claim. As to character and its outer form, conduct, can the mind conceive any more potent stimulus and uplift than a sincere and genuine belief that the human soul is really divine in its nature and possibilities? Here then is the place of this conception as one of the essentials of character.

The personal ideal and the social ideal, as we have discussed them, are matter of fact enough; yet their natural fruition is found in the great religious conception now before us. To think worthily of one's body is really, as the Apostle has it, to conceive it as the temple of the Holy Spirit; our intellectual powers, with their clearness, their grasp of the illimitable universe of thought, their evident superiority over all the unconscious and less-conscious parts of creation, are just the powers that we ascribe, in fuller perfection, to God. Above all, the selfdirecting will, seeing all, weighing causes and effects, and choosing ends and means, is the highest attribute we can 
think in the Divine. In both cases, moreover, there is one marked element in both intellectual and moral advance that is peculiarly an evidence of the Divine, and peculiarly powerful as stimulus and guide: it is the great sense of possible further advance that seizes us with such power, fills our souls with inexpressible longing for more knowledge, deeper insight, or for purer virtue and finer life; when we feel the universal aspiration voiced by the great Apostle when he cries; "I count not myself to have apprehended; but this one thing I do, forgetting those things that are behind, and reaching forth unto those things that are before, I press toward the mark." So the personal ideal and its correlative of self-respect find their natural source of power and greatness in the sense that our personal selves partake of the supreme essence of all being; that we belong to a race that sets no bounds to its perfectibility, and that each one of us has a right and a duty to covet and strive for the loftiest personal excellence. So mere morality gets the needed touch of emotion and inspiration, and virtue takes on true enthusiasm - possession by the Divine.

What is true of our hopes and obligations as to our own individual selves reaches a higher plane and a more nearly ultimate truth in our social relations. The divine nature of man expressed in the Fatherhood of God embraces the Brotherhood of Man; and all social virtues and ideals point and aspire to that brotherhood. Different times and races and individuals recognize this brotherhood in varied degrees; there is a type like Cain, in the ancient 
story, that would fain deny his obligation even to his brother according to the flesh; at the other end of the scale are the men to whom 'nothing is alien if only it is human,' the Howards and Wilberforces, the men who have taken the world to be their parish. Between are all degrees of heart and opinion: most of us must plead guilty to much imperfection of sympathy toward those of diverse color, strange creed, uncouth manners, and even opposite opinions in politics or theology. Fortunately a limited grasp and sense of brotherhood suffices fairly well for the most of life in most cases. Still it remains that partly through want of heart, - the inhumanity of man to man, - and partly through lack of intelligence, more than half of the race do not know how the rest live and labor and endure; through these defects in the sense of brotherhood as an element of character, social welfare is damaged and social progress is impeded. The social ideal as a mere conception or sentiment avails nothing when a real test comes; life demands sacrifice and devotion, and these spring only from a profound religious sense of unity with our fellow-men.

3. Religious Virtues. All the virtues are religious when they rise above their lowest levels, and religion reënforces and vitalizes them all. But as we found certain virtues that lie peculiarly in strength of character, so we realize that some of them are specially connected with religious ideas and feelings. We might almost define religion, in the sense in which we have taken it, as a profound and dominating sense of two things, - first, the 
greatness and power of the Universe of which we are but a tiny part, of God, Creator and Conservator of all things; and second, of the priceless value and inestimable possibilities of man's life, - our own and that of our fellows, near and far. Is it not clear that this leads naturally to two great virtues, reverence and devotion? Reverence, because of the greatness and glory of God and His image in humanity, and devotion, in order that the potential may become the actual, - in the words of religion, that His Kingdom may come and His Will be done in earth.

Fear depresses and lames our self-respect and confidence; conceit and vanity blind us to the worth and claims of others, and cut us off from full sympathy with them, or full realization of the sublimity of the Universe; Reverence is the golden mean by which we do homage to the great and good without in the least losing our own dignity and personality. Thus it enhances human life as a whole, for each man gains an appreciation of the general worth and yet retains his self-respect; all minds are elevated by a sense of the sublime in Nature and Providence, and are cheered and strengthened by a sense of kinship with all. Human society and individual character both need reverence if they are to approximate perfection. The best and strongest self-respect coexists with the deepest reverence, paradoxical as the statement may sound at first, for the capacity to respect is the same, whether the object of respect is self or others.

As already indicated, we use the word devotion in 
the sense of profound and enthusiastic loyalty to a cause; that is, in an active sense involving conduct, and not in the sense of certain religious states of mind. In this sense devotion is the raising of human activity to its highest terms. Oriental religions have aspired to states in which the consciousness of the individual is rapt in moveless contemplation or lost by reabsorption into the spirit of the Universe. Western religions culminate rather in a state of active participation in the processes of human progress and development. Thus devotion becomes the true positive interpretation of all doctrines of self-abnegation; it is the sacrifice of the narrower self in the larger social spirit, the self-denial that makes each of us one with all and binds us into a spiritual unity. For the individual soul it is the merging or subordination of the lesser in the greater, and the full realization of self by finding one's good in the good of all. Devotion then is religion at work, or work inspired by the religious spirit.

Here we must again defend ourselves from the charge of being in the clouds, - of imposing upon common life and ordinary characters a standard that fits only saints or the few rare moments of exaltation that common lives can boast. But here, as in some other cases, the truth that is most easily seen and described in heroic or sanctified form is valid in its due proportion for the most ordinary characters and the common tenor of life. The cup of cold water given to the thirsty neighbor at the cost of almost imperceptible sacrifice is the type of simple, natural, unconscious kindnesses that bring their own immediate 
reward in spirit and character; these quiet acts are the devotion of common days. They too involve the forgetting of self in the remembrance of others which is the essence of all the highest attainments of human conduct.

Devotion to some end or ends is a mark of the strong character, and devotion to humane and beneficent ends the mark of the good; and the most complete consecration to the highest ends is the characteristic of the greatest souls. But what is characteristic of the greatest is normal for all: other virtues than mercy are 'mightiest in the mighty,' and essential for all who claim humanity. Thus devotion is the natural consummation of the rising steps of human character, crowning all other elements, and turning the streams of power and beauty that spring from high individual perfection into the channels of highest value and joy, both for the one soul and for all souls that feel its influence. It is the solution of the great Christian paradox that he who sets out to save his own life shall lose it, but he who spends his life freely, in the cause of right, shall most truly find it. 


\section{CHAPTER XI}

\section{Notes on the Cultivation of Character}

WHILE the primary purpose of this book is a delineation of the aim of moral education, we have naturally been led to many statements and implications concerning methods. We hope at a future time to treat this topic at some length; meanwhile it may be permitted to close the present discussion with a few remarks upon some of the most salient and vital points in the question of the cultivation of character.

I. The Force of Contagion. The processes of growth will not wait upon the educator's clock; the child's character goes on developing while mother and father are quite absorbed in other affairs; out of school as well as in, on week days and Sundays, in secret ways, unperceived and unperceivable, not only by parent and teacher, but by the child himself. Even the crises and turning points may arrive and pass into permanent elements of character before the best vigilance can detect them. While we sleep the seed germinates and springs into flower and fruit, - and the fruit is of diverse and fateful forms.

Moreover, all schemes for insulating the child from con- 
NOTES ON THE CULTIVATION OF CHARACTER I 83

tact with his environment break down. Man is a social being, and the young soul will find its way to others, and receive from them stimulus, example, suggestion, information, and all the contagion which out of the unformed virginity of child-soul breeds the fixed forms of disposition, habit, tastes, principles, and ideals.) Our children must needs grow up in a human, social environment; we must pray 'not that they be taken out of the world, but only that they be kept from the evil.' The great, all-pervasive, ceaseless force in education is the spiritual atmosphere - first of the home, including the family circle, and those who enter as friends and acquaintances; later of the ever-widening sphere of general social life, with certain peculiarly potent elements, such as the church, the school, and the street; and finally the great educational mills of 'society,' business, politics.

Doubtless one should write not atmosphere, but atmospheres; one of the particular home, another of the immediate social circle to which the family belongs, another of the local community, still another of business and politics, - and finally the great comprehensive atmosphere of the race or nation. These influences differ infinitely, and may stand in bitter conflict. The forces of evil symbolized in the ancient litany of the Church as 'the world, the flesh, and the devil' still exist, and our children still need to be delivered from their deceits. It is not pessimism but plain prudence to recognize their menace and attack them with every lawful weapon, whether they appear as noxious books and newspapers, or corrupting 
plays and entertainments, or unwholesome forms of social life and custom.

Even because our children now in the shelter of the home are so soon to be exposed to the contagion of the wider world, should parents, above all persons, labor for general moral and social uplift. Concerning proposed changes in our affairs we are familiar enough with the questions "Is it good business?" and "Is it good politics?" Let us ask also, "What is the probable effect of the movement upon the spiritual atmosphere that our youths and maidens must breathe as they step out from the doors of home? Will it tend to bless or to curse childhood and youth? Will it increase or decrease the perils that beset young men and women entering upon independent careers? Finally, will it make better or worse the world of to-morrow, in which our beloved children must live their lives?" In asking such questions, and in making the answers to them a force in public opinion and action, parents, and especially fathers, ought by all considerations of interest and responsibility to lead the way.

2. The Parents' Power. The home has of course a peculiar advantage in its first chance and its intimate and potent contact; but it loses its exclusive leasehold on the child very early, and moreover it is at the most critical period of moral development that the child passes out of the family life into the world. It was a Hebrew who wrote, "Train up a child in the way he should go, and when he is old he will not depart from it"; if we desire the proverb to be true for us, we must 
needs emulate the faithful, potent, and protracted home education of the Hebrews - from which we are at present far removed.

Certainly the home and its allies, the school and the church, should forewarn and forearm: not a few specious fallacies hawked by the weaklings and crooks of the moral world can be exposed in advance by the wise parent or teacher; and the child may well learn the colors and signs of certain moral poisons. Such instruction is summed up in the Hebrew sage's precept, "If sinners entice thee, my son, consent thou not" ; but the precept is of slight value unless the lad recognizes the sinners who are likely to entice him, and the innocent or alluring guises under which they conceal the evil of their counsels.

LHuman nature - even good human nature - is of almost infinite variety; and this is true of father and mother, and true of children. Consequently, as parents constantly tell us, what will work with one child will not with another, even in the same family. The actual concrete problems of home instruction and discipline are myriad, and their solution must be left chiefly to the fathers and mothers themselves. But there are some great conditions underlying success, and chiefly two: first, the parents themselves must be worthy of their trust. It is a beautiful and yet a terrible thing that to the dawning moral sense of the child, the father and mother are the absolute pattern of perfection: it is no mere accident that the universal language of religion calls God the Father: it would perhaps be true to nature for the child to call his 
father, God. Secondly, the parents must create and preserve mutual love and intimacy with their children. All this is so simple and self-evident as to be almost absurd; and yet so it is, and it is the only way. No methods or devices can ever replace these two requisites.

The reflex force of parenthood is great: no one can estimate how much better the world is morally because of children. Into the soul of the normal man or woman the advent of a child is a call to the higher life. The very way in which Nature leads the new being into the world seems designed, when things are as they should be, to stir the deepest fountains of the moral nature. Nor is this beneficent influence of the child confined to the parents : the very sight of children has power to soften and purify the countenances of men and visibly stir their better natures. The teacher, moreover, as a sort of secondary parent, is a great debtor to this reflex influence of education.

Let parents then - and most parents do it - cherish and cultivate this divine impulse toward self-improvement: let them for their children's sake diligently prune away the minor vices of irritability, impatience, careless or profane speech, and wage a war without quarter upon the greater enemies of character, - vanity and insincerity, indolence and self-indulgence, avarice and overweening ambition; and in general sound in their own souls at every thought of their children the great prayer-call of the ancient Church, "Lift up your hearts." What would you not give, $\mathrm{O}$ father, to have your son and 
daughter say of you in years far hence, "My father was the best man I ever knew !" They will say it, and think it too, if you will give them any reasonable ground.

The crown of parenthood is influence, and the spring of influence is love. But filial love is at first not a fact, but only a possibility. The love of the child for the parent is not born with the child, but must be cultivated by daily intimacy : the baby shrinks away from the father who has been away for a week, and clings to the nurse, unrelated by blood, who has tended him daily. Moreover, as the years go on, and the child soul grows more complex and more individual, expanding into the soul of the youth or the maiden, closeness of love and sympathy is not so easy to gain and keep, and is all too easily lost, - sometimes, alas, neither parent nor child knows exactly how or why. Religion teaches us that the love of the Divine Father precedes and engenders the love of man toward God: no less is it true that the love of the human parent must precede and engender the love of the child.

"Who is your chum this year, Henry?" was asked of a boy of eighteen in high school; he thought a moment, and then answered, "Why, to tell the truth, my father is my best chum all the time." The father is one of the busiest men in the city, with large affairs and heavy responsibilities, but always with time to spend with his boys. He never lets them get far away from him; with them he fishes and hunts; they accompany him occasionally on business trips; he knows what they are thinking and doing, and spares no pains in making himself a part of 
their plans and ambitions. Best of all, he is a real flesh and blood father, and not a creature of the writer's imagination. He will never have to say, as some fathers are forced to, when their boys are growing into men, "I have no influence with my boy; he has got clear beyond my control." Rather will it be true that his sons will seek to know his opinions and wishes, and find joy in honoring them in their lives and conduct. For he has solved the problem of influence, and knows that the secret lies in the maintenance of intimacy; and he has also been willing to pay the price of intimacy, in sharing his time and thought with his children, in sympathizing with their interests, in ministering to their happiness, and living his life to the highest possible degree in common with them.

In this form the parental relation is the very type of the most powerful form of moral education, so far as moral education can come to one soul from another. The father and the mother incarnate the truth: and what is true of them is true in its measure of all who similarly influence the growth of the child's character. The Word must always be made Flesh and dwell with men : ethical truth must be put into daily conduct in the persons of men and women, and so find its way into the hearts and characters of the young. Only so can the light of righteousness be passed on from generation to generation, and grow in brightness from age to age.

3. Physical Health. The ancient ideal of a healthy soul in a healthy body has been wonderfully reaffirmed by the modern doctrine of the complete interrelation 
and interdependence of body and mind: physiology and psychology have united in their emphasis upon the truth that even the most obscure and delicate processes in one side of the organism have power to affect the other side. We must avoid indeed the false exaggeration that says there can be no worthy spiritual life in a weak or defective body: many facts refute that idea. But we must take constant account of the fact that bodily weakness and disease always threaten the life of the soul; that some forms of defect choke or deform the mental development; and that in general health and vigor in body are the best possible foundation for a genial and abundant spiritual and intellectual life.

Particularly has it been shown that many forms of bodily disorder in children check or even absolutely stop mental development. Such especially are adenoids and enlarged glands, which diminish the supply of oxygen by contracting the air passages, and so arrest development of all parts of the organic life. Intellectual development again may be hindered to almost any degree by defects of vision and hearing; this of course is especially true of school work. All these facts are becoming more and more familiar to the general intelligent public every year, and great advance is being made in discovering and eradicating these foes of normal growth. It is not quite so well known that bodily defects and diseased conditions threaten moral development, especially in their effect upon disposition and habits: it cannot be doubted that 
many a child is irritable, moody, obstinate, subject to anger and other faults of childhood, as a result of indigestion, constipation, adenoids, or some other often easily remediable physical disorder. The preservation of bodily health, then, is a duty not only to body and intellect, but also to moral character, - in other words, to full and rounded development of all the powers and capacities of the soul.

A word must be said about some more direct bodily dangers to character. The human being is endowed by nature with all the appetites and passions of the animal organism. But in so far as he is only an animal he is of course not man: and the only hope of true human life lies in the supremacy of the higher faculties over the lower impulses. Now failure to reach this condition may be due to weakness of the higher elements, or to overweening power of the lower, or, as is probably usually the case, to both of these conditions. It is the very nature of bodily appetites and passions, when over-indulged, to become the most greedy of tyrants, and usurp for their own gratification the best energy and possibilies of life: thus are produced gourmands, drunkards, and sensualists of all kinds. The new education advocates the just claims of the body to healthy and abundant life and development, for its own sake and because it is the temple and organ of the soul; for this very reason the new education must also be peculiarly vigilant in its support of the spirit in its war against the unjust and pernicious attacks of "fleshly lusts." 
The most serious danger of this kind in civilized life is probably the sexual impulse: fortunately a large amount of earnest and expert attention is now being given to the problem. Already abundant sources of helpful information and advice have been opened up for all who will ask for them; and we may well hope for great progress in education on this point. We content ourselves here with urging the matter upon the earnest attention of all parents and teachers, and indicating in the reading list a number of reliable sources of information.

The only conclusion to the question of the relation of body to mind in moral development is the idea, already often expressed or implied, of overcoming evil by good. Great is the beneficent influence of abundant and healthy bodily life, and upon this must attention be mainly fixed, not upon defects and remedies. The whole regimen of childhood and youth must be ordered so as to guarantee good digestion, clean rich blood, firm muscles, and steady nerves, and the greatest possible strength and vigor of every fiber of the physical frame. To this distinctly physical regimen needs to be added, we believe, the bodily ideal referred to in a previous chapter, which shall arouse in the child an intelligent and resolute purpose to carry forward the work begun by nature and the care of others, and to cherish and maintain the power and beauty of his physical being.

4. The School. Modern society, perhaps especially in America, tends to make unreasonable demands upon the school: education so often means schooling, that people get 
to think that education all goes on in the school; the truth is that by far the biggest and most vital part of education takes place outside of the school and largely in a manner beyond its control. Certainly we dare not refer the task of character training entirely or even mainly to the school; there are several other powerful agencies in this field, as has already been suggested earlier in the chapter.

A striking case in point may be found in recent educational history in France $\mathbf{~}^{1}$ in 1882 the Government abolished the religious instruction in the public schools and put in its place the existing moral and civic instruction. Soon after that the investigation of court records seemed to show an increase in juvenile crime, and naturally many persons were inclined to charge the increase to the discontinuance of the religious instruction. But the school authorities, among other points in answer, called attention to the fact that in 1880 the legal restrictions upon the sale of alcoholic liquors were greatly relaxed, and consequently the consumption of liquor in France had tripled, and France had passed from being seventh in the list of nations in amount of liquor consumed to the bad eminence of being first; and in $\mathrm{r} 88 \mathrm{r}$ was passed a law establishing the "full liberty of the press," and consequently the country was flooded with immoral literature; a cabinet minister declared in 1882 that there were distributed in Paris at the very doors of the schools more than 30,000 immoral

1 Report of U. S. Commissioner of Education, r900-r9or, p. Ir29. We have quoted in part almost verbatim from the American writer and the French authorities. 
papers daily. Most of us will agree with M. Buisson, of the Ministry of Education, that "If we must find some recent laws upon which to lay a part of the responsibility, it would suffice to cite the two laws which have given free scope and entire impunity, the one to the manufacture and sale of intoxicating drinks, the other to the cheap pornographic press."

It is profoundly important that the general public should realize the inability of the school to cope singlehanded with the task of creating character, or successfuly to counteract great forces of evil in the larger world into which the child is to be plunged. The limitation of school education in moral training rests mainly upon three conditions: the large number of pupils assigned to each teacher; the comparatively short hours and limited period of life given to school education; and the great burden of intellectual training that is thrust upon the school by the enormous content of the modern "curriculum," - a burden that has engrossed the attention and energy of the school almost to the exclusion of both æsthetic and moral culture. While all these conditions can be improved by educational progress, they are partly of the very nature of the school, and will always forbid our throwing anything like the entire burden of moral education upon the school and the teacher.

On the other hand it is necessary to lay great stress upon the real moral duty of the school, a duty which it and it alone can discharge ; for it is difficult to avoid the conviction that the school falls far short of undertaking or even 
comprehending this task. We can here only suggest outlines of this great subject, and must ask the considerate judgment of the reader upon so condensed an exposition.

The school is essentially a mediator between the peaceful seclusion and simple life of the home and the great wide world, with its complexity, its stress and strain, and its consequent infinite multiplication of hardships and difficulties. As the child passes from infancy by gradual stages up to youth, his spiritual and material life both pass out from the home into the world; presently he makes a final plunge when he leaves school and takes up his full adult burden of vocation and citizenship. In the modern world there are two chief parties holding an interest in the school, the family and the State; both desire the greatest good of the child, but not in exactly the same manner. Both desire for him efficiency and character; both therefore wish him to gain knowledge of the world, and to form attitudes toward it. The home can itself largely do the work of training disposition, and habits, and the personal ideal; the school must broaden the mind of the child to take in the larger relationships of life; and it must serve the State by molding the particular type of citizen required by the particular form of polity.

For these reasons, then, and some others that need not enter here, the chief contribution of the school to the cultivation of character is the broadening of both intelligence and sympathy, and especially of the former; moral intelligence, in a word, including all the spheres of mature life, 
vocation, society, political activity, is the peculiar aim of the school, which can be attained by no other agency, at least so far as the great mass of the people are concerned. It need hardly be said that this does not mean that the school and the teacher are to neglect any other way whatsoever in which they can stimulate or guide the right growth of the child's character: the school must continue the work of the home in the nurture of the disposition; it must maintain and extend the good habits that have been begun in early childhood, - obedience, industry, thoughtfulness; it must minister to the cultivation of the tastes; and it must contribute to the upbuilding of the personal ideal, - particularly, as has been pointed out, the ideal of knowledge and good thinking. Our only contention here is that the main task of school education is in the higher realms of the social ideal, the ethical imagination, and the formation of life purposes in definite and rational detail.

We need also to guard against the suspicion of advocating moral instruction as it is too often conceived by those who discuss it: we mean the type parodied by Rousseau when he says :-

"Here is the formula to which may be reduced almost all the moral lessons which are given, or may be given, to children :-

"Teacher: You must not do that. Child: And why must I not do that ? $T$. Because it is wrong. C. Wrong! What is wrong? $T$. To do what is forbidden. $C$. What is the penalty for doing what is forbidden? T. You will 
be punished. $C$. I will do it in such a way that nothing will be known of it. T. You will be watched. $C$. I will hide myself. T. You will be questioned. $C$. I will lie. $T$. You must not lie. $C$. Why must I not lie? $T$. Because it is wrong to lie. - And so on ad infinitum.

"This is the inevitable circle. ..."1

Fortunately such a travesty exists chiefly in the minds of those who wish, as did Rousseau, to use it as an argument. In any case, it has in it neither sense nor reason, and can find no justification in theory or experience. Moral education, more than any other, must use methods that are in harmony with the nature of the child, - provided only we penetrate to the true inwardness of that nature and refuse to be misled by the superficial and accidental.

The great general principle of moral instruction is simple and incontrovertible: we must seek to stimulate motives rather than to communicate precepts. There are three arguments against the extensive use of precept: first, the child knows in the main without being told what is right and what is wrong: secondly, even when he does not, our telling him will not often convince him; thirdly, the knowledge of right is no guarantee of its performance. Moral instruction should concern itself mainly not with telling what is right, but rather with imbuing the mind with ideas that will make the child want to do the right.

All this leads to the great truth enunciated by Herbart that the chief business of education is the ethical revelation 1 Émile, p. 53 (tr. Payne, New York, rgor). 
of the universe. ${ }^{1}$ We are to present mainly facts; them the child cannot reject or ignore, even when he is stirred, as he so often is, by the impulse of capricious opposition or perversity. But the facts must be such and so presented as to lead naturally to principles and ideals, and so to motives. They must be such as to touch the emotions and the will, and must be presented in such a manner and by such a person, as to do this part of their work effectively. Let it be noted that this proposition does not dream of any slightest weakening of the intellectual side of education, nor does it forget for one moment the absolute authority and value of abstract or intellectual truth; far from that, the ethical revelation of the world will evidently need to be most scrupulous and accurate in its facts and in all steps of reasoning from them; for while mere intellectual training tends to move no further than the inner consciousness of the individual, moral education marks its effects upon the life and destiny of the man and the race.

The great need of the school with respect to moral education is not first the addition of separate lessons in morals or ethics : it is rather the general moralization of the curriculum, or at least of such studies as admit of this. Two great branches of study come to mind : history and literature; to them may at once be added two others that attach themselves naturally to history: civics and economics. Space forbids any adequate discussion of this

${ }^{1}$ It seems fair to translate Herbart's phrase aesthetische Darstellung thus, in view of his identifying the æsthetic and ethical judgments. 
great problem here, and we must be content with a few brief assertions which in their isolation sound dogmatic, though they are not so intended. ${ }^{1}$ History is devitalized by insistence upon "covering the ground" in the sense of appropriating the facts contained in a certain book or set of books treating a certain period. The result is first that most of the facts, having no hold upon the life or heart of the pupil, are lost in oblivion almost as soon as the final examination is over; and secondly, that those profound and indispensable ideas and images that should be impressed indelibly upon the mind, be literally learned by heart, and so permanently influence character, never get root at all. It is a fact that the great majority of American college students could not cite one single idea from Washington's Farewell Address ; half of them do not positively know whether or no any such address ever occurred. When we come to literature we find it largely dehumanized in the interests of literary history and philology; "Macbeth" and the "Merchant of Venice," "Cicero against Catiline," Schiller's "William Tell," too often lose their real character as a portrayal and judgment of life, and become mere frameworks for remote facts and irrelevant etymology and syntax.

The question of separate ethical or moral lessons ought also to be dealt with seriously; so far we have only played at it here and there, and usually ended by declaring, first,

1 See article by the writer, "An Educational Emergency," Atlantic Monthly, July, rgro. Also, "The High School's Cure of Souls," Educational Review, April, r908. 
that it is not needed, and second, that no one could teach it successfully if it were. Of the need of all agencies that can contribute to the formation of character, no one who looks abroad into the world of society, business, and politics, can be in doubt. The question of possibility is not one for argument so much as for intelligent and resolute experiment and reflection upon the results of the experience. Schools both past and present in other lands furnish rich material for study, in both methods and results.

Finally, the internal social life of the school is just beginning to be properly recognized as an educative agency of the first rank. Here we have much yet to learn: the school is to be a microcosm, a little world in which the children can learn how to live later in the big world. Two great principles must be preserved: first, the life must be real and sincere; to the child not a preparation but life in earnest; then the school life must ring true to the virtues and ideals of all life; probably we shall have to stop punishing Harry for helping Tom with his lesson, if we expect school life to do its part toward making the world less selfish. At any rate, few symptoms in education are more hopeful than the pervasive and vital interest in the social side of school training.

5. Self-education. The deepest of all educational truths is that we cannot really be taught, but must learn: unless the mind of the pupil works there is no instruction, and unless the will of the pupil works there is no training. In the early years the teacher - official or unofficial - can and must do much for the learner; 
but as the years go on he can do less and less, and the growing soul is more and more committed to its own guard and culture. Moreover, man differs from all other animals in the long duration of his age of development: at an age when most creatures of his size are full grown he is still an almost helpless infant, and after they begin to be aged he is still putting forth the bud of new powers and capacities. Even his body requires a quarter of a century to reach perfection, and no one has yet set any limit in years to the expansion and ripening of his soul.

For these two reasons the greatest education must always needs be self-education; even the child must take himself in hand, or little will be accomplished; and after parents and teachers have done their best, the real task and the choicest results lie before the maturing youth. Instruction and training merely make beginnings, start processes, stimulate motives, and provide the simplest tools, the finest service of the educator lies in making himself no longer needed, by setting in motion the pupil's own self-educative will, and transferring to him the responsibility and the control of his own further cultivation.

It is sad to think how few people ever do take themselves seriously in hand to make the best, as Jean Paul has it, of the stuff that is in them. It is striking, on the other hand, how largely great men have made themselves and how little schools and other influences from without seem to have affected their development: the pages of biography are full of the Stephensons who did not learn 
to read until they were grown men, of the Lincolns whose academy was the field or the village store, and of the Scotts who were the "great blockheads" of the schools that they attended. Demosthenes striding up and down the shore, with pebbles in his mouth, relentlessly drilling his stammering tongue to out-talk the waves themselves, is a type of the sort of education that removes mountains and turns obstacles into stepping-stones. So is Disraeli, laughed down in his maiden speech, vowing that the unruly House should yet listen to him and mark his words well.

Self-education, then, is the consummation and fulfillment of all other training; it is the only guarantee of any large realization of the hidden possibilities of the young soul. It is the clear duty of the educator to give deliberate and earnest attention to arousing and invigorating the motives of self-culture; in particular should instruction seek most of all to conserve native interest and intellectual enthusiasm; it is far more essential that the child should continue to 'want to know' about things, than that he should know about any particular things. And discipline should seek to arouse motives and ideals and so constitute an inner moral authority that will labor for growth and improvement far more effectively and permanently than any influences from without.

The greatest stimulus and guidance of self-culture are to be found in the personal and social ideals discussed in previous chapters. The educator can be said to have done his part of the work well when he has brought the 
youth to set out into life with a worthy image of what he desires to be, both in himself and in his relations to his fellow men, and with the enthusiasm and resolution needed to keep him at work turning the ideal into the real, developing character out of the endowments of nature through the activities of life, and again investing that character in good works, to the glory of God and the blessing of himself and of mankind. 


\section{BIBLIOGRA PHY}

\section{SUgGested REAdINGS}

The following list of references makes no pretension to completeness, but is simply meant to help the reader who wishes to study further the general subject or any particular topic. The general list is divided into four groups, the first including works that have powerfully influenced the course of educational thought and practice, and hence may be called prophetic; the second class deals with the psychology and physiology of the child; the third includes practical works for both teacher and parent; and the fourth group contains all that do not fit into any of the others. In all the lists, both the four groups of the general list, and the lists for the separate chapters, we have arranged the references in what we consider the order of their fitness and value to the reader of this book.

\section{For Reading Circles}

For Teachers' or other Reading Circles, or for any persons who wish to make a careful study based upon the book, the following books are recommended as collateral reading: HARRISON, The Study of Child Nature; TANner, The Child; McCunn, The Making of Character; Froebel, Education of Man; James, Talks to Teachers.

\section{GENERAL LIST}

\section{Educational Prophecy}

Froebex: Education of Man. (Appleton.)

Rousseau: Émile. (Appleton.) One dare not mention this book without cautioning the reader against its excesses and 
paradoxes; and yet whosoever would be intelligent on modern education must know the Émile.

EMERSON: Education. References are made to the Riverside Educational Monograph edition, containing several essays bearing on education. (Houghton Mifflin Co.)

Plato: The Republic. (Golden Treasury edition.) (Macmillan.) Book II, last third (376B to end), Book III, Book VII.

\section{The Nature of the Child}

HARRIson : The Study of Child-Nature. (Chicago Kindergarten Association.)

TANNER: The Child. (Rand, McNally.) A good elementary book for the general reader.

HaLL: Youth. (Appleton.) A small volume of excerpts from his massive work on Adolescence. Indispensable for the student. To be read with some caution.

KIRKPaTrick: The Fundamentals of Child Study. (Macmillan.)

Specially strong on native tendencies.

WARNER: The Study of Children. (Macmillan.) Largely from the standpoint of the physician.

Rowe: The Physical Nature of the Child. (Macmillan.)

Tyler: Growth and Education. (Houghton Mifflin Co.) A biological view, with excellent practical deductions.

Perez: The First Three Years of Childhood. (Chicago, 1885.)

One of the earliest books on the subject, but of enduring value. Sully: Children's Ways. (Appleton.) A series of informal discussions, full of charm and suggestion.

\section{Practical Treatises}

SPENCER: Education. Chapter on Moral Education. (Appleton.) MACCunN: The Making of Character. (Macmillan.) SchofIELd: The Springs of Character. (New York.) Савот: Ethics for Children. (Houghton Mifflin Co.) A most useful handbook for the teacher in the elementary school. 
Moral Education in Public Schools. The California Prize Essays. (Ginn.)

Hyde: Practical Ethics. (Holt.)

Fenelon: The Education of Girls. (Ginn.) An excellent little book, interesting and instructive, far too little known at the present time.

Mirton: Tractate on Education. (Macmillan.) The finest essence of English humanistic education compressed into a few pages by the great poet, who was, as not every one knows, also a schoolmaster.

Coe: Education in Morals and Religion. (Chicago.)

GrIGGS: Moral Education. (New York, I905.)

\section{Miscellaneous}

Davids: The Notebook of an Adopted Mother. (Dutton.) Above all price for those who deal with small children. Full of wisdom, humor, and pathos.

James: Talks to Teachers on Psychology and to Students on Some of Life's Ideals. (Holt.)

Everetr: Ethics for Young People. (Ginn.)

Publications of the Religious Education Association (Chicago), especially the yearbook for I908, on Education and the National Character.

The Gulick Hygiene Series (Ginn), especially Book V, Control of Body and Mind.

Bibliographies: Monroe: Bibliography of Education (Appleton); KING : Psychology of Child Development (University of Chicago Press), Bibliography of children's interests, pp. 249-255; TANNER: The Child, Reading lists under each chapter; Rowe: Physical Nature of the Child, pp. I88-200.

Note: Books mentioned in the general list will be referred to as briefly as possible in the special lists, usually by the author's name alone. 


\section{SPECIAL LISTS}

\section{Introduction}

Froebel, Part I, Groundwork of the Whole.

Rousseau, Preface and Book I.

JAMES, pp. 38-63, 9I-99.

Schofield, Chap. I.

FISKE: Meaning of Infancy (Houghton Mifflin Co.)

Davidson: Education of the Greek People. (Appleton.) Chap.I,

Nature and Education.

\section{Chapter I. Native Tendencies}

TANNER, Chaps. XII, XIII, XIV, XV, XIX.

MacCunn, Part I, Chaps. I, II, IV.

Froebel, Parts I, II, III.

Sully, VII, VIII (Fear), IV (Curiosity).

Keatinge: Suggestion in Education. (London, 1907.) Chaps. VII, VIII, IX.

SchofIELd, Chap. V, Character and Heredity.

Davids, Notebook, etc., pp. 164-166; 212-215; 234-238; 240-

$243 ; 246-248 ; 252-259$.

JAMEs: Talks to Teachers, V, VI, VII, $\mathrm{X}$.

Russell: Child Observations - Imitation. (Heath.) A col-

lection of over 1200 cases of imitation in children, from infancy

up to sixteen years of age.

Dewey: How We Think. Chap. III.

\section{Chapter II. Treatment of Impulses}

JAMES: Talks, etc., III, IV, VIII, XV.

MacCunn, Part I, Chap. V, Development and Repression.

Froebel, Part III, The Boyhood of Man.

RousseaU, Books I, II. 
Davidson, Education of the Greek People, Chap. I.

EMerson, pp. 9-34.

\section{Chapter III. Disposition}

MacCunn, Part I, Chap. III.

EVERETt, Chaps. X, XVI, XXX.

Chapter IV. Habits

JAMES: Talks, Chap. VIII. See also chapter on Habit in James' Psychology, Briefer Course. (Holt.)

MacCunn, Chap. VI.

Schofreld, Chap. VI.

EVERETT, Chap. XLIII.

OpPenHeIm: Mental Growth and Control. (Macmillan.) Chap. VII.

Dewex : How We Think. Chap. III.

Sheldon: A Study of Habits. (Chicago, r903.)

Chapter V. TASTes and Appreclation

TANNER, XVII, XVIII.

Perez, Chap. XII.

Sulty, Chap. XI.

ScotT: Social Education. (Ginn.) Chap. XI.

TraCY: Psychology of Childhood. (Heath.) Chaps. III, VI.

MünSteRberg: Principles of Art Education.

Chapter VI. The Personal Ideal

HaLl, Chap. IX.

MacCunn, Part III, Chap. III.

Rousseau, Émile, pp. I23-I 28 ; r88-I9r; 217-228; 244-248.

Perez, Chap. XIII.

Everett, Chaps. XX, XXI.

The Golden Book of Marcus Aurelius (Temple Classics), Book I.

Smiles: Self-Help, Chap. XIII. 
SCHOFIELd, Chap. XII.

TANNer, Chap. $\mathrm{X}$.

Note: The whole thought and life of the Greeks and Romans was imbued with this ideal of personality, and the humanists of the Renaissance revived the conception; hence both classic and humanistic literature are rich in material on the personal ideal.

\section{Chapter VII. Conscience}

Sully, Chaps. IX, X.

Perez, Chap. XIII.

Hall, Chap. XII, pp. 356-36r.

RouSSEAU, pp. 208-2I 2.

AdLer : Moral Instruction of Children. (Appleton.) Chaps. XI-XVII.

SeElye: Duty. (Ginn.)

\section{Chapter VIII. The Social Idead}

MacCunn, Part II, Chaps. IV, VI, VII, IX.

HaLL, Chap. IX, The Growth of Social Ideals.

JAMES : Talks, etc. "On a Certain Blindness in Human Beings," . pp. 229-264.

Jane Addams: Democracy and Social Ethics. (Macmillan.) Chap. VI.

Scotr: Social Education. (Ginn.)

Davidson: Education of the Wage-Earner. (Ginn.) Chap. II. Ross: Sin and Society.

Forbush: The Boy Problem: a Study in Social Pedagogy. (The Pilgrim Press.)

Chapter IX. Strength of Character MacCunn, Part I, Chaps. II, V; Part II, Chap. VIII; Part IV, Chap. II. 
Everetr, Chaps. XI, XII, XIII, XIV, XXII, XXIII.

EMerson's Essays, Self-Reliance.

\section{Chapter X. Religion}

CoE: Education in Religion and Morals. (Chicago, r904.) SulLy, Chap. VI.

Davids, Notebook, etc. Pp. 86-90; ro6-108; I90; 224-225.

TANNER, Chap. IX.

MacCunn, Part II, Chap. VII.

Schofield, Chap. XIII.

Matthew Arnold: God and the Bible. (Macmillan.) Chap. III. Tolstor: Twenty-three Tales (Oxford University Press), especially Numbers $4,6,7$.

\section{Chapter XI. Cultivation of Character}

GrIGGS, Chap. XII. (Moral influence of the social atmosphere.) Jane Addams: The Spirit of Youth and the City Streets. (Macmillan.)

Jane Addams: Democracy and Social Ethics. (Macmillan.) Chaps. III, VI.

Pritchetr: The Ethical Education of Public Opinion. In Proceedings of the Religious Education Association, 1905, pp. 47-5 I.

Dewey: The School and Society. (University of Chicago Press.) BRIGGS: School, College and Character. (Boston, I902.)

Spalding: Education and the Higher Life. (Chicago, 1897.) Chap. V. 



\section{INDEX}

Acquisitiveness, 32.

Activity, $40 \mathrm{f.} ; 75$.

Adenoids, r89.

Adolescence, 10I; I32; $138 ; 148$.

Esthetic education, I6; I7 f.; I02 f.

See also Tastes.

Affection, as native tendency, $2 \mathrm{r}$.

Aim of education, $4 ;$ I32.

Altruism, $22 ; \mathrm{r}_{5} 8$.

Altruistic nature of education, I4I.

Amusements, value of simple, 52 .

Ancestor worship, $\mathrm{r}_{3} 8$.

Appetite, tyranny of, roo.

Appreciation of beauty, $102 \mathrm{f}$.

Approbation, love of, 3 I.

Art, appreciation of, ro6.

Athenian oath of initiation into citizenship, 148.

Athletic habit, 98 ; 99.

Athletics, in school, IOI ; II6.

Authority, 71.

Avocation, 160.

Beauty, love of, 17 ; $102 \mathrm{f}$.

Blame, 3r.

Bodily activity, $6 ; 98$.

Bodily health, 188 .

Bodily ideal, I $5 \mathrm{f}$.

Browning, on bodily vigor, II 7 .

"Breaking the will," 20.

Business, intelligence concerning, 143 , I44.

Candy, taste for, 16.

Character, analysis of, 42 ; cultivation of, Chap. XI; essential elements of, 2 ; genesis of, I; strength of, 263 .

Cheerfulness, 45 .

Child Study, 6.

Christianity, $\mathbf{1 7 x}$.

Citizenship, requirement for, 147; initiation into, 148 .
City life and education, 79 .

Civics, ethical value of, I97; study of, $146 ; 147$.

Civilization, tendency to bodily degeneracy under, 98 .

Cleanness of body, Ix6.

Coddling, 24.

Comenius, 17 .

Conscience, Chap. VII; also 37.

Conservation of native endowment, $30 ; 50 ; 56 ; 8 \mathrm{I} ; 153 \mathrm{f}$.

Considerateness, 84 .

Constructive impulse, $\mathbf{r} 2$.

Contagion, education through, $15 ; \mathrm{r} 82$.

Courage, 163 .

Courtesy, $\mathrm{r}_{5} \mathrm{r}$.

Cruelty of children, I9.

Crusoe, boy's idea of, I34.

Culture, æsthetic, Chap. V.

Curiosity, $9 ; I I$; basis of intellect, $8 \mathrm{I}$.

Debt of youth, 137 .

Destructive impulse, I2.

Development, according to fixed laws, r.

Devotion, I79.

Diet, $x 6$.

Discipline, 14; 37; 51; 66; 67; 68; $87 ; 156$.

Disease, influence of, 189 .

Disobedience, $13 ; 67$.

Disposition, 43; Chap. III; and habit, 58 .

Dolls, child's love for, 2 r.

Drawing, free-hand, rog.

Duty, I24; I3I. See Conscience.

Economic intelligence, 143.

Economics, ethical value of, 197 .

Efficiency, pride in, I2r.

Emerson, 42; 162.

Emotion, 59 .

Endurance, 78: 165 . 
Evil, overcome through good, 22; 33 ; $36 ; 92 ; 94$; I10; II6.

Facts, ethical use of, r97.

Fastidiousness, II3.

Fear, as native tendency, 25; relation to obedience, 72 ; as enemy of truthfulness, 87 .

Food, taste for wholesome, $16 ; 97$.

Foresight, 8o.

France, morality and the school in, 192 ; public schools of, I73.

Franchise, qualification for, 747 .

Froebel, I 24.

Fur, fear of, 26.

"Gang" impulse, 32.

Gladstone, 100; 172.

God, thought of, 174 .

Good humor, 47 ; 53.

Good, overcome evil through, 22; 33 ; $36 ; 92 ; 94$; 110; 116.

Greek ideal of harmonious development, 156.

"Growing-up" impulse, 27; educational value of, 29.

Guilt, feeling of, 128 .

Habit, 30 ; and disposition, 58; formation of, 6r.

Habits, Chap. IV; bad habits, $g r$.

Happiness, as native tendency, 23.

Harmonious development, 37 ; 156 .

Harmony and coördination of powers, I55.

Health and precocity, 83 .

Hebrews, religion and morality in theology of, 175 .

Herbart's doctrine of ethical presentation, I97.

Heroes, national, I49.

Higher education, privilege and responsibility of, 140.

Higher powers, control by, ${ }_{57}$.

History, ethical value of, 197 .

Home, first educative agency, 184 .

Home training, $69 ; 79 ; 185$ f.

Honesty, 167 .

Honor, ideal of, 118 ; schoolboy honor, II9; needs enlightenment, 120.
Hope, 45 ; 49.

Human ideals, harmony with, r6o.

Imagination, ethical, 38 ; 159 ; in children, as occasion of untruths, 87 .

Imitation, $14 ; 28$.

Impulses, see in general Native tendencies, Chap. I; conservation of, 30 ; mediation of, 38 .

Individual variation, 2.

Indulgence, $24 ; 34 ; 52 ; 57$.

Industry, $8 ; 6 \mathrm{I} ; 74 \mathrm{f}$.

Influence, of parents, 187 .

Instruction, moral, $195 ; 198$.

Integrity, $\mathrm{I} 63 ; \mathrm{I} 65$.

Intellectual ideal, the, II7 $\mathrm{f}$.

Jesus, $65 ; 88$; $14 \mathrm{I} ; 158$; I6I ; 17 I.

Joy, 23 f.; $45 ; 50$.

Justice, 167 .

Keats, on beauty, ro3.

Kindness, 45 ; 54.

Law, moral, 174; natural, r74.

Leisure, employment of, 160 .

Lies, $87 \mathrm{f}$.

Lincoln, Abraham, 54; II7; I50; I58; I6I; I70; I7I.

Literature, ethical value of, 197.

Love, as native tendency, 21 ; expansion of, 150; of humankind, 148 ; as culmination of character, 158 .

Manners, 151 .

Maturing impulse, $27 \mathrm{f}$.

Mediation of impulse, 38 .

Methods of moral training, Chap. XI.

Mischief, $\mathrm{x} 2$.

Modesty, I23.

Money, intelligence concerning, ${ }_{13} 8$; I43,

Moral instruction, $195 ; 198$.

Moral intelligence, I 28 ; 194 .

Moral training, Chap. XI.

Morality and religion, I72.

Mouth, impulse to put things into, 9 .

Music, 107.

Native tendencies, Chap. I; treatment of, Chap. II. 
Nature, love of, ro3.

New education, 5 .

Novels, 59 .

Obedience, $\mathrm{I}_{3} ; \mathrm{x}_{4} ; 6 \mathrm{r} ; 63 \mathrm{f}$.

Old education, 5 .

Organic character of child-life, $\mathbf{5}$.

"Ought" sense of, see Conscience.

Outdoor life, taste for, 100 .

Parent, power of, $185 \mathrm{f}$.; social responsibility of, 184 .

Parenthood, education for, 22; reflex influence of, 186.

Parents, suggestions to, 3 ; $14 ; 18 ; 20$; $29 ; 30 ; 31 ; 38 ; 40 ; 53 ; 56 ; 67 ; 69$; $71 ; 81 ; 87,89 ; 90 ; 104$; 106; 110 ; I $20 ; 129 ; 154 ; 160 ; 168$.

Parks and playgrounds, 105.

Passions, tyranny of, 190 .

Patience, $163 ; 165$.

Perseverance, 78 ; $163 ;$ r 65 .

Personal ideal, Chap. VI.

Physical perfection, ideal of, II6.

Pictures, use in education, Io6.

Plato, 5,$164 ; \mathrm{r} 68$.

Play, $8 ; 76 ; 99$.

Playgrounds and parks, ro5.

Political intelligence, 146 .

Positive vs. negative, $36 ; 68 ; 92 ; 154$.

Praise, love of, $3 \mathrm{I}$.

Precept, weakness of, I96.

Precocity, 82.

Priggishness, 83 .

Processes, educative, 39.

Prophylaxis, against bad habits, 93.

Puberty, 32.

Pugnacity, I9.

Punishment, 38 .

"Puppy-love," 33.

Purposes, as elements in strength of character, 159.

Questions, children's, Ir ; 8r.

Reading, love for, roo f.

Reason, development of, 82 ; supremacy of, 158 .
Reliability, I30.

Religion, Chap. X.

Religious conception of man, 175 .

Religious instruction in schools, 172 ;

I73.

Repression in education, $35 ; 36 ; 153$; I56.

Responsibility, 79, 130.

Restlessness of child, 7 ; ro2.

Reverence, I79.

Richter, Jean Paul, 85; 87.

"Romancing" in children, 87 .

Rousseau, 2 ; 36 ; 52 ; 155 ; 195 .

Scenery, love of, I04.

School, $69 ; 79 ; 83 ; 89$; IOI; I35; I46; I9I $\mathrm{f}$.

Self-abnegation, 180.

Self-assertion, I8 f., 37 ; $7 \mathrm{r}$.

Self-command, 168 .

Self-control, $158 ; 163 ;$ I68.

Self-education, $30 ; 39 ;$ Ir 4 ; $199 \mathrm{f}$.

"Self-reporting" in school, 89.

Self-respect, 20 ; 1 I $4 \mathrm{f}$.

Senses, aided by movement, 8 ; development of, 9 .

Sense-hunger, 9 .

Service, ideal of, 138 .

Sex nature and training, 32 ; ror ; r 19 r.

Sight, development of, Io.

Singing, rog.

Smiles, Samuel, on bodily degeneracy, due to civilized life, 98 .

Social contagion, 182.

Social ideal, the, Chap. VIII.

Social impulse, 23 ; 132.

Social intelligence and sympathy, 143 .

Social life of school, 199.

Social nature of man, $55 ; 133 \mathrm{f}$.

Social relations, $124 ;$ I 34 .

Social sympathy, I 43 .

Socrates, I50 ; 158 ; 16r.

State and school, I94.

Strength of character, Chap. IX.

Suggestibility, I3 f.; $39 ; 57 ; 64 ; 78$; 86.

"Tabula rasa" fallacy, 6 .

Tastes, 16, Chap. V.

Teachers, suggestions for ; $14 ; 29 ; 30$; 
31; $34 ; 35 ; 40 ; 67 ; 69 ; 71$; 81; |Vanity, I14.

$87 ; 89$; 104; 106; 120; 129; 154; Vices, petty, 29. I60.

Temperance, see Self-control.

Tendencies, native, Chap. I.

Things, ideas of, Ir.

Thoughtfulness, $6 \mathrm{r} ; 80 \mathrm{f}$.

Thoughtlessness, 85 .

Touch, development of, ro.

Toys, 76 .

Vigor, in native tendencies, $I 8$.

Virtues, religious, 178.

Vocation, choice of, III ; 159.

Wholesome tastes, 96 .

Wilfulness, 18.

Will, development of, 64 ; elements of,

Treatment of native tendencies, Chap. Wordsworth, I24. II.

Truthfulness, 6I ; 85 f. ; I63 ; 166. 
THE following pages contain advertisements of a few of the Macmillan books by the same author, or on kindred subjects 


\section{THE MAKING OF CHARACTER}

Some Educational Aspects of Ethics

By JOHN MacCUNN, M.A., LL.D.

Balliol College, Oxford

Professor of Philosophy in University College, Liverpool

Cloth, I2mo, \$r.25 net; by mail, $\$ 1.35$

The book has proved one of the most fruitful discussions of the subject which is coming to be recognized as the leading problem of educational methods. It opens with a discussion of congenial endowment, its nature and treatment, including heredity, vital energy, temperament, capacities and their development, habit and its limitations. Educative influence, conditions of bodily health, of family, school friendship, livelihood, religious and social organizations, and moral ideals are the subjects of a second part. Sound judgment is the title of the third part dealing with its education, the growth of the individual's ideal, and the practical value to him of theory of a moral ideal. The book closes with a stimulation section on self-development and selfcontrol.

\section{BOOKS BY MISS JANE ADDAMS}

Which Touch of the Problems of Moral Development

\section{The Spirit of Youth and the City Streets}

Cloth, I2mo, $\$ 1.25$ net; by mail, $\$ 1.33$

The book expresses the amazed regret of an exceptionally wise and experienced observer that an intelligent people should be content to leave so fundamentally important factor in the life of youth as is recreation in the hands of those who look at it from the point of personal greed, as is too often the case with those who open the dance halls and moving picture shows of the congested quarters of our large cities.

\section{Democracy and Social Ethics}

Cloth, I2mo, Leather back, ix +281 pages, $\$ 1.25$ net; by mail, $\$ 1.35$

"Too much emphasis cannot be laid upon the efficiency and inspiration afforded by these essays. . . The book is startling, stimulating, and intelligent." - Philadelphia Ledger.

PUBLISHED BY

THE MACMILLAN COMPANY

64-66 Fifth Avenue, New York 


\title{
THE DEVELOPMENT OF THE CHILD
}

BY

\author{
NATHAN OPPENHEIM, \\ Attending Physician to the Children's Department of Mt. Sinai \\ Hospital Dispensary.
}

12mo. Cloth. \$1.25, net

"This is one of the best Child-Study books that has ever appeared. ... No student of the child can afford to be without this book. It contains much that is new, but each proposition is so well authenticated by an array of actual facts that conviction of the author's position on any question discussed is bound to ensue. The author deserves the highest possible credit for giving us so much that is valuable in the way of scientific ChildStudy." - Child-Study Monthly.

"This book should be read by all who are interested in the proper education and training of children. They will find in it a good deal of original thought and many valuable suggestions." - New York Herald.

"It is difficult to restrain one's enthusiasm when speaking of this book. The chapter 'Heredity and Environments' might well be printed as a mother's tract for general circulation." - The Outlook.

"This is an extremely helpful book. It is a book with a mission for mankind. The author has a great purpose, and his treatment is both scholarly and original." - Fournal of Education.

"A lucid, well-reasoned, and trustworthy guide." - Sat. Evening Gazette, Boston.

"Remarkably interesting and thoughtful work."-Boston Transcript.

The book is for any one who has in any capacity the care of a growing child, for the primary school teacher, for the physician who advises its parents, but most of all for every parent.

\section{THE MACMILLAN COMPANY}




\section{MENTAL DEVELOPMENT IN THE CHILD AND THE RACE}

BY

JAMES MARK BALDWIN, M.A., Ph.D., \&c.

12mo. Cloth. \$2.25 net

"This summary sketch can give no idea of the variety of topics which Prof. Baldwin handles or of the originality with which the central thesis is worked out. No psychologist can afford to neglect the book, and its second part will be eagerly expected."- Prof. Titchener, in The Dial.

"Its pages breathe something of the intimacy, the frankness, the personal charm, of a clever investigator's note-book. The substance of it all - of the experiments and discussions themselves - is capital. The discussion is of a richness and breadth of which the foregoing gives but a scant idea." - The Nation.

"This book is distinguished for its richness of observations, ingenuity of interpretations and originality of experiment. ... The book shows qualities which one goes far to seek in a work of this kind . . . a criticism of results which is very sure and always original, together with large views of the whole which enable him to interpret his observations and ideas in a general theory with remarkable effects."

- M. HAVARD, in Revue de Met. et Morale.

"It is a vigorous book which requires severe meditation and reveals in the author one who has profound knowledge of psycho-social questions, and a thinker of the first rank. It constitutes a most formal and severe refutation of individualism."

- Prof. Morselli, in Rivista di Filos. Scient.

"This volume on genetic psychology is one of the most noteworthy that have been added in recent times to the library of psychology and education." - Prof. FerRari, in Riv. Sper. di Fren.

\section{THE MACMILLAN COMPANY}

66 FIFTH AVENUE, NEW YORK. 


\section{Kirkpatrick's Fundamentals of Child Study}

A Discussion of Instincts and Other Factors in Human

Development with Practical Application

By EDWARD A. KIRKPATRICK, B.S., M.Ph.

Head of the Department of Psychology and Child Study of the State Normal School, Fitchburg, Mass.

I2mo, Cloth, 405 pages, $\$ 1.25$ net

"The questions propounded to readers at the close of the successive chapters are a specially valuable feature of the book; which deserves recognition as a work of high merit and utility." - The Outlook.

\section{Warner's The Study of Children and Their School Training}

By FRANCIS WARNER, M.D.

I2mo, Cloth, 283 pages, $\$ 1.00$ net

"The method of observing and describing children set forth by Dr. Warner is of great practical value. It is the outcome of twenty years of experience of a practical and successful physician; and gains through having been tested by the personal examination of one hundred thousand children in schools in and near London." - Educational Review.

\section{Rowe's Physical Nature of the Child and How to Study It}

By STUART H. ROWE, Ph.D.

Head of Department of Psychology and Principles of Education, Brooklyn Training School for Teachers, New York; formerly Supervising

Principal of the Lovell School District, New Haven, Conn.,

and Lecturer on Pedagogy in Yale University

I2mo, Cloth, 227 pages, go cents net

"A scientific treatment of the physical nature of the child in such form as every teacher in the public school may be able to understand and use." - Educational Review.

PUBLISHED BY

THE MACMILLAN COMPANY

64-66 Fifth Avenue, Now York 


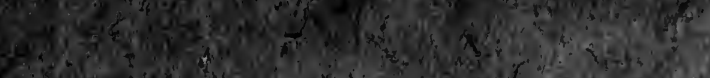

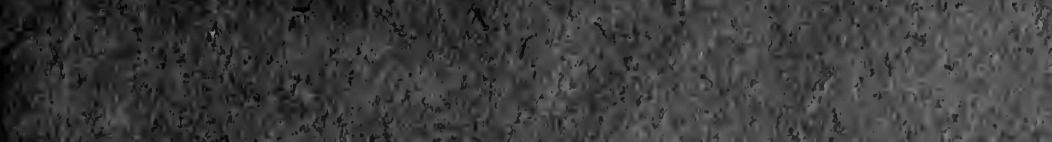
C.

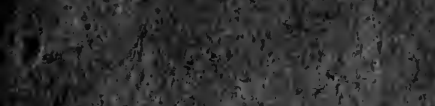

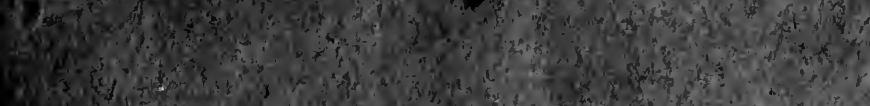

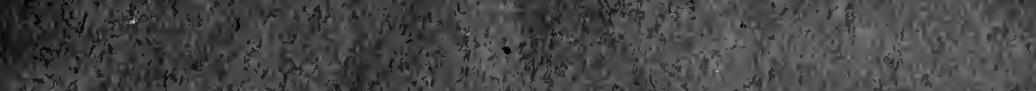

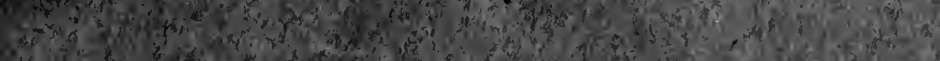

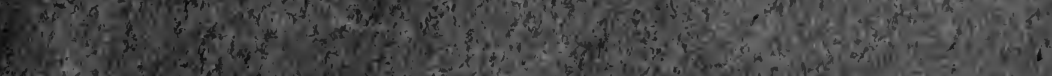
(c) 3. Anct

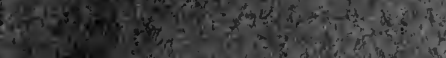
19. (5)

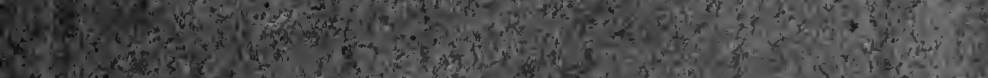
(12.

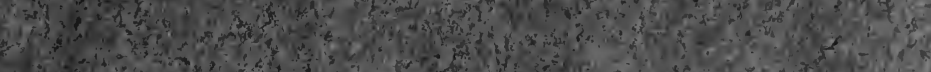

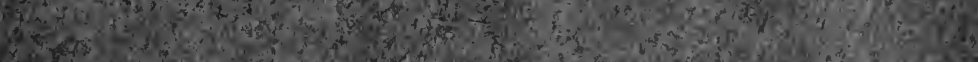
1. 4.

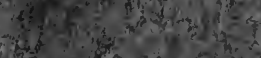

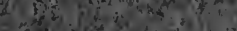

(x)

(3)

(x)

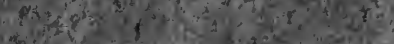
a

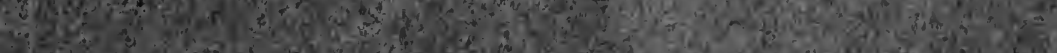
1.

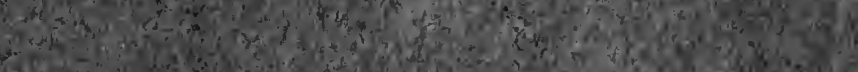

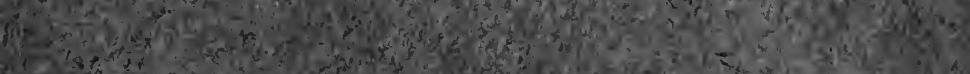

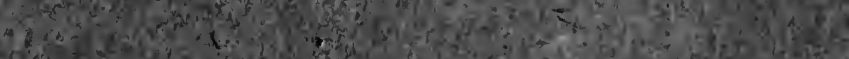

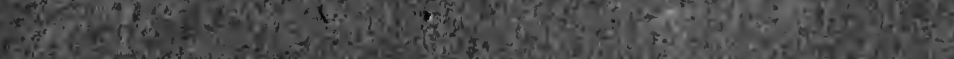

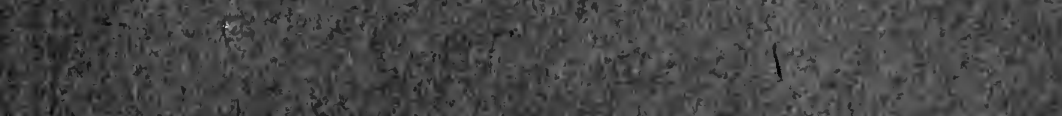

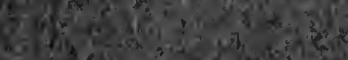


578367

$$
\text { BJ } 152 f^{\circ}
$$

UNIVERSITY OF CALIFORNIA LIBRARY 
